\title{
The cultural complexity of problem-based learning across the world
}

Citation for published version (APA):

Frambach, J. M. (2014). The cultural complexity of problem-based learning across the world. [Doctoral Thesis, Maastricht University]. Datawyse / Universitaire Pers Maastricht.

https://doi.org/10.26481/dis.20140326jf

Document status and date:

Published: 01/01/2014

DOI:

10.26481/dis.20140326jf

Document Version:

Publisher's PDF, also known as Version of record

\section{Please check the document version of this publication:}

- A submitted manuscript is the version of the article upon submission and before peer-review. There can be important differences between the submitted version and the official published version of record.

People interested in the research are advised to contact the author for the final version of the publication, or visit the DOI to the publisher's website.

- The final author version and the galley proof are versions of the publication after peer review.

- The final published version features the final layout of the paper including the volume, issue and page numbers.

Link to publication

\footnotetext{
General rights rights.

- You may freely distribute the URL identifying the publication in the public portal. please follow below link for the End User Agreement:

www.umlib.nl/taverne-license

Take down policy

If you believe that this document breaches copyright please contact us at:

repository@maastrichtuniversity.nl

providing details and we will investigate your claim.
}

Copyright and moral rights for the publications made accessible in the public portal are retained by the authors and/or other copyright owners and it is a condition of accessing publications that users recognise and abide by the legal requirements associated with these

- Users may download and print one copy of any publication from the public portal for the purpose of private study or research.

- You may not further distribute the material or use it for any profit-making activity or commercial gain

If the publication is distributed under the terms of Article $25 \mathrm{fa}$ of the Dutch Copyright Act, indicated by the "Taverne" license above, 


\section{THE CULTURAL COMPLEXITY of problem-based learning across the world}

Janneke Frambach 



\section{THE CULTURAL COMPLEXITY}

of problem-based learning across the world 
The research reported here was carried out at

\section{Maastricht University in Leaming!}

in the School of Health Professions Education

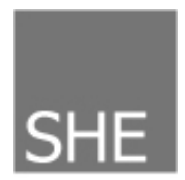

and in the context of research school ICO

(Interuniversity Centre for Educational Research)

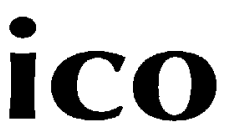

(C) Janneke M. Frambach, Maastricht 2014

ISBN 9789461593108

Cover design and illustrations: Janneke Sleijpen

Production: Datawyse | Universitaire Pers Maastricht 


\title{
THE CULTURAL COMPLEXITY of problem-based learning across the world
}

\author{
DISSERTATION \\ to obtain the degree of Doctor at Maastricht University, \\ on the authority of the Rector Magnificus, Prof. dr. L.L.G. Soete, \\ in accordance with the decision of the Board of Deans, \\ to be defended in public, \\ on Wednesday 26 March 2014 at 14.00 hours \\ by \\ Janneke Marly Frambach
}

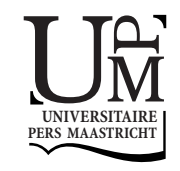




\section{Promotor}

Prof. dr. C.P.M. van der Vleuten

\section{Copromotor}

Dr. E.W. Driessen

\section{Assessment Committee}

Prof. dr. D.H.J.M. Dolmans (chair)

Prof. dr. A.F.P.M. de Goeij

Prof. dr. M.C.E. Gwee, National University of Singapore

Prof. dr. D.L. Southgate, St. George's Hospital Medical School, London

Prof. dr. G.J. Wesseling 
For Milan, who is my home

And for my friends abroad, who are my home away from home Amber, Amira, Artur, Beatriz, Elana, Erdal, Gil, Jelena, José, Kaisa, Lilo, Marco, Marianne, Muluken, Murat, Sammy, Solrun, Verena, ... 



\section{Contents}

Chapter 1 Introduction to the cultural complexity of problem-based learning 11

Chapter 2 The cultural complexity of group discussions in PBL 23

Chapter 3 The cultural complexity of self-directed learning in PBL 49

Chapter 4 The cultural complexity of preparing learners for practice in PBL 65

$\begin{array}{lll}\text { Chapter } 5 & \text { The cultural complexity of implementing PBL } & 87\end{array}$

$\begin{array}{lll}\text { Chapter } 6 & \text { Studying cultural complexity with activity theory } & 105\end{array}$

Chapter 7 From cultural complexity to cultural awareness, activity and action 119

$\begin{array}{lll}\text { Appendix A An overview of research paradigms } & 139\end{array}$

Appendix B An overview of quality criteria for research 143

$\begin{array}{ll}\text { Summary } & 147\end{array}$

$\begin{array}{ll}\text { Samenvatting (Dutch summary) } & 153\end{array}$

$\begin{array}{ll}\text { Acknowledgements } & 159\end{array}$

$\begin{array}{ll}\text { About the author } & 163\end{array}$

$\begin{array}{ll}\text { SHE dissertation series } & 165\end{array}$

$\begin{array}{ll}\text { ICO dissertation series } & 167\end{array}$ 

"Believing, with Max Weber, that man is an animal suspended in webs of significance he himself has spun, I take culture to be those webs, and the analysis of it therefore not an experimental science in search of law, but an interpretative one in search of meaning."

Clifford Geertz, 1973 - The Interpretation of Cultures 

CHAPTER 1

Introduction to the cultural complexity of problem-based learning

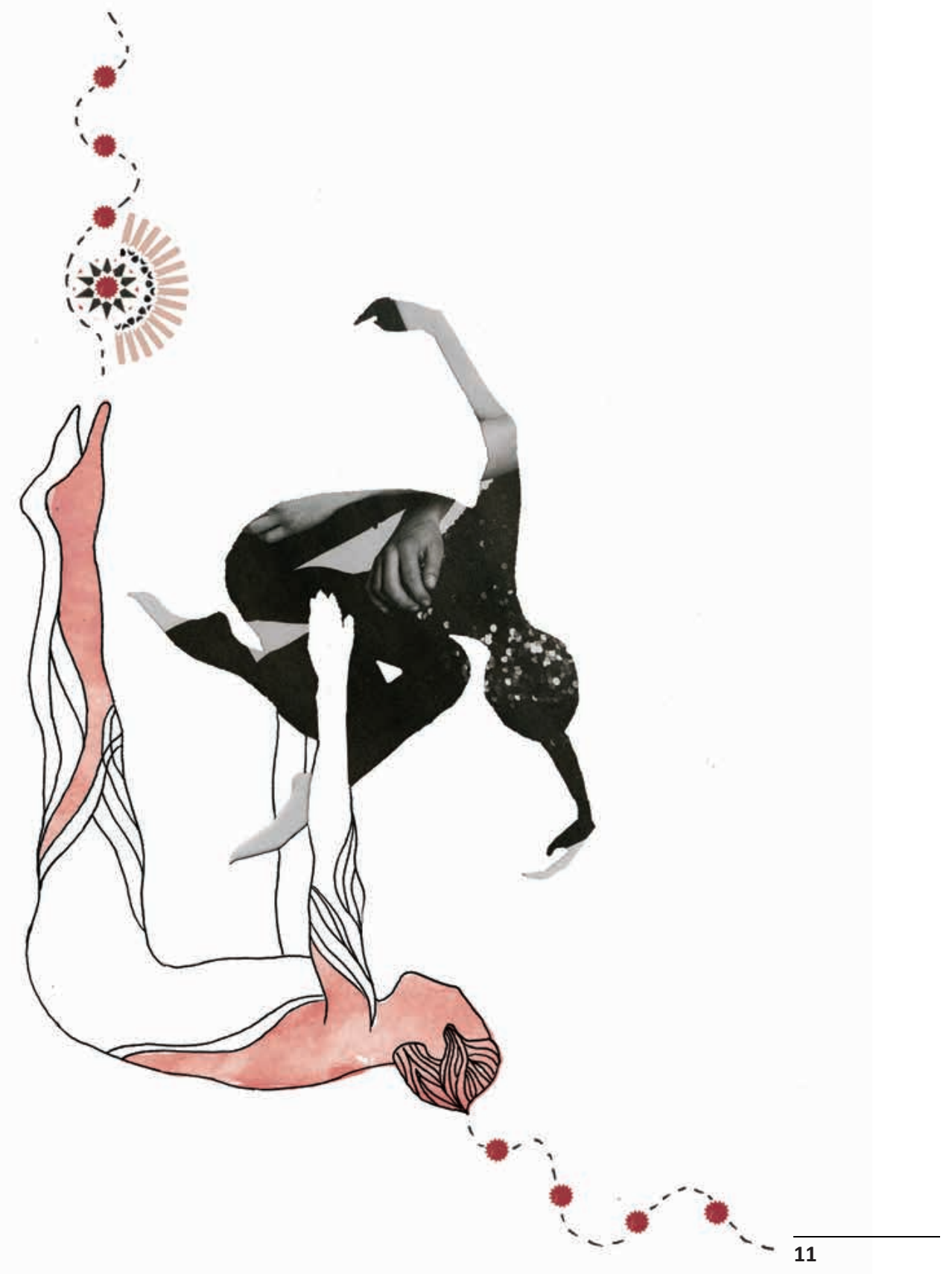


CHAPTER 1 
This chapter introduces the main concepts of this dissertation, discusses its background, and presents the dissertation's problem statement, aim and research questions. Also, it explains the perspectives that are used in this dissertation, and outlines how each chapter contributes to the dissertation's aim.

\section{The cultural origins of problem-based learning}

Problem-based learning (PBL) has been defined in many ways. ${ }^{1}$ The essence of its definition in this dissertation, complementary to the many existing definitions, is that $P B L$ is an educational approach that inherently carries a set of cultural norms and values.

The concept of PBL was developed and first implemented in 1968 in Canadian medical education as an answer to changing societal and educational needs. Students were overloaded with rapidly growing amounts of scientific information, and there was a general dissatisfaction with conventional teaching methods, which did not seem to deliver graduates fit for clinical practice. ${ }^{2}$ Since its inception in Canada, PBL has been implemented, practiced and discussed in a large variety of shapes and ways, though a number of essential characteristics have been identified: “(i) problems are used as a trigger for learning; (ii) students collaborate in small groups for part of the time; (iii) learning takes place under the guidance of a tutor; (iv) the curriculum includes a limited number of lectures; ( $v$ ) learning is student-initiated, and (vi) the curriculum includes ample time for self-study." ${ }^{3}$ Student-centered, as opposed to teacher-centered, learning is considered the key stone of PBL philosophy. ${ }^{4}$ A typical example of a PBL format is that students analyze a clinical problem in a small group, during which they activate prior knowledge and identify knowledge gaps. This leads them to jointly formulate learning objectives that they individually address during self-study time. Lectures, laboratory training and skills sessions can for example be used as resources. The group then gathers again to discuss their answers to the learning objectives and to apply this to the clinical problem case. During the group sessions, the tutor acts as a facilitator, for example by asking critical questions. Learning based on clinical problems is noted to enable an integration of basic and clinical sciences, including psychosocial, professional and ethical aspects of clinical problem cases. ${ }^{1}$

The characteristics of PBL can be defined as carrying a specific set of cultural norms and values, that can be associated with the Socratic learning approach as described by Tweed and Lehman. ${ }^{5}$ The authors offer a framework of cultural differences in learning that focuses on Socratic and Confucian approaches. They argue that a Socratic learning approach reflects culturally Western values, while a Confucian learning approach reflects culturally Chinese values. ${ }^{5}$ Examples of Socratic learning principles are verbal expression, individualism, independency, rationalism, tendency to question and evaluate, self-directed learning and acquiring self-generated knowledge. ${ }^{5}$ Confucian learners are characterized as effortful, respectful, pragmatic, persistent, diligent, learning and 
understanding by memorization, and acquiring knowledge from authorities and structured tasks. ${ }^{5}$ Tweed and Lehman emphasize, however, that this distinction should not be considered mutually exclusive and geographically restricted. At the cultural level, the Socratic learning approach refers to a set of educational principles that might be more common in the West, but not restricted to it, nor adopted by every Western institute and student. Western students also employ Confucian approaches, and it has been argued that, at the individual level, the Confucian-Socratic framework should be viewed as a continuum present in each individual. ${ }^{6}$ Evidently, the Confucian-Socratic framework is only one way of conceptualizing cultural differences in learning, while many other inter- and intra-regional approaches can be identified. ${ }^{7}$ The framework serves the purpose of this dissertation, however, by exposing the cultural origins and nature of PBL.

Essential characteristics of PBL, i.e. emphasis on student-centered learning, learning by discussing with others, identifying knowledge gaps during problem analysis, and generating knowledge through self-study, are compatible with the Socratic learning principles of verbal expression, independency, rationalism, self-directed learning, acquiring self-generated knowledge, and a focus on questioning and evaluating. PBL, as such, can be conceptualized as a Socratic learning approach that reflects culturally Western values. Previously, the philosophical roots of PBL have frequently been attributed to Socrates and other founding Western philosophers such as Aristotle, ${ }^{8-10}$ and to more contemporary Western philosophers such as Popper. ${ }^{10}$ Certain elements of PBL have also been found compatible with ancient Chinese educational philosophy, such as its focus on cooperative learning and the integration of knowing and doing. ${ }^{11}$ The roots of PBL are complex and reflect ancient influences between East and West, though it was developed in a contemporary Western cultural context and can mainly be conceptualized as a Socratic learning approach.

Another central concept of this dissertation, that arguably shares even more definitions than PBL, is culture. In this dissertation it is defined as shared motives, values, beliefs and identities of members of collectives, ${ }^{12,}{ }^{13}$ placed in and interacting with a dynamic social context. ${ }^{14}$ This definition enables the conceptualization of major concepts such as Western culture, while it simultaneously acknowledges numerous subcultures, and it implies that culture is contextually but not geographically bound. Culture needs to be analyzed in its particular context, because it is impossible to "isolate 'pure' cultural beliefs and behaviour from the social and economic context in which they occur". ${ }^{15}$ Indeed, 'pure' cultural beliefs and behaviour are virtually empty concepts considering the heterogeneous composition of current societies and individuals, which undergo a continuous process of change. ${ }^{15}$ It follows that the cultural values of PBL were shaped by the context in which PBL originated, and, as is the focus of this dissertation, interact with the dynamic cultural and social contexts to which this Socratic learning approach was subsequently transported. 


\section{The globalization of problem-based learning}

Since its original implementation in the late 1960s, PBL has become a globally distributed product. Its spread across the globe has been characterized as one of the most significant innovations in medical education. ${ }^{16-18}$ Despite an ongoing debate about its effectiveness, ${ }^{3,19-21}$ the unwavering popularity of the approach is apparent, as evidenced by its continuous promotion in different parts of the world. ${ }^{1,17,22-24}$ The cultural nature of PBL, as a key aspect of importance for its globalization, however, is rarely addressed. PBL's educational principles are often assumed to be universally valid, but its conceptualization as a Socratic learning approach suggests otherwise.

As exemplified by Tweed and Lehman's work, previous research has shown the existence of cross-cultural differences in learning styles, approaches, beliefs, behaviors and preferences. ${ }^{13,25-27}$ These differences create distinct educational contexts in which it might be problematic to apply learning approaches with different origins. Research outside medical education has pointed to the problematic nature and complexity of implementing and applying educational models that were developed in one context to a different context. ${ }^{28-31}$ Differences in students' learning beliefs and behaviors, in teachers' backgrounds, and in other relevant educational and institutional factors might not be considered, and complicate the cross-cultural implementation of education. Consequently, the applicability and appropriateness of Western-developed educational models and tools for non-Western contexts has been questioned. ${ }^{28,}{ }^{30,32}$ Beside the educational context, moreover, another potentially problematic area is the professional work context for which students are trained. It can be questioned whether outcomes of foreign educational models, such as students' skills and competencies, are applicable to local work settings.

Reviewing PBL's spread across the world, cross-cultural differences seem not to have limited its globalization, although it has been noted that cultural factors influence the decision of medical schools whether or not to adopt a PBL curriculum. ${ }^{33}$ Moving below the surface of PBL's globalization, however, it becomes apparent that crosscultural differences influence and complicate the way it is implemented and practiced across contexts. A number of studies on implementing PBL in an Asian context point to the conflicting and potentially challenging nature of certain $\mathrm{PBL}$ aspects in relation to local cultural values. ${ }^{11,34-36}$ For example, the open communication style expected of students in PBL might conflict with reticence as an Asian cultural value, which affects group dynamics in PBL. ${ }^{11,34-36}$ PBL's effectiveness for example for China has been questioned, which has been attributed "to the different cultural backgrounds of Chinese and Western students". ${ }^{37}$ Also the potential of PBL to enforce social and cultural change, by equipping its graduates with particular skills, has led to questions about its applicability in an Asian setting. ${ }^{38}$ Furthermore, a study on PBL in a Middle Eastern medical school noted cultural influences on group productivity, ${ }^{39}$ and a study on implementing PBL in a 
medical school in a sub-Saharan African context reported that the approach was eventually abandoned due to an unfavourable local context. ${ }^{40}$

Despite these potential complications, at the same time, evidence shows that PBL has successfully been implemented across cultural contexts. A PBL experiment at universities in Malaysia, Indonesia and the Philippines showed "an 'Asian' version of PBL", which worked well for students and tutors. ${ }^{41}$ Lee et al., Gwee, and Khoo identified a number of Asian cultural values that are compatible with the PBL approach, such as placing the group before the individual, collaborative learning, a strong drive for achievement, and self-discipline. ${ }^{11,34,36}$ Gwee argued that the cultural attitudes that are compatible with PBL can mitigate impeding cultural attitudes, and that PBL can be highly successful in Asia. ${ }^{34}$ Lam et al. reported that teachers in a PBL curriculum in Hong Kong felt that "better graduates were being produced with the new curriculum" compared with the previous conventional curriculum. ${ }^{42}$ Also a PBL experiment in the United Arab Emirates, while shaped by cultural experiences and expectations, showed favourable results. ${ }^{43}$ In South Africa, PBL has been valued for its potential to train students for rural work environments and for the culturally diverse South African context. ${ }^{44,45}$ In Uganda as well, PBL was reported to stimulate medical graduates' motivation and confidence to work effectively in rural areas. ${ }^{46}$

This brief - and not exhaustive - overview of existing literature suggests that PBL might be a valuable approach across a wide range of cultural contexts, but that implementation and application challenges are plentiful. Implementing and applying $\mathrm{PBL}$ is not without challenges anywhere, $8,47,48$ but might be additionally challenging and complex in cultural and educational contexts unfamiliar with cultural values and conditions of the Socratic learning approach. Moreover, PBL's interaction with these contexts seems to shape distinct PBL processes and outcomes across cultural contexts. In other words, the globalization of PBL is characterized by a cultural complexity that raises questions about its cross-cultural applicability.

\section{The cross-cultural applicability of problem-based learning}

The studies discussed above indicate the complexity of applying PBL across cultural contexts, but are often confined to one institution or region, and rarely address PBL's role in students' future work context beside the educational context. The implications of the cultural complexity that characterizes the globalization of PBL need to be investigated, both in more detail and in a wider scope, to provide more insight in the crosscultural applicability of PBL. There is a call for more research on the role of cultural values in $\mathrm{PBL}$, including cross-cultural, comparative research that focuses on cultural differences and similarities. ${ }^{36,49,50}$ Questions on how cross-cultural differences and similarities shape and challenge PBL processes and outcomes across the world, and on how these processes shape graduates for local work contexts need to be addressed to 
inform the worldwide use of this popular approach. Lively debates at medical education conferences and online discussion platforms, ${ }^{51-53}$ and the continuously growing number of medical schools worldwide that introduce PBL underline the pressing need for more research and insights in the cross-cultural implementation and application of PBL and the implications of globalization in medical education in general. The aim of this dissertation is to explore the cross-cultural applicability of PBL by addressing the following research questions:

\section{Research question 1: How is PBL shaped across cultures?}

Research question 2: How does PBL shape learners across cultures?

The formulation of these questions assumes that PBL interacts with the context in which it is placed, and that it shapes, as well as is shaped by, this context. This assumption is informed by a constructivist paradigm and a socio-cultural perspective. The field of medical education is characterized by a diversity of research paradigms and theoretical strands and perspectives. ${ }^{54-56}$ Following from a review of relevant paradigms, as overviewed in appendix $A$, a constructivist paradigm was considered to align with the topic and aim of this dissertation. In a constructivist paradigm, reality and knowledge are viewed as constructions that result from interactions between people. This implies that multiple truths exist, and that these are dependent on people in a particular context, which aligns with how culture is defined in this dissertation: as constructed by members of collectives who, placed in and interacting with a dynamic social context, construct shared motives, values, beliefs and identities.

A useful theoretical and methodological lens that enables the investigation of this 'culture in context' and its implications, and that logically follows from a constructivist stance, is socio-cultural theory. Socio-cultural theory addresses how individuals, while interacting with their cultural, social, economic, political and historical context, are shaped by this context, as well as shape this context itself. ${ }^{57,58}$ Besides providing a useful lens to study cultural issues, socio-cultural theories have moreover been promoted as useful perspectives to investigate learning, precisely because of their ability to take the (cultural) context in which learning takes place, as a major interacting entity, into account. ${ }^{55,57,58}$ The above research questions follow from this perspective, as they assume that PBL interacts with the cultural context in which it is placed, including the learners in this context, and that both are shaped, or constructed, by this interaction.

While the constructivist and socio-cultural lens serve as an overarching theoretical perspective in this dissertation, the dissertation is not methodologically confined to the socio-cultural approach. In two chapters a different methodological approach is employed that nonetheless is compatible with and serves the overarching perspective and research questions. Each chapter of the dissertation deconstructs a different element of the cultural complexity of PBL, aimed to enrich understanding about its cross-cultural 
applicability. Together the chapters form a stepwise uncovering - though not exhaustive - of how PBL is constructed and constructs learners across cultures.

Chapter 2 focuses on group discussions in PBL, as a major element in PBL curricula. The chapter describes and compares how first and third year medical students shape PBL group discussions, and how they are shaped by these discussions, across three medical schools, located in the Middle East, East Asia and Western Europe, respectively. The chapter takes an explicit socio-cultural approach and focuses on the interaction between the PBL group discussions, students, and the wider context, and identifies relevant factors of influence on processes and outcomes of the group discussions across the three cultural contexts.

Chapter 3 focuses on self-directed learning in PBL. The chapter describes and compares how students shape self-directed learning in PBL, and how students are shaped by the self-directed learning element of PBL across the same three medical schools as in chapter 2. The chapter clarifies the interaction between the self-directed learning element of PBL, the students, and the surrounding context, and identifies relevant factors that shape self-directed learning processes and outcomes across the three contexts. The data for chapters 2 and 3 were collected simultaneously in a cross-cultural, comparative case study, which is why some overlap between the chapters, especially in the method sections, was inevitable.

Chapter $\mathbf{4}$ connects the educational context with students' future work context and focuses on how PBL prepares students for practice in a cultural context very different from the one in which PBL was originally developed. The chapter mainly focuses on research question 2 and describes how fifth year medical students and graduates from a PBL curriculum in a sub-Saharan African context feel their education prepares or has prepared them for work in their local setting. A comparison is made with students and graduates from a conventional curriculum in the same context. Rather than an explicit socio-cultural approach, this chapter employs mixed methods to grasp the multifaceted elements of students' and junior doctors' preparedness for practice.

Chapter $\mathbf{5}$ focuses on the complexity of implementing PBL in the same sub-Saharan African context as in chapter 4 . The chapter compares how fifth year students from three curricula in this context feel prepared for practice: a PBL curriculum that successfully coped with implementation challenges, a PBL curriculum that heavily suffered from implementation challenges and eventually was abandoned, and a conventional curriculum. The chapter describes the major role of the context in how PBL and students are shaped. The data for chapters 4 and 5 were collected simultaneously using the same mixed methods approach, which is why the chapters show some overlap.

Chapter 6 reflects on how the cultural complexity of PBL, and of cultural issues in medical education in general, can be studied. This methodological chapter elaborates on the socio-cultural approach used in chapters 2 and 3 - socio-cultural activity theory and proposes it as a useful practical and theoretical framework to study cultural complexity, and in this case, to inform the cross-cultural applicability of PBL. The chapter 
discusses the theoretical background of activity theory and the research steps involved in the cross-cultural case study of chapters 2 and 3 to demonstrate activity theory's practical use.

Chapter 7 summarizes and discusses how the previous chapters have answered the two research questions, and which conclusions and implications this yields for the cross-cultural applicability of PBL. The chapter distinguishes a practical and a critical discussion of the dissertation's conclusions and implications. Furthermore, strengths and limitations of the research are discussed, and directions for future research are indicated. The chapter describes how from deconstructing cultural complexity, as exemplified in this dissertation, next steps can be taken to raise cultural awareness, to address and take advantage of cultural activity, and to take action to construct optimal, context-sensitive educational innovations.

This dissertation is based on articles. Some repetition of information can therefore not be avoided. As indicated above, it lies beyond the scope of this dissertation to address the cultural complexity of PBL across the world in full. Probably that would lie beyond the scope of any feasible research project. This dissertation aims to explore, rather than determine, the cross-cultural applicability of PBL. The next chapters deconstruct the cross-cultural nature of some essential elements of PBL, but it should be noted that more constructions exist that are left untouched in this dissertation.

\section{References}

1. Taylor D, Miflin B. Problem-based learning: where are we now? AMEE Guide No. 36. Med Teach 2008;30(8):742-63.

2. Barrows HS. Problem-Based Learning in Medicine and Beyond: A Brief Overview. New Dir Teach Learn 1996;68:3-12.

3. Schmidt HG, Rotgans JI, Yew EH. The process of problem-based learning: what works and why. Med Educ 2011;45(8):792-806.

4. Dolmans $\mathrm{DH}$, Wolfhagen $\mathrm{IH}$, van der Vleuten $\mathrm{CP}$, Wijnen $\mathrm{WH}$. Solving problems with group work in problem-based learning: hold on to the philosophy. Med Educ 2001;35(9):884-9.

5. Tweed RG, Lehman DR. Learning considered within a cultural context: Confucian and Socratic approaches. Am Psychol 2002;57(2):89-99.

6. Gurung RAR. Comparing cultural and individual learning tendencies. Am Psychol 2003;58(2):145-6.

7. Signorini $P$, Wiesemes $R$, Murphy R. Developing alternative frameworks for exploring intercultural learning: a critique of Hofstede's cultural difference model. Teach High Educ 2009;14(3):253-64.

8. Savin-Baden M. Problem-based Learning in Higher Education: Untold Stories. Buckingham: Open University Press 2000.

9. Schmidt HG, Moust, JHC. Probleemgestuurd Onderwijs. Praktijk en Theorie [Problem-based Learning. Practice and Theory]. Groningen: Wolters-Noordhoff 1998.

10. Wang SY, Tsai JC, Chiang HC, Lai CS, Lin HJ. Socrates, problem-based learning and critical thinking - A philosophic point of view. Kaohsiung J Med Sci 2008;23(3):S6-S13.

11. Lee WM, Wong FK, Mok ES. Problem-based learning: ancient Chinese educational philosophy reflected in a modern educational methodology. Nurse Educ Today 2004;24(2):136-44. 
12. House RJ, Hanges PJ, Javidan M, Dorfman PW, Gupta V. Culture, leadership and organizations: The GLOBE study of 62 Societies. Sage Publications Inc 2004.

13. Joy S, Kolb DA. Are there cultural differences in learning style? Int J Intercult Relat 2009;33(1):69-85.

14. Taylor JS. Confronting "culture" in medicine's "culture of no culture". Acad Med 2003;78(6):555-9.

15. Helman CG. Culture, Health and IIIness, 5 edn. London: Hodder Arnold 2007.

16. Frenk J, Chen L, Bhutta ZA, Cohen J, Crisp N, Evans T, et al. Health professionals for a new century: transforming education to strengthen health systems in an interdependent world. Lancet 2010;376(9756):1923-58.

17. Neville AJ. Problem-based learning and medical education forty years on. A review of its effects on knowledge and clinical performance. Med Princ Pract 2009;18(1):1-9.

18. Maudsley G. Do we all mean the same thing by "problem-based learning"? A review of the concepts and a formulation of the ground rules. Acad Med 1999;74(2):178-85.

19. Kirschner PA, Sweller J, Clark RE. Why minimal guidance during instruction does not work: An analysis of the failure of constructivist, discovery, problem-based, experiential, and inquiry-based teaching. Educ Psychol 2006;41(2):75-86.

20. Schmidt HG, Van der Molen HT, Te Winkel WWR, Wijnen WHFW. Constructivist, Problem-Based Learning Does Work: A Meta-Analysis of Curricular Comparisons Involving a Single Medical School. Educ Psychol 2009;44(4):227-49.

21. Shanley PF. Viewpoint: leaving the "empty glass" of problem-based learning behind: new assumptions and a revised model for case study in preclinical medical education. Acad Med 2007;82(5):479-85.

22. Amin Z, Hoon Eng K, Gwee M, Dow Rhoon K, Chay Hoon T. Medical education in Southeast Asia: emerging issues, challenges and opportunities. Med Educ 2005;39(8):829-32.

23. Bate E, Hommes J, Duvivier R, Taylor DC. Problem-based learning (PBL): Getting the most out of your students - Their roles and responsibilities: AMEE Guide No. 84. Med Teach 2014;36(1):1-12.

24. Gukas ID. Global paradigm shift in medical education: issues of concern for Africa. Med Teach 2007;29(9):887-92.

25. Apfelthaler G, Hansen K, Keuchel S, Mueller C, Neubauer M, Ong SH, et al. Cross-cultural Differences in Learning and Education: Stereotypes, Myths and Realities. In: Palfreyman D, McBride DL, eds. Learning and Teaching Across Cultures in Higher Education. London: Palgrave MacMillan 2007.

26. Charlesworth Z. Learning styles across cultures: Suggestions for educators. Educ \& Train 2008;50(2):11527.

27. Li J. Mind or virtue: Western and Chinese beliefs about learning. Curr Dir Psychol Sci 2005;14(4):190-4.

28. Altinyelken HK. Pedagogical renewal in sub-Saharan Africa: the case of Uganda. Comp Educ 2010;46(2):151-71.

29. Elliott J, Tudge J. The impact of the west on post-Soviet Russian education: change and resistance to change. Comp Educ 2007;43(1):93-112.

30. Nguyen PM, Elliott J, Terlouw C, Pilot A. Neocolonialism in education: Cooperative Learning in an Asian context. Comp Educ 2009;45(1):109-30.

31. Rappleye J, Imoto Y, Horiguchi S. Towards 'thick description' of educational transfer: understanding a Japanese institution's 'import' of European language policy. Comp Educ 2011:iFirst Article.

32. Chan S. The Chinese learner: A question of style. Educ \& Train 1999;41(6-7):294-304.

33. Jippes M, Majoor GD. Influence of national culture on the adoption of integrated and problem-based curricula in Europe. Med Educ 2008;42(3):279-85.

34. Gwee MC. Globalization of problem-based learning (PBL): cross-cultural implications. Kaohsiung J Med Sci 2008;24(3 Suppl):S14-22.

35. Walker A, Bridges $E$, Chan B. Wisdom gained, wisdom given: instituting PBL in a Chinese culture. J Educ Admin 1996;34(5):12-31.

36. Khoo HE. Implementation of problem-based learning in Asian medical schools and students' perceptions of their experience. Med Educ 2003;37(5):401-9. 
37. Lam TP, Wan XH, Ip MS. Current perspectives on medical education in China. Med Educ 2006;40(10):940-9.

38. Conway J, Little P, McMillan M. Congruence or conflict? Challenges in implementing problem-based learning across nursing cultures. Int J Nurs Pract 2002;8(5):235-9.

39. Das Carlo M, Swadi H, Mpofu D. Medical student perceptions of factors affecting productivity of problem-based learning tutorial groups: does culture influence the outcome? Teach Learn Med 2003;15(1):59-64.

40. Mufunda J, Chatora R, Ndambakuwa Y, Samkange C, Sigola L, Vengesa P. Challenges in training the ideal Doctor for Africa: lessons learned from Zimbabwe. Med Teach 2007;29(9):878-81.

41. Hussain RMR, Mamat WHW, Salleh N, Saat RM, Harland T. Problem-based learning in Asian universities. Stud High Educ 2007;32(6):761-72.

42. Lam TP, Khoo US, Chan YS, Cheng YH, Lam KF. The first batch of graduates of a new medical curriculum in Asia: how their teachers see them. Med Educ 2004;38(9):980-6.

43. Mpofu DJS. Introducing problem-based learning into a traditional medical school: student and staff perceptions of the United Emirates University's innovation. PhD Diss, Maastricht University 1999.

44. Singaram VS, Dolmans DH, Lachman N, van der Vleuten CP. Perceptions of problem-based learning (PBL) group effectiveness in a socially-culturally diverse medical student population. Educ Health 2008;21(2):116.

45. Iputo JE. Faculty of health sciences, walter sisulu university: training doctors from and for rural South african communities. MEDICC Rev 2008;10(4):25-9.

46. Kaye DK, Mwanika A, Sewankambo N. Influence of the training experience of Makerere University medical and nursing graduates on willingness and competence to work in rural health facilities. Rural Remote Health 2010;10(1):1372.

47. Dolmans DH, De Grave W, Wolfhagen IH, Van der Vleuten CP. Problem-based learning: future challenges for educational practice and research. Med Educ 2005;39(7):732-41.

48. Moust JHC, van Berkel HJM, Schmidt HG. Signs of erosion: Reflections on three decades of problembased learning at Maastricht University. High Educ 2005;50(4):665-83.

49. Leung WC. Why is evidence from ethnographic and discourse research needed in medical education: the case of problem-based learning. Med Teach 2002;24(2):169-72.

50. Yazigi A, Nemr E, Abou Jaoude S. Implementation of problem-based learning in Asia: similarities between Far East and Middle East medical schools. Med Educ 2004;38(2):223.

51. Sim D, Patil N, Rehatta N, Kwan C. PBL is not suitable for Asian students. Symposium, Sixth Congress of the Asian Medical Education Association, 23-26 March, 2011, Kuala Lumpur.

52. PBL aspac. Discussion platform on PBL in the Asian-Pacific region. http://www.yahoogroups.com/neo/groups/pblaspac/info

53. Hodges B, Ho M-J, Martimianakis T, Segouin C. The Globalisation of Medical Education and its Discontents. Symposium, Conference of the Association of Medical Education in Europe, 25-29 August, 2012, Lyon.

54. Mann K, Dornan T, Teunissen P. Perspectives on learning. In: Dornan T, Mann K, Scherpbier A, Spencer J, eds. Medical Education: Theory and Practice. Churchill Livingstone Elsevier 2011:17-38.

55. Mann KV. Theoretical perspectives in medical education: past experience and future possibilities. Med Educ 2011;45(1):60-8.

56. Bunniss S, Kelly DR. Research paradigms in medical education research. Med Educ 2010;44(4):358-66.

57. Nasir NiS, Hand VM. Exploring Sociocultural Perspectives on Race, Culture, and Learning. Rev Educ Res 2006;76(4):449-75.

58. Tsui ABM, Lopez-Real F, Edwards G. Sociocultural Perspectives of Learning. In: Tsui ABM, Lopez-Real F, Edwards G, eds. Learning in School-University Partnership: Sociocultural Perspectives. New York: Routledge 2009:25-43. 



\section{CHAPTER 2 \\ The cultural complexity of group discussions in PBL}
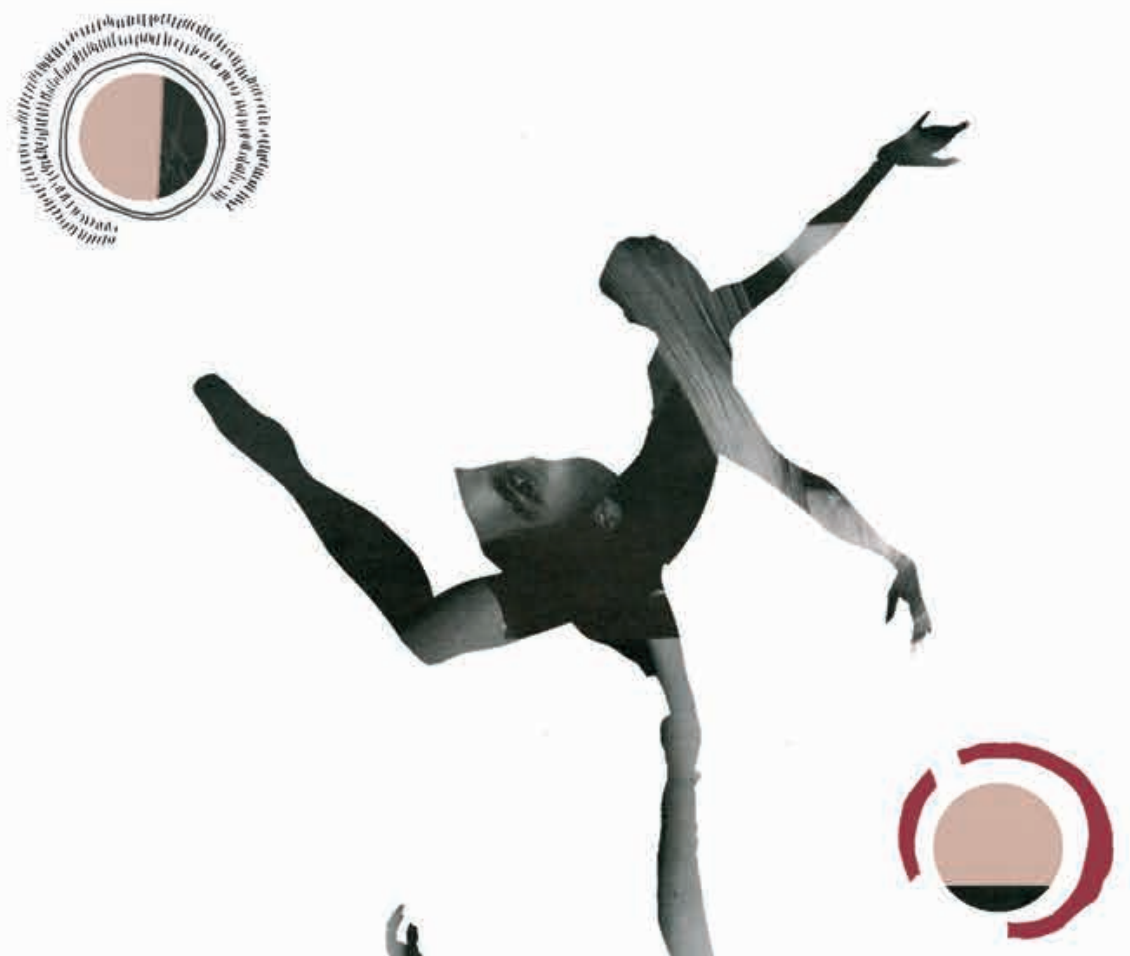

Published as:

Frambach JM, Driessen EW, Beh P, van der Vleuten CPM. Quiet or questioning? Students' discussion behaviors in student-centered education across cultures. Studies in Higher Education 2013; aheadof-print:1-21 
CHAPTER 2 


\section{Introduction}

Many studies have confirmed the widely acknowledged notion that communication styles differ across cultural contexts. ${ }^{1-3}$ This also applies, by implication, to the way students communicate with their peers and their teachers. ${ }^{4}$ In recent years, there has been a steady increase in the number of higher education institutions worldwide that have introduced student-centered education, which is intrinsically different from traditional teacher-centered approaches. The former aims to focus on students' learning rather than on teachers' teaching. ${ }^{5}$ Institutions embrace this approach partly because it encourages students to take charge of their own learning, which is assumed to stimulate lifelong learning, critical thinking, motivation, and independent problem-solving skills. ${ }^{5-7}$ One of the educational tools in student-centered education is small group work, where students are expected to actively engage in critical discussions about learning topics, problem cases, or projects. Active participation in discussions is assumed to enhance students' collaborative skills, independence, motivation, and critical thinking. 8

Several authors have contended that this type of interactive and independent behavior reflects typically Western values, such as individualism and a focus on verbal interaction. e.g. $10-12$ Values of other cultures may not be compatible with the Western values residing in the student-centered approach. This leads to the question as to how the communication styles of students from different cultures are expressed and shaped in discussions in student-centered education, which might shed light on - possibly unintended - cross-cultural differences in processes and outcomes in student-centered higher education. Research has indeed indicated that interactive, team-based and teacher-independent discussions in student-centered education can cause tensions due to their not being consistent with learning approaches and communication styles in non-Western settings. ${ }^{11,13-15}$ In student-centered education, students are expected to show rather assertive behaviors - such as speaking up, asking questions, and challenging the opinions of others - and students' responses to this may vary between cultures thereby shaping learning processes and outcomes in different ways.

Cross-cultural differences in communication styles have been extensively researched, particularly in Eastern and Western cultures. e.g. 3, 16, 17 Eastern cultures are often characterized as collectivistic, in contrast to Western cultures, which are regarded as individualistic. ${ }^{18,19}$ Collectivism refers to being concerned with the group rather than the individual, interdependence of group members, and behaviors that are shaped by group norms and values. ${ }^{20}$ It should be noted though that cultural diversity within Eastern and Western regions can be larger than across, and they cannot be characterized straightforwardly as either collectivistic or individualistic. Previous research has, however, shown a general preference of Eastern cultures for collectivistic communication styles, which tend to favor harmonious group relations, avoidance of conflict, and indirect communication as opposed to a more confrontational, direct, and outspoken style 
of individualistic cultures. ${ }^{3,16,21}$ Consequently, it seems logical to assume that the distinction between individualistic Western cultures and collectivistic Eastern cultures is likely to lead to cross-cultural differences in communicative behaviors demonstrated by students in discussions in student-centered education.

This socio-cultural study attempted to identify the existence and nature of such cross-cultural differences by investigating the discussion process and the development of students' communicative behaviors in student-centered education in three institutions of higher education in different cultural regions: East Asia, the Middle East, and Western Europe. This way, the study aims to provide insight into how cross-cultural differences in communication styles are expressed and shaped in student-centered education, and how this may impact on the cross-cultural applicability of studentcentered methods in higher education.

\section{The case of problem-based learning}

Problem-based learning (PBL) is the student-centered educational model that was selected as the object of this case study. Originally developed in the West, more specifically in medical education in Canada in the 1960s, PBL has spread to different disciplines and countries around the world, ${ }^{7,13,22}$ though its effect remains controversial. ${ }^{23-25}$ In contrast to teacher-centered, lecture-based educational approaches, PBL places students at the center of the educational process by encouraging them to direct their own learning processes, construct knowledge actively, and develop problem-solving and team communication skills. ${ }^{26,27}$ Tutorials take a central role in PBL, during which a small group of students collaboratively discusses a learning issue presented as a problem case, aided by a tutor who acts as a facilitator rather than a knowledge transmitter. $^{7}$

Despite PBL's spread around the world, its cross-cultural applicability has been questioned. In a study of the implementation of PBL in a Chinese context, Walker, Bridges and Chan found that cultural tensions affected group dynamics, the discussion process, and communication issues, with Chinese students showing a strong sense of politeness, harmony, and conformity as well as reluctance to directly introduce arguments in the discussion. ${ }^{28}$ Khoo described several Asian cultural attitudes that might be incompatible with PBL, such as fear of confrontation, dependency on and respect for authority, a distaste for outspokenness, reluctance to ask questions, and low participation in class discussions. ${ }^{14} \mathrm{He}$ also identified aspects, however, that seem quite compatible with PBL, such as strong self-discipline and collaboration among students. Also Hussain et al. report positive reactions to PBL in three Asian universities, but at the same time they show inhibitions to students' development of critical thinking during PBL sessions, due to a non-confrontational attitude. ${ }^{29}$ However, they emphasize that also in Western universities the achievement of critical thought might be difficult for students. 
Although the majority of studies on the implementation of PBL in non-Western settings has been conducted in East Asia, the few studies that were conducted in the Middle East suggested that similar issues and difficulties with PBL are encountered in this region, and that these seem to be, at least partially, attributable to cultural factors. ${ }^{11,30-32}$ Based on these considerations, PBL was selected as the discussion-based, studentcentered educational model to be examined in this study.

\section{A socio-cultural approach}

Because of the paucity of empirical comparative studies of student-centered education in Western and non-Western settings, a socio-cultural approach was used to explore the impact not only of cultural but also of educational and possibly other factors on students' discussion behaviors. Socio-cultural theory is based on the work of several Russian scholars, notably Vygotsky, ${ }^{33}$ on which others have elaborated, e.g. Rogoff ${ }^{34}$ and Engeström. ${ }^{35}$ Socio-cultural theorists emphasize that individuals are inherently influenced, or mediated, by their environment and cannot be understood outside of it. $^{36,37}$ Individuals continuously internalize their social, cultural, and contextual surroundings, while at the same time influencing their surroundings by externalizing their inner values and beliefs. ${ }^{38}$ This socio-cultural perspective led to the following research question: to what extent do students across three cultures externalize their cultural backgrounds and simultaneously internalize the discussion aspect of PBL, and how does this shape their discussion behaviors and skills?

As remarked above, a socio-cultural approach allows for consideration of other factors - besides PBL and students' cultural backgrounds - which might mediate students' discussion behaviors. Interestingly, research on the implementation of PBL in the West has also revealed problems with the PBL process, notably superficiality of small group discussions. ${ }^{39}$ More contextual factors besides cultural ones may play a role, such as institutional, organizational, and curricular aspects. By adopting an explorative and open socio-cultural perspective, this study aimed for broad coverage of contextual factors to build a comprehensive picture of the influences shaping students' discussion behaviors and skills in student-centered higher education across cultures. For a more extensive discussion of how socio-cultural theory can be used to study students' behavior and development in problem-based learning see our previous paper. ${ }^{11}$

\section{Method}

\section{Methodology}

Consistent with the socio-cultural perspective that guided this study, the participants were investigated in their natural setting. A comparative, instrumental case study ${ }^{40}$ was 
deemed suitable for this purpose, because it enables investigation of an issue as a holistic phenomenon, encompassing its cultural and contextual setting, while comparison of multiple cases could provide insight arising from differences and similarities across cases.

\section{Setting}

As PBL is most widely used in medical education - the discipline where it was originally developed - the study was conducted in medical schools. To enable informative comparisons, it was decided to include a Western medical school and two medical schools in different non-Western settings. For selection of the latter, nine international medical education experts were asked to suggest medical schools that met the following criteria: 1) location in a non-Western cultural setting; 2) PBL as a substantial teaching method in the undergraduate curriculum; 3) more than five years of experience with $P B L$ in the curriculum. Eleven of 22 suggestions met all criteria, from which a medical school in Hong Kong and a medical school in the Arab part of the Middle East were selected based on their locations in different Eastern cultural regions. Since the Middle Eastern school wished to remain anonymous, its national location is not revealed here. Thick description of cultural and other contextual factors was used to overcome the wideness of the term Middle East, as Middle Eastern nations share but evidently also differ in cultural characteristics. The selection of a medical school in the Netherlands as a Western case was based on pragmatic reasons, but the school met selection criteria two and three, while of necessity failing criterion one. The study was approved by the ethical review boards of the Hong Kong and the Middle Eastern schools, while no approval was required for the study at the Dutch school.

Table 1 lists several PBL aspects for the three schools. Since their foundation, the Dutch and the Middle Eastern school had used PBL as the major educational method in the undergraduate years, with relatively few teacher-based lectures. The Hong Kong school had implemented PBL as part of an overall curriculum reform in the 1990s aimed at moving from a traditional teacher-centered curriculum to a student-centered one. The reform resulted in a hybrid curriculum that was partly lecture-based and partly PBL.

Table 1. Characteristics of PBL in the three institutions.

\begin{tabular}{lccc} 
& Middle Eastern school & Hong Kong school & Dutch school \\
Period of applying PBL & $>30$ years & $>10$ years & $>30$ years \\
Average number of lectures per week & 4 & 7 & 2 \\
Average PBL group size & 10 & 10 & 10 \\
Average number of discussion sessions per & $2(2)$ & $2(1)$ & $2(1)$ \\
week: Year 1 and 2 (Year 3) & & English & Dutch \\
Language of instruction & English (formally) & & \\
\hline
\end{tabular}




\section{Data collection}

As the study was conducted within the framework of a broader research project on the cross-cultural applicability of PBL, ${ }^{11}$ data collection methods focused also on other PBL aspects besides group discussions. In each of the institutions, data were collected during one month of field work between November 2009 and April 2010. In the Middle Eastern and Hong Kong schools, data were collected by the first author and in the Dutch medical school by an external research assistant to ensure that data collection was done by an outsider to the school in question. Several qualitative data collection methods were used.

Firstly, a total of 88 individual in-depth interviews were conducted with students, tutors, and key staff involved in PBL, lasting an average of one hour each. The interviews were semi-structured, with questions focusing on practices, experiences, perceptions, preferences, and difficulties relating to PBL; PBL discussion sessions; adaptive behaviors of students in response to PBL and PBL discussions; the development of discussion and other PBL-related skills; changes and differences between year levels; students' past educational experiences; and the nature, meaning, and influence of cultural and other contextual factors. The participants were asked to give oral and written informed consent, and they received a symbolic gift as gratitude. The interviews were audio recorded and transcribed verbatim.

Interview participants were recruited purposively to include both male and female students, students from different PBL groups, and students born and raised in the local setting. A number of students who had lived and attended school in another country for some time were also included, because this was expected to yield richer comparative information. Approximately equal numbers of students from the first and the third year were included to detect differences with respect to experienced difficulties and discussion behaviors and skills. The students were recruited through announcements in lectures and in PBL sessions. The tutors were also selected purposively to include tutors with different disciplinary backgrounds, and tutors from the first and third year. Table 2 presents demographic data on the student and tutor samples. Key staff involved in PBL were selected through snowball sampling. At each institution they included (former) deans of medicine and/or education, directors of medical education departments, and staff who were involved in the PBL implementation from the beginning and had performed a range of coordinating roles. 
Table 2. Demographic information about the student and tutor samples.

\begin{tabular}{|c|c|c|c|}
\hline & $\begin{array}{l}\text { Middle Eastern } \\
\text { school }\end{array}$ & $\begin{array}{l}\text { Hong Kong } \\
\text { school }\end{array}$ & $\begin{array}{l}\text { Dutch } \\
\text { school }\end{array}$ \\
\hline \multicolumn{4}{|l|}{ Students } \\
\hline Mean age: first-year students & 17.3 & $18.6^{*}$ & 19.1 \\
\hline Mean age: third-year students & 19.0 & $21.0 * *$ & 21.3 \\
\hline Gender: female & $42.1 \%$ & $47.4 \%$ & $88.9 \%$ \\
\hline Ethnicity: Arab, Chinese, Dutch, respectively & $97.4 \%$ & $94.7 \%$ & $77.8 \%$ \\
\hline $\begin{array}{l}\text { International experience: students who had } \\
\text { lived abroad >1 year }\end{array}$ & $15.8 \%$ & $15.8 \%$ & $16.7 \%$ \\
\hline \multicolumn{4}{|l|}{ Tutors } \\
\hline Gender: female & 6 of 6 & 1 of 6 & 2 of 5 \\
\hline Disciplinary background & $\begin{array}{c}\text { Anatomy (2) } \\
\text { Histology } \\
\text { Medical education (3) }\end{array}$ & $\begin{array}{c}\text { Anatomy } \\
\text { Biochemistry } \\
\text { Pathology (3) } \\
\text { Surgery }\end{array}$ & $\begin{array}{c}\text { Anatomy (2) } \\
\text { Pharmacology } \\
\text { Orthopaedics } \\
\text { Family medicine }\end{array}$ \\
\hline Ethnicity: Arab, Chinese, Dutch, respectively & 6 of 6 & 4 of 6 & 5 of 5 \\
\hline
\end{tabular}

*Excluded: 2 unknown, 1 outlier, **Excluded: 1 unknown, 1 outlier

Secondly, a total of 32 PBL discussion sessions were observed. An observation sheet was developed which focused on discussion behaviors, cultural differences in learning and communication, and other contextual factors that might affect the discussions. For the observations, different PBL groups from the first and the third year were randomly selected. Before the session, the researcher was briefly introduced and the students were asked to conduct the session as usual. The researcher took field notes and filled in the observation sheet, without participating in the session. Table 3 shows how the observations and interviews were distributed over the three institutions.

Table 3. Number of interviews and observations at the three institutions.

\begin{tabular}{lcccc} 
& Middle Eastern school & Hong Kong school & Dutch school & Total \\
Interviews first-year students & 9 & 10 & 9 & 28 \\
Interviews third-year students & 10 & 9 & 9 & 28 \\
Interviews PBL tutors & 6 & 5 & 5 & 17 \\
Interviews key PBL staff & 5 & 30 & 5 & 15 \\
Total number of interviews & $\mathbf{3 0}$ & 6 & 8 & $\mathbf{8 8}$ \\
Observations in year 1 & 5 & 6 & 2 & 13 \\
Observations in year 3 & 5 & $\mathbf{1 2}$ & $\mathbf{1 0}$ & $\mathbf{3 2}$ \\
Total number of observations & 10 & & & 13 \\
\hline
\end{tabular}


Thirdly, documents about the implementation and application of PBL were obtained from key staff, such as information booklets for students, course schedules, problem cases, forms to evaluate students, information about the curriculum, and general evaluations of PBL. Finally, additional contextual information about the institutional and local culture was collected by participant observation during lectures, in faculty offices, and during leisure activities. The researchers recorded this information in a research journal.

\section{Data analysis}

Template Analysis, a specific step-wise type of thematic analysis, was used to analyze the data. ${ }^{41,42}$ In Template Analysis a succession of coding templates consisting of hierarchically structured themes is developed and iteratively applied to the data with themes being modified continuously as the analysis progresses. Figure 1 presents the different templates and the related steps. To start with, the researchers formulated themes that were a priori anticipated to be identified in the analysis, such as difficulties that students encountered in the discussion sessions, or strategies which they developed to deal with the sessions. The first and second author independently coded a subsample of the interview transcripts with these themes, during which they identified new themes, modified existing themes and deleted redundant themes. Coding was performed using Atlas.ti Version 6.2 (Scientific Software Development, GmbH, Berlin, Germany), a software program for qualitative data analysis. After reaching agreement on the occurrence and interpretation of themes through discussion, the two authors developed an initial coding template, which was applied to half of the interview transcripts.

After the final template was developed and iteratively applied to the first half of the transcripts, the researchers interpreted the findings while focusing on the identification of patterns, causes, frequency, meaning, and salience with regard to tensions and difficulties in PBL discussions, students' change and development, factors influencing student behaviors, and comparisons between the three institutions and between first-year and third-year students across and within the institutions. The focused template that resulted from the interpretation was applied to the remaining half of the transcripts with particular attention for disconfirming evidence, and was also used to analyze the observation sheets, field notes, documents and research journal. A final interpretation resulted in a conceptual model encompassing the relationships between cultural and other contextual factors, cross-cultural differences in students' communicative behaviors and development in relation to PBL discussions. 


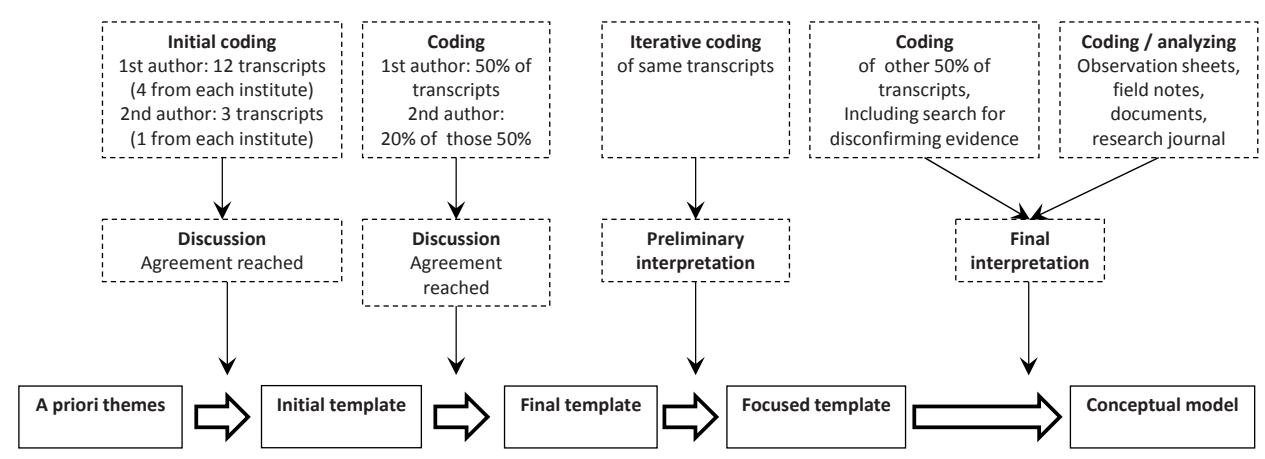

Figure 1. The Template Analysis process.

\section{Trustworthiness}

Several measures were taken to enhance the study's trustworthiness. First, triangulation of data was achieved through multiple data collection methods. Second, data collection continued until saturation occurred. Third, the coding process was iterative, included a search for disconfirming evidence, and was conducted independently by two researchers. Fourth, to increase awareness of researcher bias the researchers kept a reflexive research journal during fieldwork. Fifth, the data were collected by researchers who were outsiders to the institutions they investigated, as this was assumed to encourage participants to give honest answers. Finally, a member check among a sample of the interview participants was conducted. In response to the question asking whether they agreed with summaries of preliminary results and would provide comments, confirmatory responses were received as well as some additional comments and clarifications. The latter were taken into account in the analysis and interpretation of the data.

\section{Results}

The results from the four data sources (interviews, observations, documents, and context information) are presented in an integrated manner. Students of the three schools were found to internalize PBL and externalize their cultural backgrounds to different degrees, which led to cross-cultural differences in discussion behaviors. Behaviors of speaking up, asking questions, and challenging others in the discussion were found to be influenced by four cultural factors: (1) uncertainty and tradition, (2) group relations and face, (3) hierarchical relations, and (4) achievement and competition. Compared with the Western case, the two non-Western cases showed a stronger impact of these factors, which generally had an adverse effect on the discussion process. 
This relationship, however, was not straightforward, as six other contextual factors were also found to either inhibit or enhance discussion behaviors: (1) the nature of students' prior school education, (2) the scope of PBL implementation, (3) students' personal characteristics, (4) language of instruction, (5) tutor behavior, and (6) the assessment system. In the three schools, the students' discussion behaviors and skills and their development from the first to the third year were shaped by complex interactions between contextual factors, cultural factors, and the PBL discussion sessions. The conceptual model is presented in figure 2. Below, the different factors in the model and their interactions are discussed - not in order of importance - and illustrated by quotes from the interviews. Table 4 provides a detailed overview of the potential of the contextual factors to inhibit or enhance discussion dynamics.

Table 4. Discussion inhibiting and enhancing elements of contextual factors.

\begin{tabular}{|c|c|c|}
\hline Contextual factor & Inhibiting the discussion & Enhancing the discussion \\
\hline Prior education system & Traditional, teacher-centered system & Student-centered system \\
\hline Scope of implementation & Content of PBL covered in lectures & $\begin{array}{l}\text { Content mainly covered in PBL ses- } \\
\text { sions }\end{array}$ \\
\hline Personality differences & Dominant and quiet students & Curious and confident students \\
\hline Language of instruction & $\begin{array}{l}\text { Other than native language if not suffi- } \\
\text { ciently mastered by all students }\end{array}$ & $\begin{array}{l}\text { Formal or informal use of native } \\
\text { language }\end{array}$ \\
\hline Tutor behavior & Dominant tutor or inactive tutor & $\begin{array}{l}\text { Active tutor who stimulates and } \\
\text { explains }\end{array}$ \\
\hline Assessment system & No substantial assessment in PBL session & Substantial assessment in PBL session \\
\hline
\end{tabular}

\section{Uncertainty and tradition}

In the Middle Eastern case, feelings of uncertainty appeared to inhibit students from speaking up in the discussion. First-year students in particular experienced uncertainty in the PBL discussion sessions, which was aggravated by the teacher-centered nature of their secondary school education (see the discussion on prior education below). Having to discuss a problem case without relevant prior knowledge gave rise to feelings of uncertainty, which prevented students from speaking up. As a tutor explained:

"The first year is difficult to students. They face many difficulties. ... The system of education is different from the system in secondary schools. In the discussion meeting, they were very angry and confused, because they did not yet have any medical knowledge. So they did not say anything. ... They are afraid to say anything, to think." (Middle East tutor 5) 


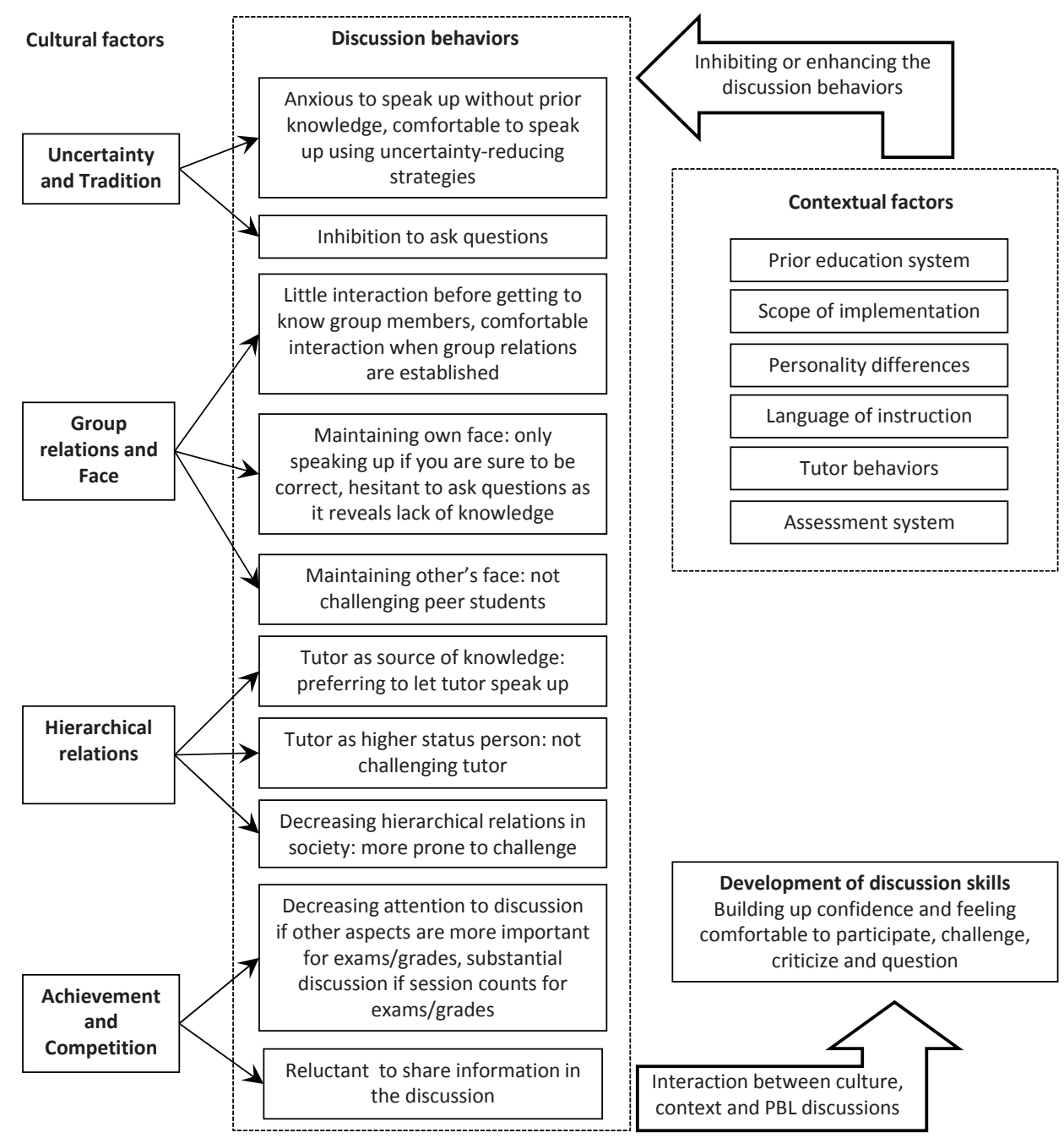

Figure 2. Conceptual model of factors involved in cross-cultural differences in students' discussion behaviors and skills.

However, the Middle Eastern students developed uncertainty-reducing strategies to cope with their anxiety, thereby mitigating their feelings of uncertainty in discussion sessions. For example, before the discussion session, they asked the topic of the problem case from senior students - since the cases changed only slightly year to year which enabled them to prepare for the session. Also, some students organized informal meetings before the actual session, in which they checked if all the learning topics had been covered and agreed on who would talk about what, thereby eliminating most of the uncertainties for the formal discussion session with the tutor. A third-year student commented: 
"Before the debriefing session, we have a small meeting with a group of the class and try to discuss the information. ... So before the session we try to fulfill all the learning objectives and after that, in the session, everyone is ready to discuss the problem from all points." (Middle East third-year student 3)

In Hong Kong, uncertainty among students was also found, but the scope of PBL implementation (see discussion on the scope of implementation below) enabled students to reduce their anxiety to the extent that it did not inhibit them from speaking up. In the Dutch case, feelings of uncertainty were also present, but to a lesser degree compared with the other two institutions. First-year Dutch students indicated that they felt uncertain about the expected depth of the discussion. Another result from the interviews and observations was that in all three institutions, third-year students were more confident than first-year students in participating actively and communicating in the discussions.

A factor that was mainly found in the Middle Eastern case was tradition, which was strongly related to uncertainty - though the latter related more to ambiguous situations, whereas the former was about opposing change out of respect for tradition, and stimulating a moderate, humble, and devout attitude. This had the effect of inhibiting questioning. A staff member explained how a traditional religious perspective could contribute to students' reluctance to ask questions in the discussion:

"In Islam, Haram is prohibited, and if you commit it, you will go to ... it is evil ... you will never see paradise. Halal is the opposite, it is something acceptable, it is good to do, and if you do it, you will go to paradise. With the first unwelcome question from a child [referring to previous quote: questions about God for example, you know the very fantastic questions of the very young children trying to discover life], we tell him that this is Haram and this is prohibited, 'you should not ask this question'. So the question itself is prohibited. When you keep telling your baby this, after some time, he takes life as Haram or Halal and he tries to avoid what is Haram." (Middle East staff 5)

However, it was noted by both Middle Eastern and Hong Kong participants that traditional values were changing throughout society (see the discussion on hierarchical relations below).

\section{Prior education system}

The results indicated that the more traditional and teacher-centered the secondary education of the students had been, the more obstacles they experienced to participating in discussions (table 4). Secondary school education was characterized as teachercentered by both the Middle Eastern and Hong Kong respondents. Dutch secondary schools were characterized as more student-centered, and Dutch students did not see their previous education as an obstacle to participating in PBL discussions. Nevertheless, they also needed time to get used to the PBL system. An aspect that might also be of influence on the degree to which students experienced difficulties was age. Table 2 
shows that the Middle Eastern students had a lower average age than the Hong Kong and Dutch students when entering university, which might partly account for a higher level of anxiety.

Interestingly, in the Hong Kong and Middle Eastern cases, students who had attended international secondary schools or who had had Western educational experiences (table 2) were characterized as more vocal, in terms of both fluency in the English language and attitude. This underlines the influence of prior educational experiences. A Hong Kong tutor explained:

"These students are very much coached to express and communicate. ... They know how important it is to be able to go out there. Many local students don't know that yet. They think, 'If I know it, I can do multiple choice and I will have a good career'." (Hong Kong tutor 1)

\section{Scope of implementation}

The results indicated that the more learning content was covered in lectures instead of in PBL sessions, the less likely students were to engage in critical and in-depth discussions during the PBL sessions to construct their own knowledge (table 4). In the hybrid, partly lecture-based approach of the Hong Kong school (table 1), the students often repeated factual knowledge from the lectures in the PBL sessions rather than asking critical questions about it or trying to construct their own knowledge by challenging existing views. On the other hand, the Hong Kong hybrid approach reduced uncertainty, making students less afraid to speak up in the discussions, because of their higher degree of prior knowledge as a result of the lectures.

\section{Group relations and face}

Middle Eastern students were found to lay strong value on group relations, which could make them feel uncomfortable about taking part in the discussion if they did not know the other group members yet.

"Especially in the first year, I didn't know the people in my class, I didn't know anyone of the students. We were all very shy, we didn't talk at all in the discussion session, that was not nice. I felt shy, I didn't talk too much." (Middle East third-year student 2)

After a while, however, when students became friends and grew to trust one another, they felt more confident in participating. The school had adapted its policy to this group focus, and groups were allowed to stay together for one year, as opposed to six weeks in the Dutch case and up to one semester in Hong Kong, which created a safe group environment to comfortably participate in discussions. Dutch students on the other hand indicated they were happy about changing groups every six weeks, which for them meant a continuous challenge to participate. 
In Hong Kong too, students were found to focus on group relations, which was mainly expressed in students' concern about maintaining their own and others' face in front of the group. This affected their behavior in that they were less ready to speak up, ask questions, and challenge their peers. For example, concern about losing face meant that students would only say something if they were sure it was correct, both contentwise and pronunciation-wise (see the discussion on language of instruction below).

"You see, for the Chinese, face is very important. Face means that if I do a poor job everyone will laugh at me, and I'll feel terrible. I have shamed myself, I've shamed my school education, my parents. Probably that is related to not speaking too much. My parents have always taught me it's better to listen than to blablabla. Generally the Chinese are more reserved. Secondly, if you speak, then make sure you speak well. If you can't speak well then there's a double reason for not speaking. I think an element of that is that they're very embarrassed. So instead of pronouncing a word they don't even try." (Hong Kong staff 1)

Furthermore, Hong Kong students were hesitant to ask questions, because they interpreted this as revealing a lack of knowledge, which they perceived as loss of face in front of the group. Hong Kong and Middle Eastern students were also concerned about their group members' face loss, because they valued harmonious and friendly group relations. Consequently, they were reluctant to challenge their peers by directly speaking to them, asking them critical questions, opposing their statements, or commenting on their behavior in the discussion session. Dutch students were found to be more concerned with the discussion process than with group relations, and were more ready to express criticism of group members.

"You just say, 'I think you talk way too much and you are interrupting all the time'. You just say that. And also, you just say, "I think you are really well prepared always and I like your contributions to the group'. Yeah, you just say it honestly." (Dutch third-year student 2)

However, while gaining familiarity with the purpose and process of PBL, Middle Eastern and Hong Kong students were more ready to make critical comments in the discussion.

"Well, sometimes there are some things that are hard to say to my colleagues, but it is for their own good, so I have to tell them." (Middle East first-year student 2)

"My tutor of the last block, he emphasized criticism very much. He says that being a doctor, you should have critical thinking instead of admiring others' opinions. ... Sometimes it embarrasses me to criticize so directly, but I think this is a step that you cannot avoid so we should get used to it, not feeling ashamed or trying to escape from it." (Hong Kong first-year student 7) 


\section{Personality differences}

In all three institutions, large differences in discussion behaviors were observed between individual students. Differences based on gender (table 2) were not found. Very quiet or very dominant students were not appreciated by the group (table 4).

"I was in a group in which nobody said anything, you had to point at people to get them to talk." (Dutch third-year student 3)

"Some are quite dominating and they will just talk a lot. Then you don't have a chance to speak up." (Hong Kong third-year student 2)

\section{Language of instruction}

Discussion behaviors were also affected by the language of instruction (table 4). The Hong Kong sessions were conducted in English, the second language of most students and tutors, which was a problem for those who felt their English fluency was not up to standard. While most tutors had an adequate level of English, large differences were found between individual students (see also the discussion on prior education system above for language differences between local students and students who had attended international secondary schools). Concerns about loss of face would cause these students to remain silent - even if they felt they really had something to say - just because they did not know how to say it. In the Middle Eastern case, the students were informally allowed to speak Arabic during the sessions, which enhanced interaction and participation.

\section{Hierarchical relations}

In the Hong Kong and Middle Eastern cases, a focus on hierarchical relations was found to influence students' discussion behaviors in terms of how they approached the tutor. Students were inclined to depend on their tutor as a source of knowledge, rather than on themselves, as this tutor explained about first-year students:

\footnotetext{
"Every time they want to say something or to discuss anything, they look at me. I try to tell them not to look at me. I am not the center of the session, they are the center of the session. ... But they still feel that the teacher should be the center of everything, should be the one to give the answers, and should be the one who has the upper hand on them.... They still feel like this, but I think it will take a transition time, as I told them, after a while, you will feel the reverse." (Middle East tutor 3 )
}

The results did indeed show that students increasingly learned to depend on themselves instead of on the tutor during the discussions. In Hong Kong, it was noted that relations between students and staff had generally become less hierarchical since the implementation of PBL. 
"What is so nice is that in the last ten years I've students smiling at me, you know. I see students smiling at me on the streets and on the wards, and I say 'Why is that guy smiling at me? Oh yes, he was in my PBL group'. They say 'Hi Professor X', isn't that nice? In the old days, if they know you're professor $X$ giving a lecture, they would be trying to run away, because they're afraid I would ask them a question." (Hong Kong staff 1)

Another effect of the importance of hierarchical (and group) relations in the Middle Eastern and Hong Kong cases was that students felt the tutor should not be challenged. Respect for the teacher was valued highly by the students, and openly disagreeing with a teacher was considered disrespectful, even though students might actually disagree with the teacher.

"I think Chinese people in general are less willing to challenge. They are the last ones to question. It is not that they are necessarily convinced by you, but they may not voice their disagreement. It is proof of serenity on hierarchical level. They are quieter." (Hong Kong tutor 1)

Interestingly, in both the Hong Kong and Middle Eastern cases, respondents characterized their society as moving away from traditional values, with people becoming more vocal and willing to challenge authority, which was reflected in students' behavior in the discussions and elsewhere.

"Certainly the post-nineties generation of students is far more willing to challenge authority." (Hong Kong tutor 3)

"Students in this generation are different from our generation. They are more confident as a generation. ... I do not know, we felt more respect for the older people." (Middle East tutor 1)

In the Dutch case, a critical attitude towards the tutor was not unusual, and was even encouraged by some tutors.

"I always say, every time to all of my groups, like, if there is anything you don't agree with, about how I'm doing it, you should say so. And students do that." (Dutch tutor 4)

Dutch society was generally characterized as less hierarchical than non-Western societies, and it was argued that this affected how students approached their tutor during the discussions.

"I think it is due to, everybody is equal and everyone's opinion is important and everyone has a voice. ... And there is the tutor, who often is a clinician and of course he stands above me, but the gap is not very big. We are not so shy as to never dare to criticize him or never dare to ask a critical question." (Dutch third-year student 5)

\section{Tutor behaviors}

Within each of the institutions, large differences were found in the way tutors facilitated the discussion sessions, and this had a major impact on students' discussion behav- 
iors. While some tutors dominated the discussion to the extent that students had no opportunity to speak at all, other tutors displayed a lack of motivation, remaining passive during the sessions, neither stimulating the discussion nor giving explanations when students got stuck (table 4). Neither type of behavior stimulated students to engage in a lively discussion.

"I once had a tutor who would do the entire discussion herself. And we just listened to her, she was talking very well and we were convinced by what she was saying, but we were not discussing you know. ... If the tutor just wants to talk we can't tell her or him to shut up." (Middle East third-year student 2)

\section{Achievement and competition}

In Hong Kong and the Middle East, respondents felt their society was characterized by a strong focus on achievement, and being successful and being the best were highly valued.

"I think it is a general condition that Hong Kong students or Hong Kong teachers or Hong Kong parents lay a lot of stress on your grades and the exam results, on your performance." (Hong Kong third-year student 1)

"Every student seeks to be the greatest one in his career and wants to be a great professor. In our faculty, I dream of becoming the greatest doctor." (Middle East third-year student 3)

Competition was closely related to achievement, with students continuously competing to be the best among their peers. A consequence for the discussion sessions was that some students were reluctant to share the information with peers.

"The idea of being the best one on the list, or the top of the list, in the minds of some students is that you have to keep the information that you find between the sessions secret, you keep it to yourself. They think that exchanging information with other students will mean that the other students will be better than you." (Middle East third-year student 3)

The cultural factors of achievement and competition were found to be less prominent among the Dutch students, although these students too were characterized as exam focused. In all the institutions, however, it was the nature of the assessment system that ultimately determined to what extent an exam-directed focus inhibited or enhanced discussion behaviors.

\section{Assessment system}

Assessment during the discussion sessions influenced discussion behaviors (table 4). In the Hong Kong case, the tutor continuously assessed students on participation and communication aspects, which contributed to students' final grade. As a result of this assessment and their focus on achievement, first-year Hong Kong students managed to 
overcome their anxiety about contributing to the discussions, and became keen to participate, debate, and challenge their peers.

"In the first two years... you are just fighting to talk, because the more you talk supposedly the higher the mark you get." (Hong Kong third-year student 4)

"Most of the students focus strongly on the continuous assessment. They are always worrying about the scores. ... They say, 'So we have to say something in the tutorial, otherwise there will no score that day'." (Hong Kong first-year student 4)

Third-year Hong Kong students, by contrast, were observed to be less active than the first-year students. They had discovered that, in practice, it was virtually impossible to fail the PBL assessment, because only in very extreme cases tutors would fail students. This made it unnecessary for the students to try hard in the sessions. In the Dutch case too, students felt that the assessment of their behavior in the sessions had no substantial consequences. In the Middle Eastern case, students felt more confident to speak up as they realized they were not assessed on the content of their contributions to the discussion.

"First I was not talking much in our class. But after, I got the idea that it is not something related to degrees and exams and something like that. We are just free to talk about what we know about that subject." (Middle East third-year student 10)

\section{Discussion}

\section{Main findings}

The aim of this study was to investigate how the cultural backgrounds of students across three cultures were expressed in the PBL discussions, and how this shaped students' discussion behaviors and skills. Four cultural factors related to students' backgrounds were externalized by the students, causing interference with the discussion process. Uncertainty and tradition, group relations and face, hierarchical relations, and achievement and competition were generally found to inhibit students from speaking up, asking questions, and challenging others in discussions. However, a focus on group relations in the Middle Eastern case and, in the Hong Kong case, a focus on achievement coupled with the nature of the assessment system were found to improve discussion dynamics as well. Cultural values in the Dutch case seemed to reflect a lesser presence of the four cultural factors identified in this study, which in general was found to enhance discussion dynamics.

Previous research has also found these cultural factors to be related to communication behaviors. Hwang, Francesco and Kessler, for example, pointed to a relation between concern about face loss and reluctance to ask questions. ${ }^{43}$ Gudykunst's intercul- 
tural communication theory posits relationships between uncertainty, group relations, and hierarchical relations on the one hand and higher levels of anxiety about communicating with strangers or higher status persons on the other hand. ${ }^{1}$ Fassinger reported a relation between achievement and classroom interaction, with students' participation increasing if they perceived it would have a positive effect on their grades. ${ }^{44}$ The cultural factor of uncertainty and tradition, as well as group relations and face, can be argued to include two separate factors each. Because of the high degree of interrelatedness with regard to the topic under investigation, however, in this study they were conceptualized as single factors, though it should be noted that a range of different possibilities and perspectives for categorizing and conceptualizing culture and cultural factors exists. $^{\text {e.g. } 18,45,46}$

In addition to cultural factors, six mediating contextual factors were identified that, depending on their nature, either inhibited or enhanced students' discussion behaviors. While the distinction between cultural and other contextual factors was sometimes hard to make considering the interrelatedness of all factors, these six factors related more to either organizational decisions or individual characteristics rather than culture. In the three institutions alike, the nature of the secondary school system, the scope of PBL implementation, students' personalities, language of instruction, the behavior of tutors, and the assessment system were found to impact on the discussions.

This is consistent with previous research reporting the strong influence of traditional, teacher-centered and exam-focused secondary schools on students in the Middle East and Hong Kong, ${ }^{30,47-49}$ language difficulties of non-Western students in Western educational models, ${ }^{14,30,50}$ and the importance of the scope of PBL implementation, personality differences between students, the assessment system, and the major mediating role of the tutor in discussion sessions. ${ }^{23,26,39}$ The role of personality differences is furthermore emphasized by previous research that found individual variations to be larger than cultural variations in preferences for direct communication styles. ${ }^{51}$

The current study showed that interactions between contextual factors, cultural factors, and the student-centered educational model determined how students internalized the discussion aspect of PBL, and consequently how their discussion skills developed. In each of the institutions, these skills were found to increase as students moved from first to third year. Generally, students gained confidence and felt more comfortable - sometimes helped by their own coping strategies - in participating in the discussions, asking questions, and criticizing and challenging the statements or behaviors of others. The students at the three institutions differed considerably, however, in the rate of development of discussion behaviors and skills. The stronger impact of the four cultural factors in the non-Western schools compared to the Western school generally meant that students experienced more difficulty in engaging in student-centered discussions, a problem that was augmented by the traditional nature of their teachercentered secondary school systems. The difference between the two non-Western institutions in the scope of PBL implementation accounted for differences in the devel- 
opment of discussion behaviors and skills. While the hybrid implementation in Hong Kong stimulated students to actively engage in discussions because the lectures reduced their feelings of uncertainty, the 'full' PBL implementation in the Middle Eastern case - and in the Dutch case - encouraged students to use the discussions to build knowledge, which stimulated them to engage in more critical discussions.

\section{Implications}

\section{Cultural and contextual challenges}

The findings justify doubts that have been expressed (see the introductory section) about the cross-cultural applicability of student-centered education. They also show that a student-centered, discussion-based educational model poses more challenges in non-Western cultures than in a Western culture, leading to different processes and outcomes in terms of students' discussion behaviors and skills. The comparison of a Western case and two non-Western cases yielded a conceptual model of cross-cultural differences affecting students' behaviors and skills in student-centered discussions. By incorporating other contextual factors in the model, the study underscores the major mediating role of contextual factors in relation to cultural factors, and justifies the assumption that the relationship between cultural factors and discussion behaviors and skills is not straightforward. Moreover, the substantial involvement of contextual factors implies that a student-centered, discussion-based educational method is likely to pose challenges in any culture, including Western cultures in which cultural values might be compatible with the method, but other contextual factors could complicate students' adaptation. Despite these challenges, however, this study appears to demonstrate that it is quite feasible to use a student-centered approach in higher education in different cultures - a claim that is supported by the fact that the three institutions had each been applying the model for over a decade. Apparently, difficulties can coexist with cross-culturally different, context-specific, yet solid discussion processes in student-centered higher education.

The complexity of individualism-collectivism

This study appears to confirm the expectation that a distinction between collectivistic Eastern cultures and individualistic Western cultures would be reflected in students' communication behaviors, and consequently, that student-centered education may pose more challenges in non-Western settings due to their collectivist orientation. Previous research showed that the cultural factors of uncertainty and tradition, group relations and face, and hierarchical relations are interrelated, while they were all related to the cultural concept of collectivism. ${ }^{1,21}$ However, the two non-Western cases were also characterized by a strong focus on competition and achievement, which is often associated with individualism rather than collectivism. ${ }^{52,53}$ 
A number of previous studies has suggested that the concepts of collectivism and individualism are far more complex than is generally thought, as for example is evidenced by studies in Hong Kong, in which participants scored high on both individualism and collectivistic face concerns. ${ }^{43,53}$ Thus, some societies may be defined as collectivistic in certain aspects, but as individualistic in others, which seems consistent with this study's findings. The question is how this plays out in the cross-cultural implementation of discussion-based, student-centered education. The results of the current study suggest that a focus on the individualistic factor of achievement - which also other studies have found to be of major importance in Hong Kong and of influence on Hong Kong students $^{54}$ - can mitigate the inhibiting effects of collectivistic factors, although this depends heavily on certain contextual factors, notably the assessment system. Further research might investigate how collectivistic and individualistic factors can be used as a balance to optimize discussion processes in higher education across cultures.

\section{The flexibility of learning approaches}

Although student-centered education seems to confront students and teachers in nonWestern settings with specific challenges, the results indicate that non-Western students, to a certain degree, do adapt their learning behaviors in respect of communication and discussion to fit with the Western student-centered model. At the same time, however, a non-Western cultural and contextual background may inhibit the development of these behaviors and skills. Interestingly, previous studies have showed that Chinese students who were studying in the West were very capable of adapting their different learning approach to fit with the Western method, ${ }^{55,56}$ or at least adapted their approaches more than students taking the same course in China. ${ }^{15}$ So, while students might be very able to change their learning approach when learning in a different cultural environment, they may encounter more problems when a new method is applied in their own cultural setting, in which their learning and discussion approaches seem to be less flexible, but still able to change.

\section{Limitations and conclusions}

A limitation of the study is its heavy reliance on self-reported interview data, which should be interpreted with caution. The trustworthiness of the data, however, was enhanced by triangulation of data from different sources and different groups of participants. A second limitation is that the cross-sectional rather than longitudinal student sample prevented investigation of the actual long-term development of individual students. However, in the interviews the third-year students were explicitly asked to focus on their development since their enrolment in university. Their recall of what it felt like to be a first-year student generally coincided with the views expressed by the first-year students in the study. 
The findings from this qualitative study do not lend themselves to generalization. However, researchers might take from the results those aspects and implications they deem applicable to their own setting, as the study's transferability was enhanced by providing thick description of the factors involved. Future research might investigate more cases in different as well as in similar cultural settings, and furthermore focus on other aspects of student-centered education beyond the discussion aspect. The conceptual model presented in this study could serve as a starting point for such research.

The results of the current study emphasize that educationalists in higher education across cultures, and future research on cross-cultural differences in education should consider the role of contextual factors, specifically in mediating the effects of cultural factors. By contextualization of cross-cultural findings the ecological validity of a study can be increased as it better approximates real-life situations. By focusing on the influence of context and culture, this study has provided evidence for the cross-cultural applicability of student-centered education, although it should be accepted that its process and outcome, or students' behaviors and skills, are likely to differ across contexts.

\section{Acknowledgements}

The authors would like to thank the staff and participants from the three institutions who contributed to this research. The authors are grateful to Mereke Gorsira for editing the manuscript, and to University Fund Limburg SWOL for funding the Hong Kong case study.

\section{References}

1. Gudykunst WB. Theorizing about intercultural communication. Thousand Oaks: Sage Publications 2005.

2. Hu G. Potential cultural resistance to pedagogical imports: The case of communicative language teaching in China. Language, Culture and Curriculum 2002;15(2):93-105.

3. Smith PB. Communication Styles as Dimensions of National Culture. Journal of Cross-Cultural Psychology 2011;42(2):216-33.

4. Hofstede G. Cultural Differences in Teaching and Learning. International Journal of Intercultural Relations 1986;10:301-20.

5. Cannon R, Newble D. A handbook for teachers in universities and colleges: A guide to improving teaching methods, 4 edn. London: Kogan Page 2000.

6. Lonka K, Ahola K. Activating instruction: How to foster study and thinking skills in higher education. European Journal of Psychology of Education 1995;10(4):351-68.

7. Barrows HS. Problem-Based Learning in Medicine and Beyond: A Brief Overview. New Directions for Teaching and Learning 1996;68:3-12.

8. Del Favero L, Boscolo P, Vidotto G, Vicentini M. Classroom discussion and individual problem-solving in the teaching of history: Do different instructional approaches affect interest in different ways? Learning and Instruction 2007;17(6):635-57.

9. Schmidt HG, Moust, J.H.C. Probleemgestuurd Onderwijs. Praktijk en Theorie [Problem-based Learning. Practice and Theory]. Groningen: Wolters-Noordhoff 1998. 
10. Altinyelken HK. Pedagogical renewal in sub-Saharan Africa: the case of Uganda. Comparative Education 2010;46(2):151-71.

11. Frambach JM, Stevens FCJ, Driessen EW, Van der Vleuten CPM. Compatible contradictions: the paradox of applying a western learning model in a non-western context. Unpublished manuscript 2012.

12. Nguyen PM, Elliott J, Terlouw C, Pilot A. Neocolonialism in education: Cooperative Learning in an Asian context. Comparative Education 2009;45(1):109-30.

13. Gwee MC. Globalization of problem-based learning (PBL): cross-cultural implications. Kaohsiung Journal of Medical Sciences 2008;24(3 Suppl):S14-22.

14. Khoo HE. Implementation of problem-based learning in Asian medical schools and students' perceptions of their experience. Medical Education 2003;37(5):401-9.

15. Wang Y, Harding R, Mai L-W. Impact of cultural exposure on young Chinese students' adaptation in a UK business school. Studies in Higher Education 2011;iFirst Article.

16. Brew FP, Tan J, Booth H, Malik I. The Effects of Cognitive Appraisals of Communication Competence in Conflict Interactions: A Study Involving Western and Chinese Cultures. Journal of Cross-Cultural Psychology 2011;42(5):856-74.

17. Yeung V, Kashima Y. Culture and stereotypical communication: Are people from Eastern cultures more stereotypical in communication? Journal of Cross-Cultural Psychology 2011;43(3):446-63.

18. Hofstede G. Culture's consequences. Comparing values, behaviors, institutions, and organizations across nations, 2 edn. Thousand Oaks: Sage Publications 2001.

19. Triandis HC. Individualism and Collectivism. Boulder, CO: Westview 1995.

20. Hui CH, Triandis HC. Individualism - Collectivism: A study of cross-cultural researchers. Journal of CrossCultural Psychology 1986;17(2):225-48.

21. Oetzel J, Ting-Toomey S, Masumoto T, Yokochi Y, Pan X, Takai J, Wilcox R. Face and Facework in Conflict: A Cross-Cultural Comparison of China, Germany, Japan, and the United States. Communication Monographs 2001;68(3):235-58.

22. Savin-Baden M. Problem-based Learning in Higher Education: Untold Stories. Buckingham: Open University Press 2000.

23. Dochy F, Segers M, Van den Bossche P, Gijbels D. Effects of problem-based learning: a meta-analysis. Learning and Instruction 2003;13(5):533-68.

24. Kirschner PA, Sweller J, Clark RE. Why minimal guidance during instruction does not work: An analysis of the failure of constructivist, discovery, problem-based, experiential, and inquiry-based teaching. Educational Psychologist 2006;41(2):75-86.

25. Schmidt HG, Van der Molen HT, Te Winkel WWR, Wijnen WHFW. Constructivist, Problem-Based Learning Does Work: A Meta-Analysis of Curricular Comparisons Involving a Single Medical School. Educational Psychologist 2009;44(4):227-49.

26. Dolmans DH, De Grave W, Wolfhagen IH, Van der Vleuten CP. Problem-based learning: future challenges for educational practice and research. Medical Education 2005;39(7):732-41.

27. Visschers-Pleijers A. Tutorial group discussion in problem-based learning: Studies on the measurement and nature of learning-oriented student interactions. PhD diss, Maastricht University 2006.

28. Walker A, Bridges E, Chan B. Wisdom gained, wisdom given: instituting PBL in a Chinese culture. Journal of Educational Administration 1996;34(5):12-31.

29. Hussain RMR, Mamat WHW, Salleh N, Saat RM, Harland T. Problem-based learning in Asian universities. Studies in Higher Education 2007;32(6):761-72.

30. Bridger J. From passive to active learners: The 'lived experience' of nurses in a specialist nephrology nursing education programme. Journal of Workplace Learning 2007;19(2):78-91.

31. Mpofu DJS. Introducing problem-based learning into a traditional medical school: student and staff perceptions of the United Emirates University's innovation. PhD Diss, Maastricht University 1999.

32. Yazigi A, Nemr E, Abou Jaoude S. Implementation of problem-based learning in Asia: similarities between Far East and Middle East medical schools. Medical Education 2004;38(2):223. 
33. Vygotsky LS. Mind in Society. The Development of Higher Psychological Processes. Cambridge: Harvard University Press 1978.

34. Rogoff B. Children's Guided Participation and Participatory Appropriation in Sociocultural Activity. In: Wozniak RH, Fischer KW, eds. Development in Context: Acting and Thinking in Specific Environments. Hillsdale: Lawrence Erlbaum Associates 1993:121-53.

35. Engeström Y. Activity theory and individual and social transformation. In: Engeström $Y$, Miettinen R, Punamäki R-L, eds. Perspectives on activity theory. Cambridge: Cambridge University Press 1999:19-38.

36. Rogoff B, Chavajay P. What's Become of Research on the Cultural Basis of Cognitive-Development. American Psychologist 1995;50(10):859-77.

37. Vásquez OA. Chapter 2: Cross-National Explorations of Sociocultural Research on Learning. Review of Research in Education 2006;30:33-64.

38. Engeström Y, Miettinen R. Introduction. In: Engeström Y, Miettinen R, Punamäki R-L, eds. Perspectives on activity theory. Cambridge: Cambridge University Press 1999:1-16.

39. Moust JHC, van Berkel HJM, Schmidt HG. Signs of erosion: Reflections on three decades of problembased learning at Maastricht University. Higher Education 2005;50(4):665-83.

40. Stake RE. Case Studies. In: Denzin N, Lincoln Y, eds. Handbook of Qualitative Research, 2 edn. Thousand Oaks: Sage Publications 2000:435-54.

41. King N. Using templates in the thematic analysis of text. In: Cassel C, Symon G, eds. Essential Guide to Qualitative Methods in Organizational Research. London: Sage Publications 2004:256-70.

42. King N. Template Analysis. 2010. http://www.hud.ac.uk/hhs/research/template_analysis/.

43. Hwang A, Francesco AM, Kessler E. The relationship between individualism-collectivism, face, and feedback and learning processes in Hong Kong, Singapore, and the United States. Journal of CrossCultural Psychology 2003;34(1):72-91.

44. Fassinger PA. Understanding Classroom Interaction - Students and Professors Contributions to Students Silence. Journal of Higher Education 1995;66(1):82-96.

45. Geertz C. The interpretation of cultures. New York: Basic Books 1973.

46. Trompenaars F, Hampden-Turner C. Riding the Waves of Culture: Understanding Cultural Diversity in Global Business, 2 edn. New York: McGraw-Hill 1998.

47. Al Kadri HM, Al-Moamary MS, Magzoub ME, Roberts C, Van der Vleuten CPM. Students' perceptions of the impact of assessment on approaches to learning: a comparison between two medical schools with similar curricula. International Journal of Medical Education 2011;2:22-52.

48. Chan S. The Chinese learner: A question of style. Education \& Training 1999;41(6-7):294-304.

49. Leung DYP, Ginns P, Kember D. Examining the cultural specificity of approaches to learning in universities in Hong Kong and Sydney. Journal of Cross-Cultural Psychology 2008;39(3):251-66.

50. Ladyshewsky R. East meets West: The influence of language and culture in clinical education. Australian Journal of Physiotherapy 1996;42(4):287-94.

51. Park HS, Levine TR, Weber R, Lee HE, Terra LI, Botero IC, et al. Individual and cultural variations in direct communication style. International Journal of Intercultural Relations 2012;36:179-87.

52. Fontaine JRJ, Poortinga YH, Delbeke L, Schwartz SH. Structural equivalence of the values domain across cultures - Distinguishing sampling fluctuations from meaningful variation. Journal of Cross-Cultural Psychology 2008;39(4):345-65.

53. Liao YA, Bond MH. The Dynamics of Face Loss Following Interpersonal Harm for Chinese and Americans. Journal of Cross-Cultural Psychology 2011;42(1):25-38.

54. Brown GTL, Wang Z. Illustrating assessment: How Hong Kong university students conceive of the purposes of assessment. Studies in Higher Education 2011;iFirst Article.

55. Gieve S, Clark R. 'The chinese approach to learning': Cultural trait or situated response? the case of a self-directed learning programme. System 2005;33:261-76.

56. Gu Q, Schweisfurth M. Who Adapts? Beyond Cultural Models of 'the' Chinese Learner. Language, Culture and Curriculum 2006;19(1):74-89. 



\section{CHAPTER 3}

\section{The cultural complexity}

\section{of self-directed learning}

in PBL

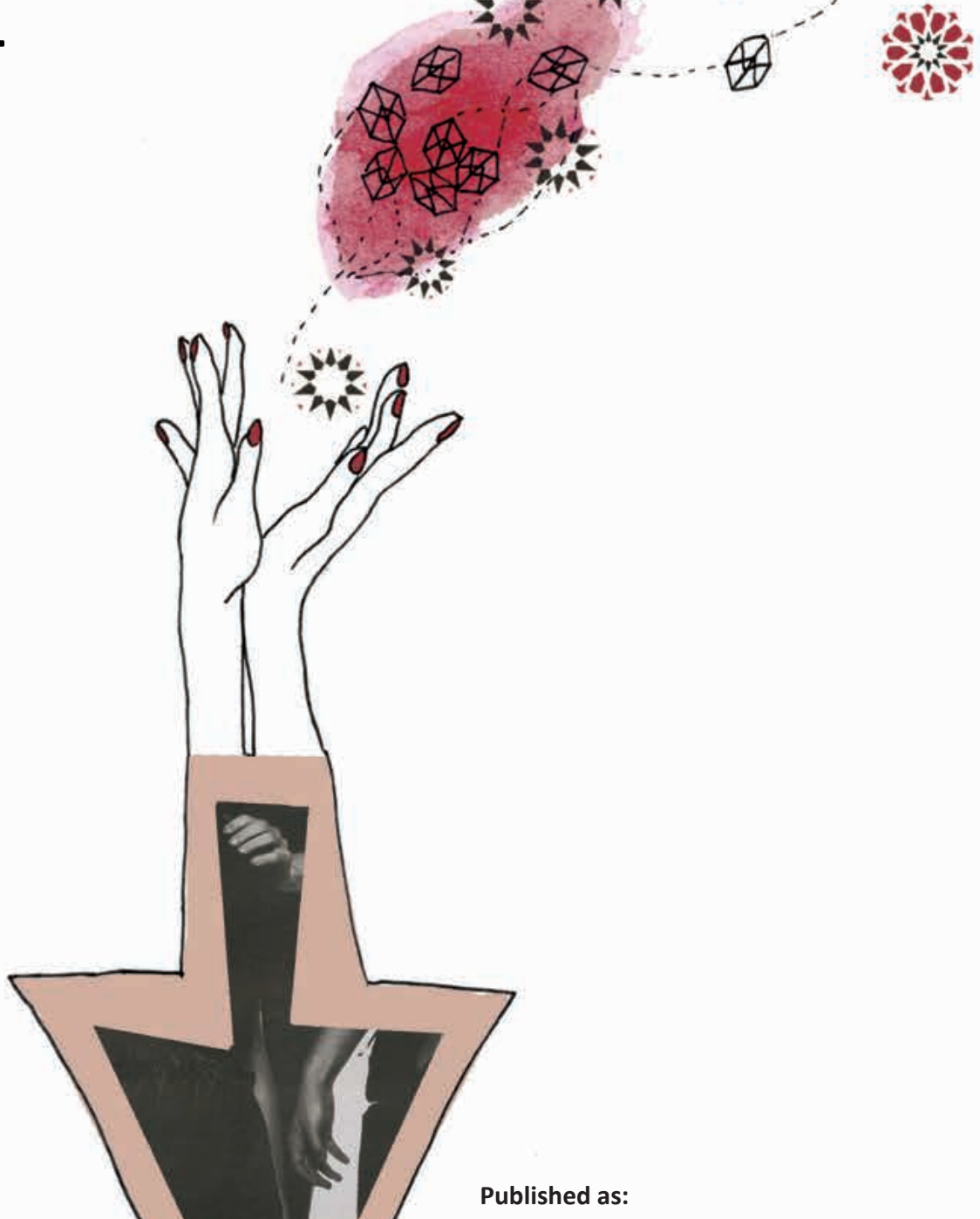

Frambach JM, Driessen EW, Chan LC, van der Vleuten CPM. Rethinking the globalisation of problem-based learning: how culture challenges self-directed learning. Medical Education 2012;46(8):738-47. 
CHAPTER 3 


\section{Introduction}

It is generally acknowledged that educational methods reflect cultural and ideological values. ${ }^{1-3}$ Addressing the cross-cultural implications of this notion is increasingly urgent in view of the continuing dissemination of educational methods around the globe. The globalisation of student-centred methods, including problem-based learning (PBL), is particularly widespread. ${ }^{4,5}$ These methods are advocated, particularly in medical education, for their ability to foster self-directed, lifelong learning, which is considered indispensible in the light of the rapid growth in medical information and the discrepancies between medical graduates' competencies and communities' needs. ${ }^{6,7}$ Counterarguments that the assumption of shared values across cultures may be false seem to be largely ignored. ${ }^{8}$ Driven by ideological or other motives, the globalisation movement promotes the standardisation of education methods and practices across cultures, apparently with little regard for cultural differences. ${ }^{9,10}$ Research outside medical education has revealed differences between cultures in students' learning and preferences for educational approaches. ${ }^{11-13}$ Consequently, the cultural origin of a supposedly 'international' educational approach may compromise its suitability for other cultural contexts. $^{3}$

Rooted in Western culture, student-centred, problem-based methods may not be of a truly international nature ${ }^{3,14}$ and their compatibility with non-Western cultures has been questioned. ${ }^{15}$ Gwee ${ }^{5}$ and Khoo ${ }^{16}$ pointed to Asian cultural attitudes that might be difficult to reconcile with the educational principles of PBL, but also noted attitudes that might mitigate this discrepancy. The few empirical studies into the cross-cultural applicability of PBL reported positive views among students and staff, 6, 7, 17, 18 but also noted problems and assumed differences with Western practice. ${ }^{17-19}$ Most of these studies were limited to the implementation phase of PBL or shortly thereafter and to single institutions, countries or regions, mainly in Asia. Researchers of the cross-cultural applicability of PBL might cast their nets wider to include more cultures and look beyond the implementation stage of PBL. A sound understanding of the role of crosscultural differences in medical education calls for "comparative studies of educational values and practices in different cultures and countries". ${ }^{8}$ In response to this call, we are conducting a cross-cultural research project on $\mathrm{PBL}$, after its implementation, in three medical schools in, respectively, East Asia, the Middle East and Western Europe. Our first study showed that students' communicative behaviour during PBL tutorials is a potential source of cross-cultural problems as a result of a significant impact of hierarchical relations, group relations, concern with loss of face, a focus on achievement and competition, and feelings of uncertainty (Frambach JM, Driessen EW, Beh P \& Van der Vleuten CPM, unpublished manuscript, 2012).

The present study investigates whether and how cultural factors affect one of PBL's main educational principles: self-directed learning (SDL). ${ }^{20}$ It has been argued that this 
principle relies strongly on "Western ideals of democracy, individualism and egalitarianism". ${ }^{21}$ It is defined here as:

"...the preparedness of a student to engage in learning activities defined by himself rather than by a teacher. 'Preparedness' must be understood as having both a motivational aspect and involving skilled behaviour. Thus, an accomplished self-directed learner experiences an intrinsic need to acquire knowledge, not dominated by requirements set by his teachers. In addition, he has mastered the appropriate information seeking skills, that is: he knows where and how to find information resources that would fulfil his need."22

Culture is defined as the shared motives, values, beliefs and identities of members of collectives. ${ }^{13}$ We also examine other contextual factors that may be of influence, such as the education setting and students' past experiences. ${ }^{21}$ We use a socio-cultural approach $^{23,24}$ to obtain a comprehensive picture of how cultural, societal and other contextual factors affect students' development as self-directed learners, because a sociocultural perspective is assumed to encompass the cultural and contextual environment. $^{1,25}$ Socio-cultural theorists state that humans are continuously influenced and shaped by their environment as they 'internalise' its norms and characteristics. ${ }^{26,27}$ Conversely, humans influence and transform their environment by 'externalising' their inner ideas and values. ${ }^{27}$ We expected to gain insight into the cross-cultural applicability of PBL by exploring the following research questions: How do students across different cultural contexts internalize the principle of SDL? (How does it shape them?) How do students externalise their cultural background to the process of SDL? (How do they shape it?)

\section{Methods}

\section{Setting}

A qualitative, comparative case study was conducted in two non-Western and one Western medical school. Nine medical education experts with ample international experience suggested medical schools that met our criterion of a school in a non-Western setting in which PBL has been a substantial teaching method for over 5 years. A medical school in Hong Kong and a medical school in the Middle East were selected and found willing to participate. As the latter school wished to remain anonymous, we refer to its regional rather than its national location. The Western medical school, in the Netherlands, was selected on pragmatic grounds because three of the authors are affiliated to it and it met the criterion for the use of PBL. Ethics approval was granted by the ethics 
review boards of the Hong Kong and Middle Eastern medical schools. At the Dutch medical school, formal ethics approval is not required for education research.

\section{Data collection}

Data for our research project on the cross-cultural applicability of PBL (Frambach JM, Stevens FCJ, Driessen EW \& Van der Vleuten CPM, unpublished manuscript, 2012; Frambach JM, Driessen EW, Beh P \& Van der Vleuten CPM, unpublished manuscript, 2012) were collected between November 2009 and April 2010, during 1 month of field work in each setting. Data collection was conducted by individuals outwith the respective schools, comprising the first author for the two non-Western schools and a research assistant for the Western school. Different methods were used to enable triangulation. Students, tutors and key persons involved in PBL were interviewed in depth about practices, perceptions and difficulties concerning PBL, students' development and adaptation, and the roles of cultural and other contextual factors. The semistructured interviews lasted 1 hour on average and were audio-recorded and transcribed verbatim. Oral and written informed consent was obtained. The participants received a symbolic gift. Purposive sampling ensured the inclusion of male and female students, students from different PBL groups and from the first and third years of training. Sampling across year groups enabled us to explore differences in how students with short and long exposure to PBL shaped and were shaped by SDL. Announcements were made in the lectures and PBL tutorials, and volunteering students were consequently selected according to the sampling criteria and until data collection reached saturation. Sampling of tutors focused on different disciplinary backgrounds and involvement in teaching in Years 1 and 3. Tutors were mainly recruited during observations of PBL tutorials. Key persons (deans, programme directors, coordinators) were recruited by snowball sampling.

Randomly selected Year 1 and 3 tutorials were observed, during which the researchers took field notes and filled in an observation sheet covering aspects of PBL, cultural behaviours and contextual factors. The researchers were briefly introduced at the start of the tutorials and did not participate in sessions. Documents about the implementation and application of PBL were obtained from the key persons. The researchers kept journals in which they recorded additional contextual information. They also reported personal perspectives to create awareness of potential researcher bias. To enhance the trustworthiness of the data, a member check was conducted by asking a sample of the participants to indicate agreement with and comment on a report of preliminary results. The comments were integrated with the data. 


\section{Data analysis}

Using the thematic approach of template analysis, ${ }^{28}$ a succession of coding templates, consisting of hierarchically structured themes, were applied to the data (figure 1). ATLAS.ti Version 6.2 (Scientific Software Development GmbH, Berlin, Germany) was used for the coding. All steps and decisions were documented in an audit trail. The first two coding steps were conducted independently by the first two authors. They developed an initial template after coding a subsample of the interview transcripts using preliminary themes. While analysing half of the transcripts, they developed a final template, which was iteratively applied to the same transcripts. Agreement on the occurrence and interpretation of themes was reached through discussion.

Based on an initial interpretation of the results and on comparisons between the schools and between Year 1 and 3 students across and within the schools, a focused template was developed. While analysing the remaining interview transcripts, field notes and observation sheets, summaries of the collected documents and the research journal with this template, we also looked for disconfirming evidence. A final interpretation led to the creation of a comprehensive picture representing how students' cultural backgrounds and the process of SDL shape one another.

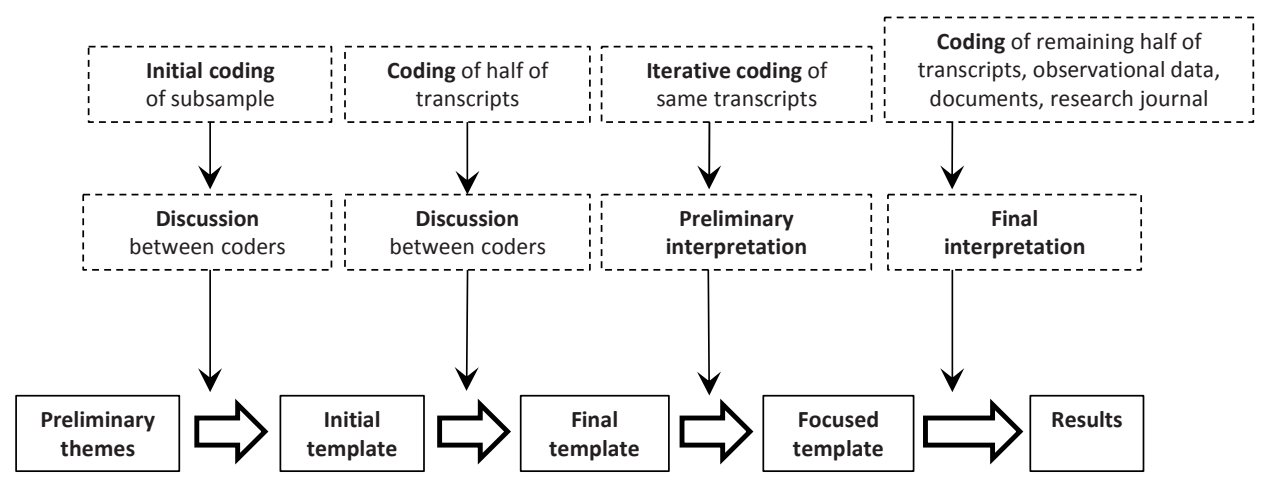

Figure 1. Steps taken in the template analysis process.

\section{Results}

Tables 1 and 2 present the number of interviews and observations in each school, and student demographics. The documents (information booklets for students, course schedules, problem cases, sheets for evaluating students in PBL, internal evaluations of $\mathrm{PBL}$ ) yielded information about the structure, content and implementation of the curricula. Table 3 shows PBL characteristics in the schools. The Dutch and Middle Eastern medical schools had applied PBL as the main educational method since their foundation, whereas the Hong Kong medical school had a hybrid curriculum with lectures and 
PBL tutorials. In all schools, tutorials lasted 90-120 minutes and consisted of students' discussion of a problem case and formulation of learning objectives. Between tutorials, students conducted self-study and attended lectures and skills sessions. In Year 3, both the Hong Kong and Dutch medical schools offered more clinical education; however, the Dutch school provided fewer but longer tutorials, and the Hong Kong school provided fewer PBL but more non-PBL tutorials.

Table 1. Number of interviews and observations at the three medical schools.

\begin{tabular}{|c|c|c|c|c|}
\hline & $\begin{array}{l}\text { Middle Eastern } \\
\text { medical school }\end{array}$ & $\begin{array}{c}\text { Hong Kong } \\
\text { medical school }\end{array}$ & $\begin{array}{c}\text { Dutch } \\
\text { medical school }\end{array}$ & Total \\
\hline \multicolumn{5}{|l|}{ Interviews, $n$} \\
\hline Year 1 students & 9 & 10 & 9 & 28 \\
\hline Year 3 students & 10 & 9 & 9 & 28 \\
\hline Tutors & 6 & 6 & 5 & 17 \\
\hline Key persons & 5 & 5 & 5 & 15 \\
\hline Interviews total & 30 & 30 & 28 & 88 \\
\hline \multicolumn{5}{|l|}{ Observations, $n$} \\
\hline Year 1 & 5 & 6 & 8 & 19 \\
\hline Year 3 & 5 & 6 & 2 & 13 \\
\hline Observations total & 10 & 12 & 10 & 32 \\
\hline
\end{tabular}

Table 2. Demographic information on the student samples.

\begin{tabular}{|c|c|c|c|}
\hline & $\begin{array}{l}\text { Middle Eastern } \\
\text { medical school }\end{array}$ & $\begin{array}{c}\text { Hong Kong } \\
\text { medical school }\end{array}$ & $\begin{array}{c}\text { Dutch } \\
\text { medical school }\end{array}$ \\
\hline Year 1 students, mean age, years & 17.3 & $18.6^{*}$ & 19.1 \\
\hline Year 3 students, mean age, years & 19.0 & $21.0^{+}$ & 21.3 \\
\hline Gender: female & $42.1 \%$ & $47.4 \%$ & $88.9 \%$ \\
\hline Ethnicity & $97.4 \%$ Arab & 94.7\% Chinese & $77.8 \%$ Dutch \\
\hline
\end{tabular}

*Excluded: 2 unknown, 1 outlier ${ }^{\dagger}$ Excluded: 1 unknown, 1 outlier

The results of the analysis are presented under the headings of the key cultural and contextual factors considered relevant to the cross-cultural applicability of PBL. These factors were valued or applied differently in the three schools, which influenced the cross-cultural process of SDL. The results from the four data sources (interviews, observations, documents, contextual information) are presented in an integrated manner. Table 4 reports an overview of key findings. 
Table 3. Characteristics of problem-based learning (PBL) in Years 1-3 in the three medical schools.

\begin{tabular}{lccc} 
& $\begin{array}{c}\text { Middle Eastern } \\
\text { medical school }\end{array}$ & $\begin{array}{c}\text { Hong Kong } \\
\text { medical school }\end{array}$ & $\begin{array}{c}\text { Dutch } \\
\text { medical school }\end{array}$ \\
Period of applying PBL & $>30$ years & $>10$ years & $>30$ years \\
Students entering yearly, $n$ & 200 & 180 & 340 \\
Lectures per week, mean & 4 & 7 & 2 \\
Average PBL group size, $n$ & 10 & 10 & 10 \\
PBL tutorials per week, mean & 2 & 2 (Year 3: 1) & 2 (Year 3: 1) \\
\hline
\end{tabular}

Table 4. Cultural and contextual factors resulting in externalisation and internalisation.

\begin{tabular}{|c|c|c|c|}
\hline $\begin{array}{l}\text { Cultural } \\
\text { factors }\end{array}$ & $\begin{array}{l}\text { Contextual } \\
\text { factors }\end{array}$ & $\begin{array}{l}\text { Externalisation: how students } \\
\text { shaped SDL }\end{array}$ & $\begin{array}{l}\text { Internalisation: how SDL } \\
\text { shaped students }\end{array}$ \\
\hline $\begin{array}{l}\text { Uncertainty } \\
\text { and tradition }\end{array}$ & $\begin{array}{l}\text { Nature of secondary educa- } \\
\text { tion: teacher or student- } \\
\text { centred }\end{array}$ & $\begin{array}{l}\text { SDL after period of adjustment } \\
\text { and with guidance from seniors }\end{array}$ & $\begin{array}{l}\text { Development of motivation } \\
\text { for SDL and an understanding } \\
\text { of its purpose }\end{array}$ \\
\hline Hierarchy & $\begin{array}{l}\text { Scope of PBL implementa- } \\
\text { tion: hybrid or full }\end{array}$ & $\begin{array}{l}\text { Self-directed learning to the } \\
\text { extent that knowledge was not } \\
\text { covered by lectures or profes- } \\
\text { sors }\end{array}$ & $\begin{array}{l}\text { Development of skills for } \\
\text { information seeking and } \\
\text { knowledge construction }\end{array}$ \\
\hline Achievement & $\begin{array}{l}\text { Content of assessment: } \\
\text { covered in lectures or PBL } \\
\text { tutorials }\end{array}$ & $\begin{array}{l}\text { Self-directed learning to the } \\
\text { extent it contributed to prepar- } \\
\text { ing for examinations }\end{array}$ & \\
\hline
\end{tabular}

Expressions of these factors, particularly achievement, were found in all three locations, but to varying degrees. Uncertainty and tradition were more apparent in the Middle East, and hierarchy was more apparent in Hong Kong. $\mathrm{PBL}=$ problem-based learning; $\mathrm{SDL}=$ self-directed learning

\section{Uncertainty and tradition in the Middle East}

Middle Eastern students expressed more feelings of uncertainty as a cultural factor compared with Dutch and Hong Kong students. Their uncertainty and difficulties in adapting to SDL were related to sharp contrasts between PBL and their prior educational experiences. Rather than feeling motivated, many students felt lost and unable to find appropriate information to address their learning objectives. Uncertainty was related to experiences of traditional, teacher-centred secondary education, but also to a culturally determined focus on tradition. Middle Eastern respondents referred to their society's respect for the 'old ways' and wariness regarding innovations. As they became used to PBL, however, their attitudes changed significantly. Students came to support the principle of SDL and information seeking became less problematic, although students still felt PBL was not easy and wanted more guidance:

"Look, here in this country we do not like change, we always like the old ways. [ . . ] So at first I was like, I do not want to change, but when I came here I found this was, as time goes 
by, I would choose this faculty for my study years at the university." (ME, Year 3, Student 8) "I think, now, while we are studying, we find it hard, but it will make us good doctors. They make us think about what we are learning, find more than one book, and talk about the same topic from different points of views." (ME, Year 1, Student 8)

Having experienced information searching and self-study in secondary school, Dutch students had less difficulty in adapting to SDL. In addition, Dutch culture places less value on tradition. Although the Dutch students were less uncertain, they required time to develop information-seeking skills and they generally preferred tutors who provided clear guidance. A particular problem for them concerned determination of the depth and breadth of the knowledge to be attained. Dutch, Hong Kong and, particularly, Middle Eastern students tried to cope with uncertainty and independence by asking senior students for advice and materials. Although it reduced insecurity, this strategy discouraged them from depending upon themselves for their learning:

"Sometimes it is too free for some students, like, what am I supposed to do now? And then they'll copy things from other students, to have that certainty of, well, 'He passed his exam with that so I will use it too.' Because at first, you really don't know where to search." (NL, Year 3, Student 2)

\section{Hybridism and hierarchy in Hong Kong}

From the outset, finding information was less difficult for Hong Kong students. As topics of tutorials were also covered in lectures in the hybrid curriculum, identifying learning needs and developing information-seeking skills were less relevant to Hong Kong students. They showed little awareness that PBL was intended to foster SDL. Whereas the lectures covered the basic sciences, the Hong Kong tutorials focused more on clinical reasoning skills. By contrast, the Dutch and Middle Eastern students had to rely on tutorials for most of their knowledge. The Hong Kong students often felt the tutorials repeated the content of lectures, which some appreciated as providing a useful opportunity for revision and a chance to apply their knowledge to a clinical case, but others considered a waste of valuable study time:

"This PBL actually helps me to memorise the facts we have learned, because we have to research the things ourselves first and then we have lectures to confirm our findings and to let us know what to memorise, and then we have to present it again during the next PBL session." (HK, Year 1, Student 2)

"Frankly, I don't know the purpose of the faculty to give us PBL." (HK, Year 1, Student 1)

Some Hong Kong students were anxious about multiple interpretations that might come up during tutorial discussions because these created uncertainty about the 'truth' and they were hesitant about trusting their peers' statements. This reflected their experience of a teacher-centred secondary education, as well as the culture of a hierar- 
chical society in which knowledge and authoritative statements about the 'truth' are expected to come from professors or experts who represent persons of higher status. Students were not used to having to rely entirely on themselves for their learning. They also attached greater value to tutorials that were facilitated by expert clinicians rather than by non-experts. Although Dutch students also preferred facilitation by expert tutors, they were comfortable relying on their peers. The impact of hierarchy was also evident in the Middle Eastern school and manifested in students' experiencing of anxiety about the requirement to search independently for the 'truth'. However, by Year 3, student anxiety in the Middle East school had abated, whereas student anxiety in Hong Kong showed little difference between the years:

"I guess the international students like it more. They like the discussion more, even when they don't find the answer. But for local students, even if they are okay with the discussion, they are very focused on finding a way to get the right answer. [...] We want to end the case and get all the answers quickly and maybe we are also more obsessed with the official version of everything. Like, we want the official answer." (HK, Year 3, Student 8)

\section{Achievement and assessment across cultures}

Middle Eastern and Hong Kong students characterized themselves and their respective societies as competitive and described themselves as striving for success and to be the best. They felt pressured to pass examinations and rank among the top students:

"I think the common characteristic of local Chinese students is that they care very much about the result. We also have students from overseas, from Australia or the UK, they always say that Hong Kong students work very hard but also care too much about their results." (HK, Year 1, Student 7)

Dutch students were also examination-focused, although their responses during interviews suggested a lower level of culture-related focus on achievement and success compared with the other two cohorts. The general feeling among the three groups of students was that they valued PBL only for its contribution to their examination preparation. This depended on examination content. In Hong Kong, examination content was mainly determined by lectures. In the Middle Eastern and Dutch schools, it depended more on PBL tutorials. However, particularly in the Middle Eastern school, the inclusion of additional topics caused students to concentrate on these predetermined additional topics and their lecture notes more than on identifying and addressing their individual learning needs. Even if they supported and understood the principle of SDL, achievement and assessment took priority, directing their attention and efforts away from SDL to examination content.

"They are exam-oriented, their strong concern is for the exams. When we discuss a problem case I say, for example: 'You should know about this thing.' They answer: 'No, it's not written 
in the preset objectives."' (ME, Tutor 1)

"What I want is group discussion. I don't want the group to gather to produce a nice document of the collected information, but I sometimes feel that's the students' goal: 'Then we have a nice summary of different sources to study for the exam.' Well, that doesn't contribute to the discussion in the group, while I think that's what's important." (NL, Tutor 1)

\section{Discussion}

This study of cross-cultural differences in PBL education practice explored how students in three different cultural contexts internalised the PBL principle of SDL and externalized their cultural background to the PBL process. Students externalized cultural factors that conflicted with cultural values residing in the PBL goal of SDL. Feelings of uncertainty about the independence required in SDL, a focus on tradition that impeded the uptake of a new approach to learning, a dependence on hierarchical sources rather than oneself or one's peers, and pressure to achieve rather than an intrinsic motivation to learn posed challenges to non-Western students in particular. This is consistent with previous reports that similar factors interfered with non-Western students' development of critical discussion behaviours in PBL (Frambach et al, unpublished manuscript, 2012). Uncertainty, tradition, hierarchy and achievement have often been identified as more prominent in non-Western than in Western cultures. ${ }^{29-31}$ This suggests a certain incongruity between PBL and non-Western cultures, which complicates the straightforward transfer of PBL to such cultural contexts.

However, cultural factors clearly do not explain all of the discrepancies in findings between the respective contexts. Several contextual factors, such as a traditional, teacher-centred secondary education, a hybrid curriculum and examination content not covered during PBL sessions further complicated students' development of SDL skills. For example, the secondary school education system in Hong Kong is very much based on knowledge acquisition and rote learning to pass examinations. Because teachers and recommended textbooks serve as the main sources of information, there is little opportunity for SDL. Therefore, it is not surprising that current Hong Kong medical students remain dependent on teachers and lectures for their learning. However, this may change in the future in response to education reform taking place in Hong Kong high schools, which emphasizes SDL by students as a major educational goal.

Our findings support earlier comments that the development of SDL and other PBL skills depends heavily on the context in which PBL is applied. ${ }^{21}$ Research suggests that SDL does not occur automatically when PBL is implemented. Carefully considered and focused efforts are needed to shape a propitious context. ${ }^{32,33}$ In fact, exposing Year 1 students to the independent learning environment of PBL without providing them with adequate guidance may, rather than promoting the development of SDL skills, cause them to become severely dependent on tutors, predetermined learning objectives and 
on rote learning in order to 'survive'. ${ }^{32,33}$ This is supported by our findings that students across three different cultures, albeit to different degrees, mentioned similar behaviours, needs and preferences with regard to alleviating uncertainty, consulting senior students, asking for tutor guidance and focusing on examination content.

A possible solution might be to strike a balance between using SDL as a means to PBL and perceiving it as an end of PBL. ${ }^{33}$ Gradual exposure to SDL, with relatively strong guidance and support in the first year, might ultimately yield the development of more SDL skills. ${ }^{33}$ Our findings suggest that this is particularly relevant in contexts in which secondary education is teacher-centred, no hybrid approach is followed, and the cultural factors of uncertainty, tradition, hierarchy and achievement are valued highly. Further research might investigate how these factors can be addressed at a practical level to foster SDL in PBL.

Despite the challenges, however, students across the three cultures increasingly internalised the principle of SDL as they moved from Year 1 to Year 3. The Middle Eastern students made substantial progress from initial uncertainty to preparedness to determine their own learning activities and find relevant information. Because of their pre-university experiences in SDL, the progress of the Dutch students was less marked, but still noticeable. Hong Kong students seemed to quickly adapt to the PBL learning environment and to develop clinical reasoning skills, but were less stimulated to develop SDL skills in terms of determining learning objectives and consulting different information sources. These findings would appear to be consistent with those of studies reporting that SDL skills develop naturally as students become used to the PBL process and curriculum. ${ }^{33,34}$ Thus, although PBL may not be cross-culturally applicable in a straightforward way, it would be wrong to conclude that it cannot be applied across cultural contexts as practice continues to prove.

This study is limited by its focus on a single medical school in each cultural setting because the cultural diversity of medical schools can be greater within than across regions. Furthermore, the characterization of Hong Kong culture as non-Western is debatable. However, a large body of research on cross-cultural differences in learning between Eastern and Western contexts is based on findings derived from studies in which Hong Kong is perceived as representing an Eastern context. ${ }^{18,30,35,36}$ Further research might focus on potentially more generalisable findings by investigating more medical schools within and across different cultural regions.

Another limitation is that the results reflect the analysis and interpretation of authors with backgrounds in Western culture and in educational and social sciences. Researchers from other backgrounds might have approached the data from a different perspective. We have attempted to reduce the effects of this bias by performing multiple quality checks as described above. In addition, one author with a non-Western background has critically revised and approved the interpretation. Furthermore, we sought to identify resonance with existing literature by Western and non-Western authors for our framework, results and interpretation. Even so, we invite researchers with 
different cultural and disciplinary backgrounds to engage in similar research to create a comprehensive and culturally sensitive picture of the subject.

This study is strengthened by its addition of empirical data from natural settings to a debate that until now has been driven largely by theory and assumptions. ${ }^{1,8}$ Its findings confirm that medical education across cultures shares many issues and frustrations, $^{37}$ but they also reveal many differences. ${ }^{1,8,10}$ The implication for the globalisation of PBL is that careful consideration must be given to cultural and contextual factors before and during the implementation and application of PBL. Educators and curriculum developers should ask themselves the following key questions: What do we want to achieve and why? Is this achievable and how do we achieve it in our setting?

A more fundamental question is whether PBL should be globalised in the first place. It is true that medical education worldwide is in need of reform, but whether one solution should be applied to all contexts is debatable. Currently, student-centred methods originating in Western culture seem to represent an 'international' standard. Yet, as this study confirms, the cross-cultural applicability of these methods may be questionable. Rather than taking on the cultural and contextual challenge of adopting studentcentred, problem-based methods, it might be wiser for medical educationalists to rise to the challenge of exploring or creating alternatives that best fit their particular context. Given the current movement towards the development of 'international standards', this is a major challenge indeed. However, the rising influence of the Asian region and rapid developments in other parts of the world may imply changes in the future landscape of medical education.

\section{Acknowledgements}

We are grateful to the three medical schools for participating in this study. We sincerely thank the staff for their support and assistance in the field work. Special thanks are conveyed to Philip Beh, Amber Yip and Niv Patil, Institute of Medical and Health Sciences Education, University of Hong Kong, and to the research coordinator and assistant at the Middle Eastern medical school. We are thankful to Fred Stevens, Department of Educational Development and Research, Maastricht University, for his support, guidance and insights during the research. Editing of the manuscript by Mereke Gorsira, Department of Educational Development and Research, Maastricht University, is gratefully acknowledged. Finally, we express deep gratitude to all the students, tutors and staff who participated in the study.

\section{Funding}

The first author received a grant from University Fund Limburg (SWOL, Stichting Wetenschappelijk Onderwijs Limburg), Maastricht University, to finance part of the research. 


\section{References}

1. Wong AK. Culture in medical education: comparing a Thai and a Canadian residency programme. Med Educ 2011;45(12):1209-19.

2. Elliott J, Grigorenko EL. Are western educational theories and practices truly universal? Comp Educ 2007;43(1):1-4.

3. Bleakley A, Brice J, Bligh J. Thinking the post-colonial in medical education. Med Educ 2008;42(3):26670.

4. Amin Z, Hoon Eng K, Gwee M, Dow Rhoon K, Chay Hoon T. Medical education in Southeast Asia: emerging issues, challenges and opportunities. Med Educ 2005;39(8):829-32.

5. Gwee MC. Globalization of problem-based learning (PBL): cross-cultural implications. Kaohsiung J Med Sci 2008;24(3 Suppl):S14-22.

6. Gwee MC, Tan $\mathrm{CH}$. Problem-based learning in medical education: the Singapore hybrid. Ann Acad Med Singapore 2001;30(4):356-62.

7. Lam TP, Khoo US, Chan YS, Cheng YH, Lam KF. The first batch of graduates of a new medical curriculum in Asia: how their teachers see them. Med Educ 2004;38 (9):980-6.

8. Hodges BD, Segouin C. Medical education: it's time for a transatlantic dialogue. Med Educ 2008;42(1):2-3.

9. Karle H, Christensen L, Gordon D, Nystrup J. Neo-colonialism versus sound globalization policy in medical education. Med Educ 2008;42(10):956-8.

10. Hodges BD, Maniate JM, Martimianakis MA, Alsuwaidan M, Segouin C. Cracks and crevices: Globalization discourse and medical education. Med Teach 2009;31 (10):910-7.

11. Tweed RG, Lehman DR. Learning considered within a cultural context: Confucian and Socratic approaches. Am Psychol 2002;57(2):89-99.

12. Li J. Mind or virtue: Western and Chinese beliefs about learning. Curr Dir Psychol Sci 2005;14(4):190-4.

13. Joy S, Kolb DA. Are there cultural differences in learning style? Int J Intercult Relat 2009;33(1):69-85.

14. Ladyshewsky R. East meets West: The influence of language and culture in clinical education. Aust $J$ Physiother 1996;42(4):287-94.

15. Sim D, Patil N, Rehatta N, Kwan C. PBL is not suitable for Asian students. Symposium, Sixth Congress of the Asian Medical Education Association, 23-26 March, 2011, Kuala Lumpur.

16. Khoo HE. Implementation of problem-based learning in Asian medical schools and students' perceptions of their experience. Med Educ 2003;37(5):401-9.

17. Hussain RMR, Mamat WHW, Salleh N, Saat RM, Harland T. Problem-based learning in Asian universities. Stud High Educ 2007;32(6):761-72.

18. Walker A, Bridges, E., Chan, B. Wisdom gained, wisdom given: instituting PBL in a Chinese culture. J Educ Adm 1996;34(5):12-31.

19. Das Carlo M, Swadi H, Mpofu D. Medical student perceptions of factors affecting productivity of problem-based learning tutorial groups: does culture influence the outcome? Teach Learn Med 2003;15(1):59-64.

20. Dolmans DH, De Grave W, Wolfhagen IH, Van der Vleuten CP. Problem-based learning: future challenges for educational practice and research. Med Educ 2005;39(7):732-41.

21. Greveson GC, Spencer JA. Self-directed learning--the importance of concepts and contexts. Med Educ 2005;39(4):348-9.

22. Schmidt HG. Assumptions underlying self-directed learning may be false. Med Educ 2000;34(4):243-5.

23. Tsui ABM, Lopez-Real F, Edwards G. Sociocultural Perspectives of Learning. In: Tsui ABM, Lopez-Real F, Edwards G, eds. Learning in School-University Partnership: Sociocultural Perspectives. New York, NY: Routledge 2009:25-43.

24. Rogoff B, Chavajay P. What's Become of Research on the Cultural Basis of Cognitive-Development. Am Psychol 1995;50(10):859-77. 
25. Vásquez OA. Chapter 2: Cross-National Explorations of Sociocultural Research on Learning. Rev Res Educ 2006;30:33-64.

26. Vygotsky LS. Mind in Society. The Development of Higher Psychological Processes. Cole M, John-Steiner V, Scribner S, Souberman E, eds. Cambridge, MA: Harvard University Press 1978.

27. Engeström Y, Miettinen R. Introduction. In: Engeström Y, Miettinen R, Punamäki R-L, editors. Perspectives on activity theory. Cambridge: Cambridge University Press 1999:1-16.

28. King N. Using templates in the thematic analysis of text. In: Cassel C, Symon G, eds. Essential Guide to Qualitative Methods in Organizational Research. London: Sage Publications 2004:256-70.

29. Hofstede G. Culture's consequences. Comparing values, behaviors, institutions, and organizations across nations, 2 edn. Thousand Oaks, CA: Sage Publications 2001.

30. Leung DYP, Ginns P, Kember D. Examining the cultural specificity of approaches to learning in universities in Hong Kong and Sydney. J Cross Cult Psychol 2008;39(3):251-66.

31. Al Kadri HM, Al-Moamary MS, Magzoub ME, Roberts C, Van der Vleuten CPM. Students' perceptions of the impact of assessment on approaches to learning: a comparison between two medical schools with similar curricula. Int J Med Educ 2011;2:22-52.

32. Miflin BM, Campbell CB, Price DA. A lesson from the introduction of a problem-based, graduate entry course: the effects of different views of self-direction. Med Educ 1999;33(11):801-7.

33. Miflin BM, Campbell CB, Price DA. A conceptual framework to guide the development of self-directed, lifelong learning in problem-based medical curricula. Med Educ 2000;34(4):299-306.

34. Dolmans DH, Schmidt HG. What drives the student in problem-based learning? Med Educ 1994;28(5):372-80.

35. Hwang A, Francesco AM, Kessler E. The relationship between individualism-collectivism, face, and feedback and learning processes in Hong Kong, Singapore, and the United States. J Cross Cult Psychol 2003;34(1):72-91.

36. Savvas M, El-Kot G, Sadler-Smith E. Comparative study of cognitive styles in Egypt, Greece, Hong Kong and the UK. Int J Training and Development 2001;5(1):64-73.

37. Eva KW. Witnessing the globalisation of medical education first-hand. Med Educ 2009;43(7):604-5. 



\section{CHAPTER 4}

\section{The cultural complexity of preparing}

\section{learners for practice in PBL}

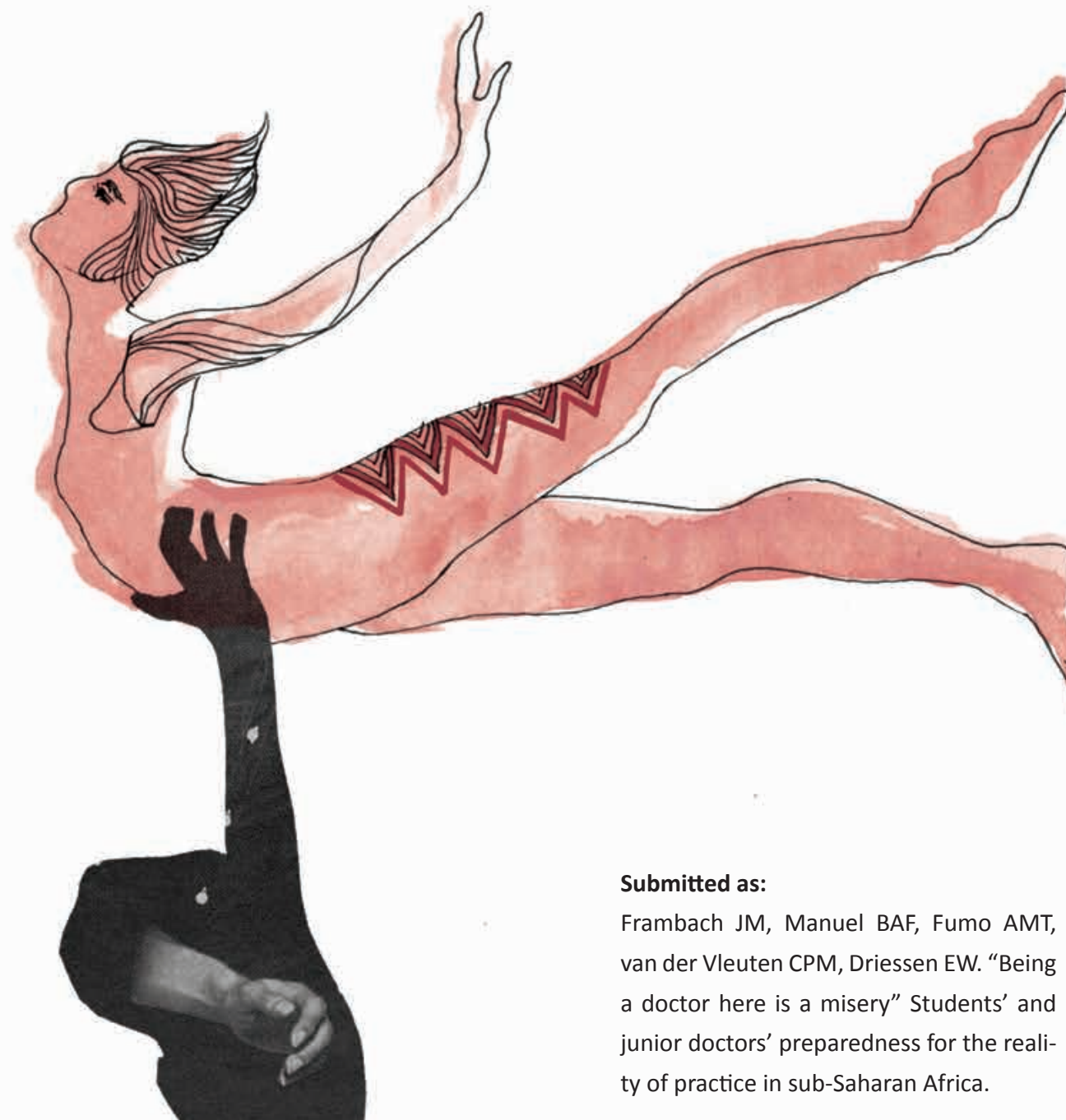


CHAPTER 4 


\section{Introduction}

Health care in sub-Saharan Africa faces a disproportionate share of the global disease burden and struggles with persistent shortages of doctors: 125000 doctors for 868 million people is scant indeed compared to Western Europe where a population half that size is served by 11 times as many doctors. ${ }^{1,2}$ Because of unequal distribution over sub-Saharan African countries, moreover, the physician-to-population ratio in some countries rates as low as 1.1 per $100000 .^{2}$ Medical schools in the region cope with scarcity of qualified faculty and poor infrastructure, which prevents them from producing enough graduates to fill this gap. ${ }^{1,3,4}$ It is moreover particularly difficult to recruit and retain graduates in rural and underserved areas where the need for care is most urgent. ${ }^{2,5}$ These concerns have stimulated several initiatives being taken in recent years to scale up and prioritize sub-Saharan African medical education, notably the Medical Education Partnership Initiative ${ }^{2}$ and the Sub-Saharan African Medical Schools Study. 4 Additionally, initiatives for global scale up of health professional education were taken, such as the development of WHO policy guidelines ${ }^{2,6,7}$ and recommendations for reforms based on global changes in health care and education. ${ }^{1}$

Each of these initiatives emphasize that scale up is needed not only in terms of quantity, but also in quality of doctors. ${ }^{1-4,6,7}$ Besides the number of qualified faculty and the state of infrastructure at medical schools, an important factor that affects the quality of doctors is the type of curriculum. ${ }^{2,4}$ Medical curricula need to produce doctors of global excellence who possess locally relevant competencies, equipped and motivated to meet the health care needs of their communities. ${ }^{1,8}$ This is particularly pressing for sub-Saharan Africa, where doctors confront a highly demanding local context, but where reforms in medical education lag behind the rest of the world. ${ }^{9,10}$ Whereas many medical schools worldwide have moved to integrated, problem-based and competency-driven curricula, a number of financial, political, and educational factors hinder adequate reforms and innovations at African schools, ${ }^{9-12}$ although they are increasingly noted to introduce community-based, problem-based, and team-based learning. ${ }^{3}$ Innovative curricula that focus on such forms of learning indeed hold great potential for scaling up the quality of sub-Saharan African doctors: they are found to encourage patient- and community-centered attitudes and motivation, communication and interpersonal skills, and self-directed, lifelong learning skills, ${ }^{13-15}$ which are essential attributes of the 'Doctor for Africa' . ${ }^{16-18}$

However, a current lack of evidence on which innovations work in which contexts, particularly in sub-Saharan Africa, leads to resistance to change by relevant stakeholders, leaving them unconvinced of the merits of innovative approaches. ${ }^{6}$ Consequently, there is an urgent call for evidence on the outcomes of educational innovations, ${ }^{1,2,6,8}$ especially for Sub-Saharan Africa, which is underrepresented in medical education research. ${ }^{9}$ This study aims to contribute to such a base of evidence that enables evidencebased decisions on improving doctors' quality in Sub-Saharan Africa and beyond. For 
this purpose, we focused on sub-Saharan African medical students' and graduates' preparedness for practice, as an outcome of educational innovation. Preparedness for practice is defined as having acquired the "clinical, professional and cultural skills required for successful practice" ${ }^{19}$ after graduation from medical school. We explored how medical graduates and students from an innovative curriculum in a sub-Saharan African context, compared with a conventional curriculum, feel their education has prepared or prepares them for practice after graduation.

\section{Methods}

\section{Setting}

We conducted the study in Mozambique, a country facing one of the most challenging health care situations in the world. ${ }^{20}$ With three doctors per 100000 inhabitants Mozambique falls below the WHO African region average of 22 per 100 000, gross national income per capita is 2.5 times lower than the regional average and prevalence of HIV is 2.5 times higher. ${ }^{21}$ We compared a conventional medical school with a school characterised by a large-scale study of sub-Saharan African medical schools as "an instructive example of innovative African medical education". ${ }^{20}$ The schools are located in the largest and the second-largest city of the country, respectively. The innovative school met our criterion for an innovative curriculum comprising curriculum-wide implementation of problem-based learning (PBL). PBL is defined here as both a method and a philosophy, characterised by student-centred, active learning in small groups using clinical cases, with integration of basic and clinical sciences and significant time for independent study. ${ }^{14,15,22}$ Founded in the late 1990s, the innovative school, which is private and faith-based, graduates an average of 25 doctors annually. The six-year problem- and community-based curriculum is adapted from a Dutch curriculum. The dominant educational methods are small group sessions and independent study supplemented by lectures, laboratory training, communication and clinical skills sessions with real patients, a four-year community programme with attachments to families and clinical rotations in the final two years.

The conventional school was founded in the late 1960s. Besides the innovative school it is the only Mozambican medical school that produced graduates until now, since two new schools have yet to deliver graduates. The school graduates an average of 80 students annually and the six-year curriculum contains community-orientated elements but is discipline-based and conventional. The main educational format is lectures with additional laboratory training, clinical rotations in years 3-6 and a community programme with visits to public health sites. At both schools, clinical training is mainly hospital-based, except for one rotation in a rural area (both schools) and one in a health centre (innovative school). Apart from the innovative-conventional contrast, the 
innovative school is private and the conventional school public, but this difference has much less impact than in for example Western settings. Both schools have scarce resources and admittance depends on academic performance. The private school charges higher tuition fees, but approximately $60 \%$ of students have scholarships, ${ }^{20}$ resulting in a similar mix of students from poor and wealthy socio-economic backgrounds in both schools.

\section{Design and procedures}

With a mixed method approach, we simultaneously collected quantitative and qualitative data enabling triangulation and complementation. ${ }^{23}$ With approval from the Deans of the participating schools and the Ethical Review Board of the Dutch Association for Medical Education we collected data in March and April 2012.

A validated questionnaire used internationally to measure competencies of the 'flexible professional' ${ }^{24}$ was adapted to the purpose of our study, translated into Portuguese by a professional translator, and cross-checked by two of the authors. The questionnaires were administered to graduates and fifth-year students from the two schools. Participation was voluntary and anonymous. For each completed questionnaire $€ 5.00$ was donated to a local health care charity chosen from the respondents' suggestions.

Logistic and contextual constraints, and lacking or outdated contact information limited opportunities for recruiting participants, particularly among graduates. Of 78 out of a total of 103 innovative school graduates which we approached by email or in person thirty responded (response rate 38.5\%). Recruitment of graduates from the conventional school either in person or via the school's Facebook page for graduates yielded 24 respondents (response rate unknown). Fifth-year students were recruited during lectures, group sessions and rotations, which yielded 36 of a total of 42 students at the innovative school and 67 of a total of 103 students at the conventional school. All approached students participated (response rates $100.0 \%$ ). Using SPSS v19, means and standard deviations were calculated, and differences between the schools were assessed using independent-samples $t$-tests. Paired-samples $t$-tests were conducted to compare individual answers to two related items. Effect sizes (ES) for significant $t$-test results were calculated and categorised using Cohen's $d$.

In-depth, semi-structured interviews were conducted with fifth-year students and graduates. We generated a purposive sample of five students and five graduates from each school, which we estimated to yield data saturation. The purposive sampling frame took account of sex, and (for graduates) graduation date (> one year) and workplace (e.g. urban teaching hospital versus rural health station) to reflect diversity of experiences. A semi-structured interview guide was developed, which was continuously adapted in the iterative data collection process, containing questions and probes on how medical school had prepared the participants for practising medicine in Mozam- 
bique, with special attention to aspects they valued particularly or felt were missing, difficulties encountered at work or on rotations and factors influencing these. As an outsider to both schools, JF conducted the interviews, which took place in English or Portuguese as chosen by the participant, and lasted 40-60 minutes. All interviewees received compensation and informed consent was obtained. The graduate interviewees were also asked to keep a work diary until they had recorded at least two work situations for which they felt well prepared and two situations for which they felt ill prepared and to reflect on these situations, focusing on the role of education and contextual factors. Six of ten graduates completed the diary; four from the innovative school and two from the conventional school. Four graduates did not complete the diary because of time constraints or personal issues.

The interviews were audio recorded and transcribed verbatim by research assistants fluent in English and Portuguese. Data saturation was achieved and member checks were conducted. Initial analysis of the data by JF yielded a coding framework of themes, which was used to code the transcripts and diaries in detail during a second round of analysis using Atlas.ti v6.2. In the iterative data analysis process the coding framework was continuously adapted and discussed with a second researcher (ED). A third researcher (BM) independently analysed and coded a sample of four transcripts, one from each group of participants. JF and BM discussed their findings and found only minor differences. Consensus was easily reached. In a third analysis round the relations and meaning of the themes were analysed and discussed in the research team, taking the analysis from the categorical to the conceptual level.

Additional information about the schools, work environments and curricula was gathered by observing educational sessions, community and hospital visits and informal interviews with key staff and leaders. An elaborate research journal was kept which informed data collection and analysis, and served reflexive purposes. In the final stage of the analysis, the qualitative and quantitative data were integrated in a conceptual model.

\section{Results}

Table 1 reports characteristics of the questionnaire respondents and interviewees. The conceptual model in figure 1 shows six areas of tension between Mozambican reality and 'ideal' medical practice that challenged doctors' motivation and preparedness for practice, and four elements of the innovative curriculum that equipped graduates with skills, attitudes and competencies to better cope with these tensions. Following our mixed methods approach, we present the integrated quantitative (tables 2 and 3) and qualitative results for the six areas of tension, with illustrative quotes from participants (table 4). 
Table 1. Characteristics of the questionnaire respondents and interviewees.

\begin{tabular}{|c|c|c|}
\hline & Innovative school & Conventional school \\
\hline \multicolumn{3}{|l|}{ Respondents to questionnaire } \\
\hline Students & $N=36$ & $N=67$ \\
\hline Mean age in years (SD) & $25.5(3.8)$ & $26.0(2.8)$ \\
\hline Female & $36.1 \%$ & $53.7 \%$ \\
\hline Graduates & $N=30$ & $N=24$ \\
\hline Mean age in years $(S D)^{*}$ & $30.6(2.5)$ & $30.8(5.1)$ \\
\hline Female** & $53.6 \%$ & $36.4 \%$ \\
\hline Graduated between & Aug 2007 - Dec 2010 & Oct 2003 - Jan 2012 \\
\hline Mean no. months of work experience & 29.8 & 36.9 \\
\hline \multicolumn{3}{|l|}{ Job title } \\
\hline General medical doctor & $63.3 \%$ & $8.3 \%$ \\
\hline Resident & $23.3 \%$ & $75.0 \%$ \\
\hline Specialist & $0.0 \%$ & $12.5 \%$ \\
\hline Other & $13.3 \%$ & $4.2 \%$ \\
\hline \multicolumn{3}{|l|}{ Workplace*** } \\
\hline Central hospital & $44.8 \%$ & $87.0 \%$ \\
\hline General hospital / rural hospital & $10.3 \%$ & $8.7 \%$ \\
\hline Health centre / health station & $27.6 \%$ & $0.0 \%$ \\
\hline Other & $17.2 \%$ & $4.3 \%$ \\
\hline \multicolumn{3}{|l|}{ Interviewees } \\
\hline Students & $N=5$ & $N=5$ \\
\hline Female & 2 & 2 \\
\hline Male & 3 & 3 \\
\hline Graduates & $N=5$ & $N=5$ \\
\hline Female & 2 & 1 \\
\hline Male & 3 & 4 \\
\hline Graduated between & Dec 2008 - Dec 2010 & Dec 2007 - Jan 2011 \\
\hline \multicolumn{3}{|l|}{ Current and past workplaces $^{\dagger}$} \\
\hline Central hospital & 3 & 4 \\
\hline Rural hospital / health centre & 3 & 2 \\
\hline Faculty of Medicine $e^{++}$ & 2 & 1 \\
\hline Other & - & 1 \\
\hline
\end{tabular}

*Innovative school: 6 missing, Conventional school: 2 missing

** Innovative school: 2 missing, Conventional school: 2 missing

*** Innovative school: 1 missing, Conventional school: 1 missing

${ }^{\dagger}$ More than one answer possibility

${ }^{++}$Part time job besides job in hospital or health centre 


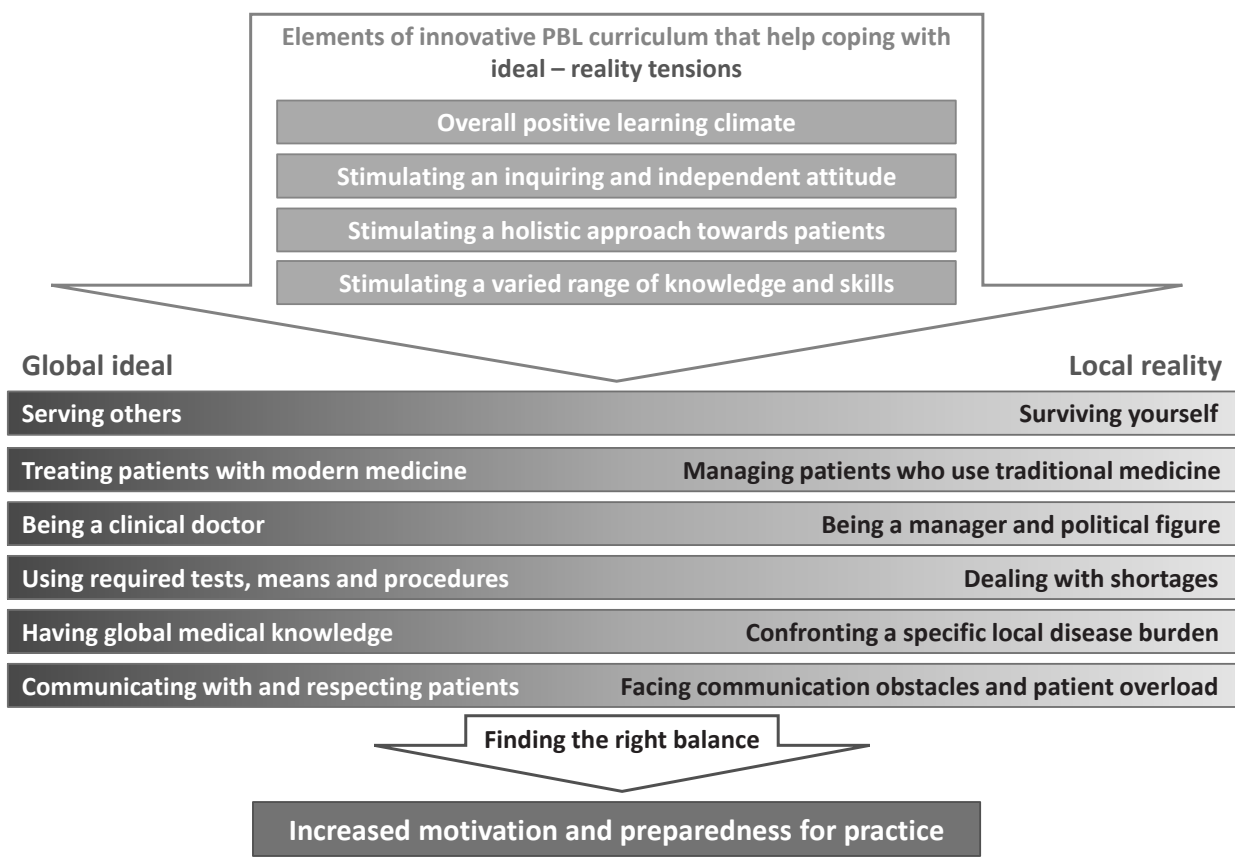

Figure 1. Conceptual model of the findings. Four elements of the innovative curriculum help graduates to strike a better balance between six ideal - reality tensions that challenge their motivation and preparedness for work.

\section{Balancing service and survival}

Many participants mentioned low motivation due to low pay and personal and professional challenges (table 4, quotes 1-3). To support themselves and their families, doctors had to supplement their income from public health care by taking jobs in private clinics. This left less energy for each job and was particularly detrimental to the public health job, as private clinics offered better pay and working conditions. These adverse effects on the health care for the most vulnerable part of the population fuelled a downward spiral: demotivated doctors causing health care problems to worsen, which demotivated doctors etc. Some participants characterised motivation as the key professional attribute of doctors in Mozambique. The innovative curriculum offered a more positive learning climate (quotes 4-5), contributing to satisfaction, preparedness and motivation. Table 2 reports that the curricula differed significantly in satisfaction (ES: 0.97), usefulness of the study programme (ES: 0.67) and the basis for work aspects (ES: 0.71-1.40), though mean scores were high for both schools (>3.8). Performing current work tasks showed no difference but the large difference for personal development (ES: 1.40) may affect motivation. Ratings for work satisfaction were relatively low for both schools (mean: 3.8 for innovative graduates, 3.0 for conventional graduates) albeit significantly higher for the innovative school (ES: 0.87). 
Table 2. Graduates' opinions about their satisfaction with their medical education (five-point scale: $1=$ very dissatisfied, 5 = very satisfied), the usefulness of their medical education for their current work (five-point scale: 1 = not useful at all, 5 = very useful), their work satisfaction (five-point scale: 1 = very dissatisfied, 5 = very satisfied), and the extent to which their medical education had provided a sound foundation for several aspects of their work (five-point scale: $1=$ not at all, $5=$ to a very high extent).

\begin{tabular}{|c|c|c|c|c|c|}
\hline & \multicolumn{2}{|c|}{ Innovative school } & \multicolumn{3}{|c|}{ Conventional school } \\
\hline & $n$ & Mean (SD) & $n$ & Mean (SD) & Effect size \\
\hline Satisfaction with study programme & 30 & $4.5(0.8)$ & 23 & $3.8(0.6)^{* *}$ & $0.97^{\ddagger \neq \ddagger}$ \\
\hline Study programme's usefulness for work & 30 & $4.6(0.7)$ & 23 & $4.1(0.8)^{*}$ & $0.67^{\ddagger \ddagger}$ \\
\hline Work satisfaction & 29 & $3.8(1.0)$ & 23 & $3.0(0.8)^{* *}$ & $0.87^{\ddagger \ddagger \ddagger}$ \\
\hline \multicolumn{6}{|l|}{ Study programme offered a sound basis for: } \\
\hline Starting work & 30 & $4.7(0.5)$ & 23 & $4.3(0.6)^{*}$ & $0.73^{\ddagger \ddagger}$ \\
\hline Further learning on the job & 30 & $4.6(0.7)$ & 23 & $4.1(0.7)^{*}$ & $0.71^{\text {㧊 }}$ \\
\hline Performing current work tasks & 30 & $4.6(0.6)$ & 23 & $4.3(0.7)$ & ns \\
\hline Future career & 29 & $4.5(0.7)$ & 23 & $4.0(0.7)^{* *}$ & $0.71^{\ddagger \ddagger}$ \\
\hline Personal development & 30 & $4.7(0.6)$ & 23 & $3.8(0.7)^{* * *}$ & $1.40^{\ddagger \ddagger \ddagger}$ \\
\hline
\end{tabular}

* Significant difference $\mathrm{P}<0.05$ Innovative versus Conventional school / ** $\mathrm{P}<0.01 / * * * \mathrm{P}<0.001$

${ }^{\ddagger}$ Small / ${ }^{\ddagger \ddagger}$ Medium / ${ }^{\ddagger \neq \ddagger}$ Large effect size ( $n s=t$-test was not significant)

$\mathrm{N}$ is mentioned for each item separately, because not all respondents answered each item.

\section{Balancing modern and traditional medicine}

Due to cultural beliefs and shortcomings of modern health care most patients preferred traditional healers over medical doctors, leading them to engage in risky traditional practices, taking toxic traditional medicines, showing poor compliance with medical treatment, leaving the hospital in critical condition or failing to seek medical care until the final stage of disease (table 4, quotes 6-7). Respecting patients' beliefs and convincing them to comply with medical treatment required excellent communication skills and cultural knowledge and sensitivity. Innovative school participants felt reasonably well prepared for this by communication skills sessions, group discussions and the extensive community programme promoting a holistic view of patients and their environment (quote 8). Nevertheless, all participants felt these skills were mostly learned in practice and the clinical rotations of the conventional school were considered to offer some degree of preparation.

\section{Balancing clinical and management tasks}

In rural hospitals and their surroundings the graduates were often the only one with a higher education degree and therefore designated as hospital manager whose tasks included strategic, financial and human resource management, management of local public health programmes and participation in local and regional politics. Participants from both schools felt ill prepared for these roles, despite a hospital management 
course in both curricula (table 4, quote 9). The innovative curriculum helped graduates deal with unfamiliar situations by fostering an inquiring and independent attitude (quote 10) and equipping students with knowledge and skills for various situations, such as leadership, presentation, communication and team skills. Table 3 shows that for 22 professional competencies, all participants felt generally competent (mean scores > 3 ), but innovative school graduates and students gave significantly higher ratings for seventeen and seven competencies, respectively, including management competencies, such as coordinating activities, mobilising the capacity of others, asserting authority, presenting ideas to an audience, knowledge of other fields, working productively with others and coping with criticism from others (ES: 0.14-1.08). For some competencies participants rated the required level significantly higher than their present level.

\section{Balancing requirements and shortages}

Medical school had taught graduates to use means, procedures and tests to diagnose and treat patients, but in practice, in rural areas in particular, graduates found that facilities and equipment were lacking or defective (table 4, quote 11) forcing them to manage with suboptimal means. Participants from both schools indicated that their main preparation for this shock of practice consisted in practical experiences focused on clinical decision making as provided by the clinical rotations (quotes 12-13). Participants from the conventional school appreciated the four years of rotations, although their effectiveness was compromised by lack of supervision and guidance (quote 14), a view that was shared by innovative school participants. Aspects of the innovative curriculum that helped graduates cope with shortages were an independent and inquiring attitude and a varied range of knowledge and skills (quote 15). Nevertheless, education had not prepared graduates for all situations they encountered. 


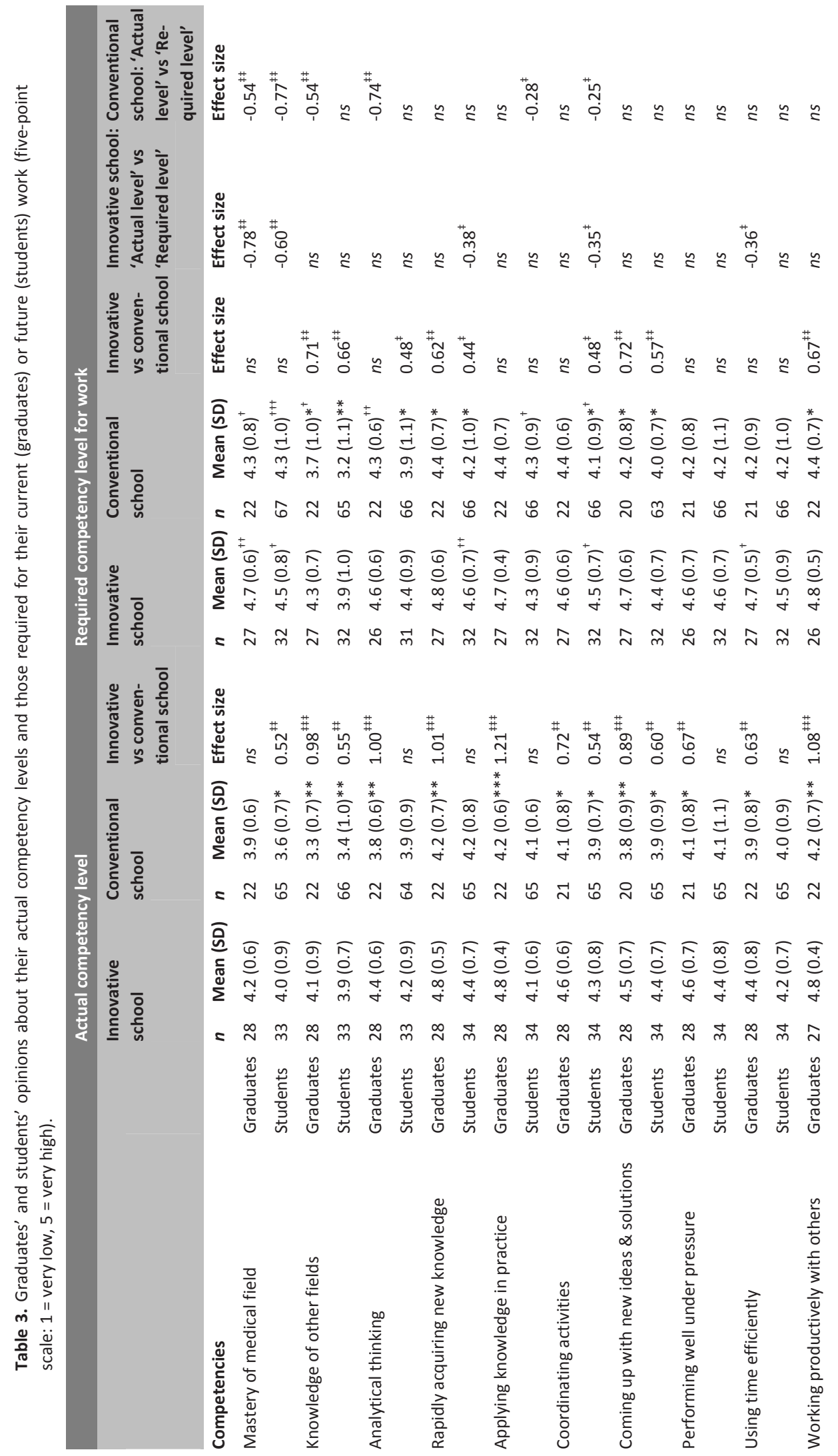




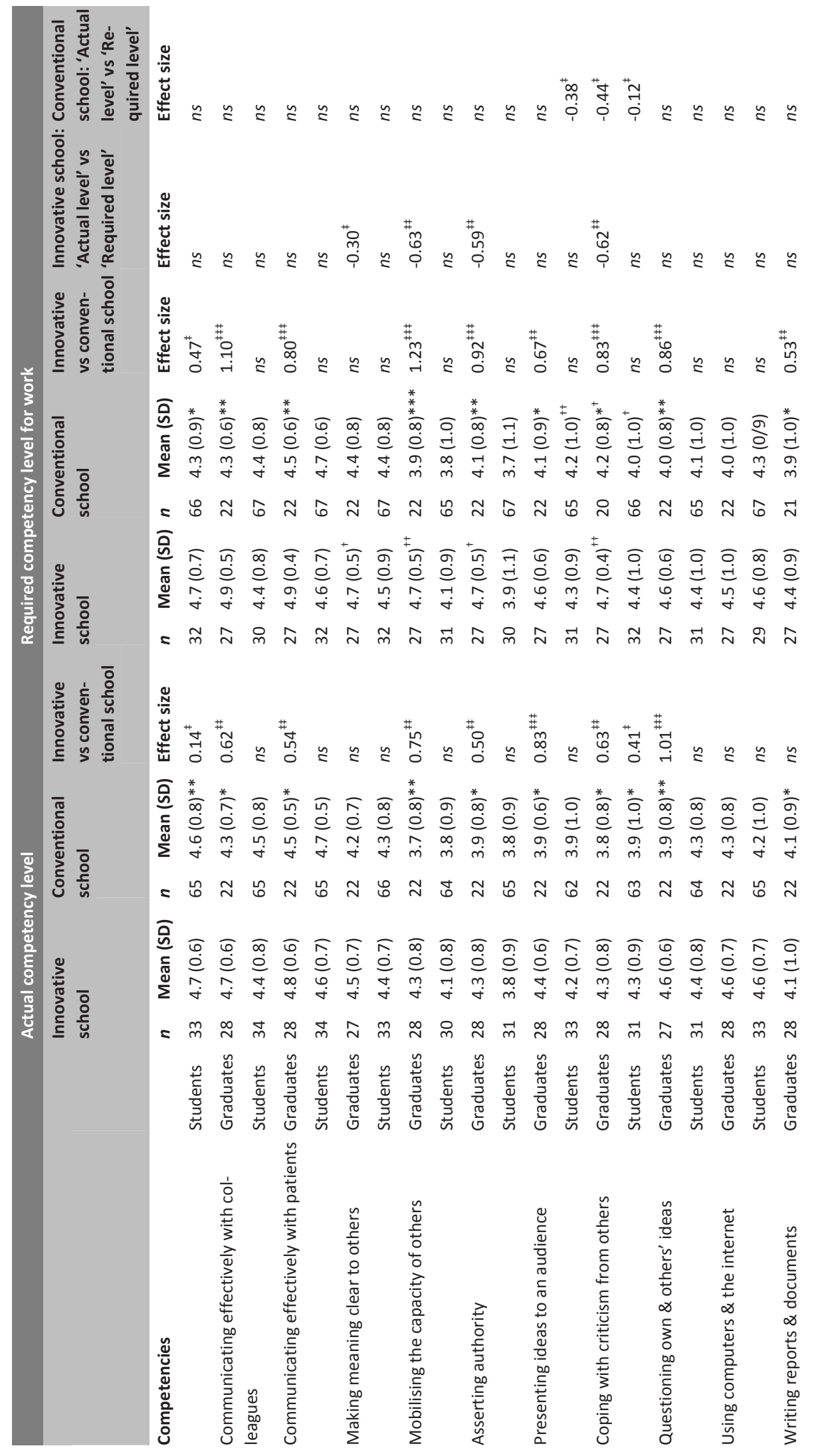




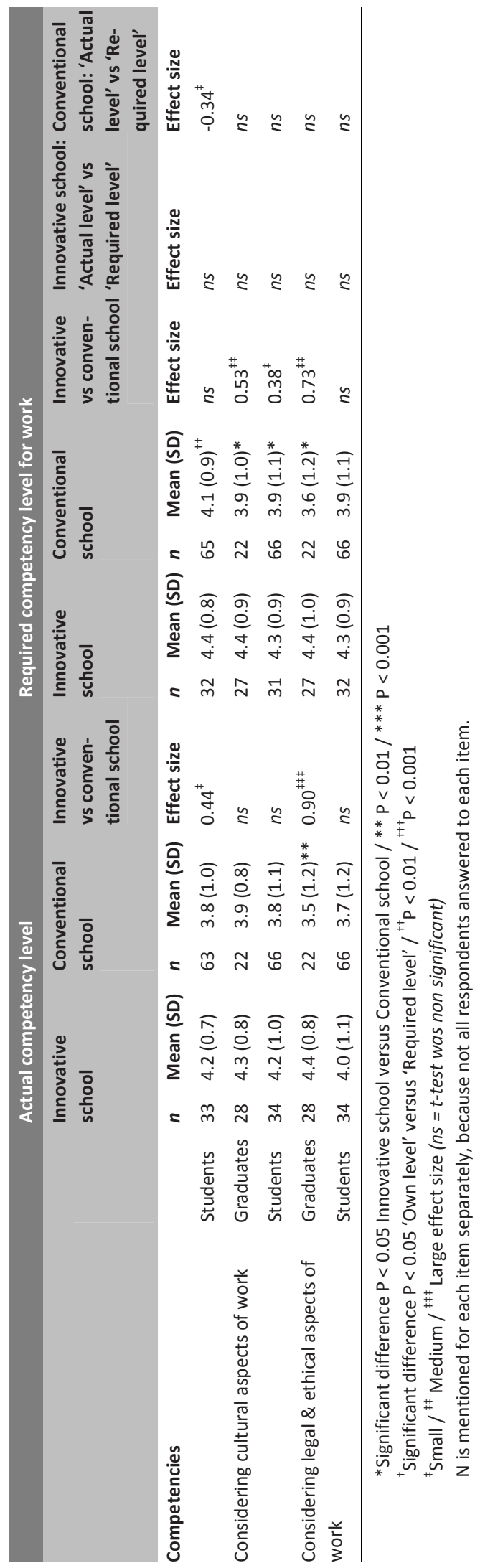




\section{Balancing global and local epidemiology}

Graduates were confronted with Mozambique's heavy burden of specific diseases, such as HIV/AIDS, malaria and tuberculosis. Besides a local, community-based perspective, the innovative curriculum also took a global perspective covering diseases uncommon in Mozambique, while the conventional curriculum focused more on basic and pragmatic medical knowledge with local relevance. While innovative school participants appreciated the broad perspective, gaps in their basic knowledge were a barrier in dealing with Mozambican reality (table 4, quote 16). All respondents rated their actual 'mastery of medical field' significantly below the required level (ES: -0.54- -0.78), implying a perceived lack of preparedness. Some interviewees referred to medical errors being common among graduates. The inquiring and independent attitude stimulated by PBL was considered advantageous for dealing with unfamiliar disease presentations, and PBL's lifelong learning philosophy was considered particularly important (quote 17). Innovative school graduates indicated significantly higher levels of competence in managing unfamiliar cases compared to conventional graduates (table 3): analytical thinking (ES: 1.00), rapid acquisition of new knowledge (1.01), applying knowledge in practice (1.21) and coming up with new ideas and solutions (0.89). Differences between students were less or not significant.

\section{Balancing good and short communication with patients}

Lack of time for communication due to heavy patient load was detrimental to patient care, especially since many patients did not speak the official language and were poorly educated and reluctant to discuss their condition, such as HIV infection, for fear of being stigmatised (table 4, quote 18). Communicating at patient level, making patients feel comfortable and gaining their trust demanded expert communication and interpersonal skills, an empathic attitude and ethical insights. Innovative school participants felt prepared for this by communication skills sessions, the community programme and group discussions on ethical issues (quote 19). Still, transitioning from skill training to the reality of hospital rotations was experienced by some as quite a shock. Early exposure to practice in the conventional school was appreciated despite criticism of insufficient structured preparation for communication and ethical behaviour and a lack of doctors serving as role models (quote 20). Table 3 shows significantly higher ratings by innovative school graduates for communicating effectively with patients and colleagues, considering legal and ethical work-related issues, performing under pressure and efficient time management (ES: 0.54-0.90). 
Table 4. Illustrative quotes from interviewees, graduates' diary entries, and textual comments from questionnaire respondents.

\section{Balancing service and survival}

Q1: I thought I would earn a good salary and that people would admire me. But I think I have neither: I don't have a good salary and people don't admire the doctor so much, they prefer to go to the traditional healer.

(CSG1, interview)

Q2: Being a doctor here is a misery. (CSG, textual comment in questionnaire)

Q3: It is very difficult to work under the present conditions. For example, I've had a situation in which I had to use my own money to buy medicine to be able to help a patient. ( . . ) So this spoils almost everything. Work is a struggle. There are colleagues who simply don't show up for work because they are not motivated. I even have colleagues saying "I will not visit the ward today" Why? "Because I'm tired, and it's nobody's business". (CSG1, interview)

Q4: My study teaches me how to take care of a patient, like not to rush in order to leave earlier, because I could lose a lot of clinical findings that would take me to the diagnose. ( . . ) And what I feel is that my studies will probably help me to not make these mistakes, [ . . but] to see everything about the patient and try to discover what he has, not just treat the symptoms, you see, but to discover the cause. (ISS1, interview) Q5: The training helped me to expose my ideas and pose questions to my superiors without difficulty. (ISG, textual comment in questionnaire)

Balancing modern and traditional medicine

Q6: Traditional healers offer an immediate solution to their problems. But when they come to me, a doctor in the hospital, and I tell them the diagnosis but that I do not have the medication to treat them, well that is no incentive to come to the hospital. ( . . ) So people rely more on traditional healers, whether it is correct or not, that is another matter, but they offer a solution right there. (CSG1, interview)

Q7: The child's mother, after being questioned, revealed that she would give him traditional medication when there were no nurses around. ( . . ) She replied that it had to do with her husband's spirits which had taken possession of the child. She never received any medical information before and her decision was to take the patient home. After she insisted for a long time, the patient was discharged. This incident made me realize that I wasn't well prepared to deal with this type of situation, because I had not been taught to give advice that was appropriate for the community, considering that my academic background was focused more on the clinical aspect and not on the socio-cultural aspect of the community. (CSG2, diary)

Q8: The course pays a lot of attention to this issue of traditional medicine. I followed a course on family health. ( . . ) There was much emphasis on this very point of communication, culture. How can we deal with the patient within this context? ( . . . ) How does a person think? This gave us a different insight into the difficulties a doctor may encounter, both in terms of communication and cultural issues. (ISS3, interview) Balancing clinical and management tasks

Q9: As director of the hospital I need to manage the finances. ( . . ) It is difficult to define the priorities and try to contain the costs to ensure that the hospital can still function despite its low budget every year. This has been very difficult because I have no notion of hospital management and during my studies I didn't learn this aspect. (ISG5, diary)

Q10:The faculty fosters a very strong investigative spirit. ( . . ) So you focus on investigating, you look for more knowledge and you discuss this with your classmates. I believe that the method, for me, was very positive, very constructive due to having to acquire this investigative attitude. (ISG1, interview)

\section{Balancing requirements and shortages}

Q11: The difficulties are similar to those of any African country, shortage of materials, shortage of medicines, not being able to do further tests. . There's a lot we don't do because there's no possibility to do it. (CSG5, interview)

Q12: We have had cases where we suspected a disease but didn't have the means to analyze and confirm our suspicion, so we had to treat the patient and wait and see. By some time he improved and only then we could confirm the diagnosis. It's a skill that develops over time. I think it's one of those things one learns on the job. 


\section{(CSG2, interview)}

Q13: I think the course offers a good preparation because most of it is done in the hospital and in the hospital you encounter reality. ( . . ) Work as such is already incorporated into the course itself. (CSG5, interview) Q14: As a student I was very afraid to ask a teacher to explain something. Because at that moment he would mark you as a bad student, ( . . ) and was able to give you a negative mark for a test. So we avoided to get involved. ( . . ) When students approach the teachers to explain something they feel they are occupying their time. They always complain: "you are always bothering me and you pay me nothing". ( . . ) So because we didn't have the teacher with us, we didn't have a lot of theory. And even our practice, it was more because the patient happened to be there, it was more experimental. We experimented because we had nobody amongst us who knew how to do things. So we experimented. ( . . . ) It's a bit strange and dangerous, isn't it, but what else could we do? We needed to learn and they needed to be treated. So we treated them. (CSG1, interview)

Q15: In the hospital where I work, I am the only doctor and there are six health workers. When I started working there, there were a lot of deaths during the admission of patients, especially in the paediatrics and medicine departments. When I asked why there were so many deaths, I received no plausible explanation. Then I decided to introduce discussions about clinical cases and hospital deaths every Tuesday. ( . . . ) After some time, the staff began to realise that our sessions were important because we could share difficulties and we could solve, together, some difficult cases. After three months, the death rate and the number of severely ill patients reduced considerably and patient care improved markedly. ( . . ) This method of discussing cases I learned during my academic education, there were always sessions about presentations of clinical cases that aimed to improve the quality of our work. (ISG5, diary)

Balancing global and local epidemiology

Q16: For me it's a bit hard here in the hospital. Maybe due to the things we have read, they are so different from what we come across here in the hospital, to do examinations, diagnoses. . Elsewhere in the world people use very sophisticated means of diagnosis, but here we have very rudimentary diagnostic tools. ( . . . ) Maybe, I think we should also have something that is more relevant to our situation here. (ISS5, interview) Q17: If there are some diseases that I only came across in books, but never actually have seen in reality, and these are appearing now, I use the PBL method. Thanks to that, I investigate to find out what it is. The fact that I finished my course doesn't mean I have seen all the diseases that patients will present. So this continuously happens. (ISG3, interview)

\section{Balancing good and short communication with patients}

Q18: The patients are very closed, they don't talk much. They don't communicate very well with a doctor, they don't ask questions. ( . . . I I don't know whether it is the doctor who intimidates the patient, or the patient who is afraid to talk to the doctor. Because this happens when people haven't attended school very much. For an educated person it is easier to ask "What is it that I have?" or "This medicine is for what exactly?" Many of our patients don't ask anything. They take the tablets home and don't take them. Or they take them during the first few days, then they start feeling better and don't take them anymore. This happens a lot with HIV treatments for example, or with tuberculosis. Many people stop taking their medicine when they feel better, and this is due to a lack of communication between patient and doctor. (CSS1, interview) Q19: The communication skill sessions are very good because they prepare the medical student, the future doctor, to understand not only the perspective of the patient he is going to deal with, but also his own attitude. (ISG4, interview)

Q20: Here in the faculty we only acquire theoretical knowledge. ( . . . ) The faculty doesn't form one's character. ( . . . ) We don't have lessons in manners, etiquette, on how to behave when we are in a hospital. (CSS3, interview)

$\mathrm{Q}=$ quote, ISG = innovative school graduate, CSG = conventional school graduate, ISS = innovative school student, CSS = conventional school student 


\section{Discussion}

Although doubts about preparedness for practice are familiar among recent graduates worldwide, ${ }^{25-27}$ our findings show that the challenges facing junior doctors in subSaharan Africa are of a different dimension altogether. Local health care is a far cry from global ideals, and reconciling medicine as taught with medicine as practised can be frustrating, to put it mildly. The challenges, moreover, sustain each other in a vicious cycle. Patients prefer traditional healers, partly due to shortages of means and personnel in modern health care. The same shortages coupled with harm inflicted by traditional medicine demoralise doctors facing an overload of severely ill patients while also having to act as hospital managers without appropriate training. A larger medical workforce and improved infrastructure are obvious solutions but lie outside the scope of what medical education can achieve: joint efforts of all stakeholders, including medical schools, ministries, donors and health care institutions, are needed. ${ }^{2,8}$

Notwithstanding these challenges, our findings provide evidence that innovative curricula focused on problem- and community-based learning can contribute to improving the quality of medical doctors in sub-Saharan Africa. Students and graduates from the innovative curriculum reported higher competency levels and a higher level of preparedness to face the challenges of practice, compared with students and graduates from the conventional curriculum. In line with worldwide research on the effects of innovative medical curricula comprising problem- and community-based learning, ${ }^{14,22,}$ ${ }^{28-31}$ these competencies and skills involve mainly the social and cognitive domains. The innovative curriculum in our study was found to stimulate an inquiring and independent attitude, a varied range of social and cognitive skills and a holistic approach towards patients. These are essential attributes for sub-Saharan African doctors, as indicated by our study and existing literature. ${ }^{16,17,32}$ The large effect sizes that we found, which in many cases are larger than those found in studies conducted elsewhere ${ }^{28,29,33}$ support claims that these innovative curricula hold promise for low-income countries in need of major reforms, as through 'transformative learning' they produce independent, critical change agents. ${ }^{1,2}$ Despite, or perhaps because of the challenges of the sub-Saharan African context, improvements in doctors' social and cognitive skills may seem even more meaningful in these low-resource settings compared with high-income settings.

The innovative curriculum in our study appeared to enhance doctors' motivation, which might counteract internal (from rural to urban and from public to private health care) and external (from low- to high-income countries) migration of doctors, ${ }^{5}$ thereby strengthening the workforce and promoting retention of doctors - key objectives of current scale up initiatives. ${ }^{2,6-8}$ Most innovative school graduates worked as general medical doctors and more often in rural health centres than conventional graduates, most of which were residents in a central hospital. This is consistent with suggestions in the literature that problem- and community-based curricula motivate graduates to work in rural areas and choose primary health care as their specialty. ${ }^{32,34}$ Whether and 
how this finding is attributable to curriculum as opposed to school location and our recruitment strategy remains to be investigated.

Practical learning during clinical rotations, including good supervision and role models, was valued highly among participants from both schools in our study, who regarded this as one of the most effective preparations for practice, which is consistent with previous research. ${ }^{19,26}$ However, its effectiveness was heavily compromised by a severe shortage of good clinical teachers, which should be a priority in scale up efforts. Possibly as a result of inadequate clinical teaching and learning, respondents from both schools felt their mastery of medical knowledge did not live up to the standards required in practice.

The innovative curriculum performed worse than the conventional curriculum in imparting basic and locally relevant medical knowledge, which is consistent with studies conducted elsewhere reporting slightly higher levels of basic medical knowledge among conventional graduates. ${ }^{29,}{ }^{30}$ With regard to locally relevant knowledge, current recommendations for health professional education emphasise alignment of knowledge with local epidemiology, which in many low-income countries means a strong focus on primary health care. ${ }^{1,2,6}$ Despite primary care's perhaps relatively low status, it is increasingly emphasized that this focus is perfectly compatible with global excellence. ${ }^{7,8}$ The attention to globally relevant medical knowledge at the expense of locally relevant knowledge in the innovative curriculum in our study may be due to the curriculum's Dutch origins, suggesting imperfect adaptation to the local context. Perhaps this is an example of large contextual differences interfering with North-South collaboration, while South-South partnerships may be more equal and advantageous. $^{12,35}$

\section{Limitations and future research}

Limitations of this study are potential bias due to small sample sizes, low response rates and voluntary participation. The sub-Saharan African setting limited opportunities for recruiting participants, particularly among graduates. However, to our knowledge this study is the first of its kind in sub-Saharan Africa to include junior doctors, and even a small sample may provide valuable insights and significant results. Another limitation is respondents self-rating their perceived rather than actual level of preparedness for work. However, perceptions of ability are precursors to actual behaviour, ${ }^{36}$ and the results are consistent with previous research on the effects of innovative curricula comprising problem- and community-based learning ${ }^{14,22,28-31}$ and with curriculum research in sub-Saharan Africa, which reports positive experiences with innovative curricula. $^{13,17,32,34,37-39}$

As the study was conducted in two Mozambican medical schools with different curricula the generalizability of the results across the sub-Saharan African region and beyond is limited. Comparative curriculum research is complicated as each curriculum 
is unique and subject to contextual factors. The implementation and definitions of PBL vary considerably worldwide, ${ }^{22}$ and sub-Saharan African medical schools even though facing similar challenges may have very different curricula. ${ }^{3}$ For transferability of our results to other settings, readers might judge which curriculum features and other aspects might be applicable to their own setting. It should be noted that the differences between the respondents from the two schools are not exclusively attributable to PBL but to the entire innovative curriculum and its context, including community-based elements.

To increase the generalizability of our results, future research might entail similar studies investigating outcomes and benefits of curricular innovations in different subSaharan African settings. In current literature (including grey sources) sub-Saharan African curricular innovations and lessons learned are well described, but evidence on outcomes is lacking, and research mainly stems from South Africa. ${ }^{9}$ Special attention should be given to involving more graduates in future studies, as curriculum research in sub-Saharan Africa has, previous to our study, almost exclusively focused on students. We found only two studies that included data on graduates, but rather than investigating preparedness for practice in general, these focus on rural areas in particular. ${ }^{32,34}$

Another direction for future research is the sustainability of curricular innovations. Though very much needed, curricular innovations in sub-Saharan Africa are particularly challenging, ${ }^{9,10}$ and innovative curricula are criticised for being resource intensive and therefore impracticable in resource-poor settings. ${ }^{18,}$ 40, 41 However, high short-term investments may prove cost-effective in the long run if they improve the quality of health care, retention of doctors and population health, turning initial investments into longer-term savings. ${ }^{6}$ Examples of successful implementation of innovative approaches in sub-Saharan Africa, including the one in this study in one of the region's poorest countries, have demonstrated their feasibility in resource-poor settings, despite the many challenges. ${ }^{13,17,20}$ Future research might focus on crucial factors for sustainable curricular innovation in these settings.

\section{Conclusions}

The challenges facing sub-Saharan African doctors are immense and sustain each other in a vicious cycle, affecting doctors' motivation and preparedness for practice. Innovative problem- and community-based curricula, compared with conventional curricula, hold promise for scaling up the quality of sub-Saharan African doctors, and indirectly the health care system. These curricula deliver independent, critical change agents with good social skills and a focus on their patients and their community, able to find a balance between the reality of sub-Saharan African health care and global health care ideals. Effects of innovative, transformative curricula may be larger in sub-Saharan Africa compared with high-income settings. Curricular innovations, however, need to 
be backed up by concerted efforts of all stakeholders together to train more doctors and teachers and improve the infrastructure of medical schools and health care systems.

\section{Acknowledgements}

We are grateful to all medical students and graduates who participated in this study and to the staff of the participating schools who facilitated this study. We thank Mereke Gorsira (Department of Educational Development and Research, Maastricht University) for editing the manuscript. We thank the Research Centre for Education and the Labour Market for providing us with the REFLEX questionnaire. We are grateful to Bernard Groosjohan (Eduardo Mondlane University) for his assistance in research logistics in Mozambique.

\section{References}

1. Frenk J, Chen L, Bhutta ZA, Cohen J, Crisp N, Evans T, et al. Health professionals for a new century: transforming education to strengthen health systems in an interdependent world. Lancet 2010;376(9756):1923-58.

2. World Health Organization. Transformative scale up of health professional education. An effort to increase the numbers of health professionals and to strengthen their impact on population health. 2011. http://whqlibdoc.who.int/hq/2011/WHO_HSS_HRH_HEP2011.01_eng.pdf.

3. Chen C, Buch E, Wassermann T, Frehywot S, Mullan F, Omaswa F, et al. A survey of Sub-Saharan African medical schools. Hum Resour Health 2012;10:4.

4. Mullan F, Frehywot S, Omaswa F, Buch E, Chen C, Greysen SR, et al. Medical schools in sub-Saharan Africa. Lancet 2011;377(9605):1113-21.

5. Sherr K, Mussa A, Chilundo B, Gimbel S, Pfeiffer J, Hagopian A, et al. Brain drain and health workforce distortions in Mozambique. PLoS One 2012;7(4):e35840.

6. World Health Organization. Report on the WHO/PEPFAR planning meeting on scaling up nursing and medical education. 2009. http://www.who.int/hrh/resources/scaling-up_planning_report.pdf.

7. World Health Organization. WHO consultation on the transformative scale-up of medical, nursing and midwifery education. First technical reference group meeting: medical education experts. 2010. http://www.who.int/hrh/resources/medical_experts_first_meeting.pdf.

8. Celletti F, Reynolds TA, Wright A, Stoertz A, Dayrit M. Educating a new generation of doctors to improve the health of populations in low- and middle-income countries. PLoS Med 2011;8(10):e1001108.

9. Greysen SR, Dovlo D, Olapade-Olaopa EO, Jacobs M, Sewankambo N, Mullan F. Medical education in sub-Saharan Africa: a literature review. Med Educ 2011;45(10):973-86.

10. Gukas ID. Global paradigm shift in medical education: issues of concern for Africa. Med Teach 2007;29(9):887-92.

11. Burdick W. Challenges and issues in health professions education in Africa. Med Teach 2007;29(9):8826.

12. Kent A, Burch VC. Are we addressing the health sciences education needs of sub-Saharan Africa? Med Educ 2011;45(10):966-8.

13. Kiguli-Malwadde E, Kijjambu S, Kiguli S, Galukande M, Mwanika A, Luboga S, et al. Problem Based Learning, curriculum development and change process at Faculty of Medicine, Makerere University, Uganda. Afr Health Sci 2006;6(2):127-30. 
14. Koh GC, Khoo HE, Wong ML, Koh D. The effects of problem-based learning during medical school on physician competency: a systematic review. CMAJ 2008;178(1):34-41.

15. Wood DF. Problem based learning. BMJ 2003;326(7384):328-30.

16. Cape Town Declaration. Med Educ 1995;29:385-6.

17. Kwizera EN, Igumbor EU, Mazwai LE. Twenty years of medical education in rural South Africa-experiences of the University of Transkei Medical School and lessons for the future. S Afr Med J 2005;95(12):920-2, 4.

18. Mufunda J, Chatora R, Ndambakuwa Y, Samkange C, Sigola L, Vengesa P. Challenges in training the ideal Doctor for Africa: lessons learned from Zimbabwe. Med Teach 2007;29(9):878-81.

19. Daly M, Perkins D, Kumar K, Roberts C, Moore M. What factors in rural and remote extended clinical placements may contribute to preparedness for practice from the perspective of students and clinicians? Med Teach 2013;35(11):900-7.

20. The Sub-Saharan African Medical Schools Study (SAMSS). Site Visit Report: Faculty of Medicine, Catholic University of Mozambique. 2009. http://www.samss.org/samss.upload/wysiwyg/Full\%20Site\%20Visit\%20Reports/Catholic\%20-\%20Mozambique.pdf.

21. World Health Organization. Mozambique: Health profile. 2012. http://www.who.int/gho/countries/moz.pdf.

22. Neville AJ. Problem-based learning and medical education forty years on. A review of its effects on knowledge and clinical performance. Med Princ Pract 2009;18(1):1-9.

23. Schifferdecker KE, Reed VA. Using mixed methods research in medical education: basic guidelines for researchers. Med Educ 2009;43(7):637-44.

24. Research Centre for Education and the Labour Market, Maastricht University. REFLEX questionnaire. http://www.fdewb.unimaas.nl/roa/reflex/.

25. Goldacre MJ, Taylor K, Lambert TW. Views of junior doctors about whether their medical school prepared them well for work: questionnaire surveys. BMC Med Educ 2010;10:78.

26. Illing JC, Morrow GM, Rothwell nee Kergon CR, Burford BC, Baldauf BK, Davies CL, et al. Perceptions of UK medical graduates' preparedness for practice: a multi-centre qualitative study reflecting the importance of learning on the job. BMC Med Educ 2013;13:34.

27. Morrow G, Johnson N, Burford B, Rothwell C, Spencer J, Peile E, et al. Preparedness for practice: the perceptions of medical graduates and clinical teams. Med Teach 2012;34(2):123-35.

28. Prince KJ, van Eijs PW, Boshuizen HP, van der Vleuten CP, Scherpbier AJ. General competencies of problem-based learning (PBL) and non-PBL graduates. Med Educ 2005;39(4):394-401.

29. Schmidt HG, Vermeulen L, van der Molen HT. Longterm effects of problem-based learning: a comparison of competencies acquired by graduates of a problem-based and a conventional medical school. Med Educ 2006;40(6):562-7.

30. Watmough S, Cherry MG, O'Sullivan H. A comparison of self-perceived competencies of traditional and reformed curriculum graduates 6 years after graduation. Med Teach 2012;34(7):562-8.

31. Watmough SD, O'Sullivan H, Taylor DC. Graduates from a reformed undergraduate medical curriculum based on Tomorrow's Doctors evaluate the effectiveness of their curriculum 6 years after graduation through interviews. BMC Med Educ 2010;10:65.

32. Iputo JE. Faculty of health sciences, walter sisulu university: training doctors from and for rural South african communities. MEDICC Rev 2008;10(4):25-9.

33. Colliver JA. Effectiveness of problem-based learning curricula: research and theory. Acad Med 2000;75(3):259-66.

34. Kaye DK, Mwanika A, Sewankambo N. Influence of the training experience of Makerere University medical and nursing graduates on willingness and competence to work in rural health facilities. Rural Remote Health 2010;10(1):1372.

35. De Maeseneer J, Egilman D, Burdick WP, Kaufman A. Medical schools in sub-Saharan Africa. Lancet 2011;378(9799):1294. 
36. Bandura A. Social foundations of thought and action: A social cognitive theory. Englewood Cliffs, NJ: Prentiss-Hall 1986.

37. Singaram VS, Dolmans DH, Lachman N, van der Vleuten CP. Perceptions of problem-based learning (PBL) group effectiveness in a socially-culturally diverse medical student population. Educ Health 2008;21(2):116.

38. Iputo JE, Kwizera E. Problem-based learning improves the academic performance of medical students in South Africa. Med Educ 2005;39(4):388-93.

39. Green-Thompson LP, Mclnerney P, Manning DM, Mapukata-Sondzaba N, Chipamaunga S, Maswanganyi T. Reflections of students graduating from a transforming medical curriculum in South Africa: a qualitative study. BMC Med Educ 2012;12:49.

40. Banda S, Yikona J. Medical education. Lancet 2001;358(9279):423.

41. McLean M. Sustaining problem-based learning reform: advice in hindsight! Med Teach 2004;26(8):7268. 


\section{CHAPTER 5}

\section{The cultural complexity of implementing PBL}

\section{Submitted as:}

Frambach JM, Manuel BAF,

Fumo AMT, Groosjohan B, van der Vleuten CPM, Driessen EW. The fit and misfit of innovative curricula in subSaharan Africa: a comparative study from Mozambique.

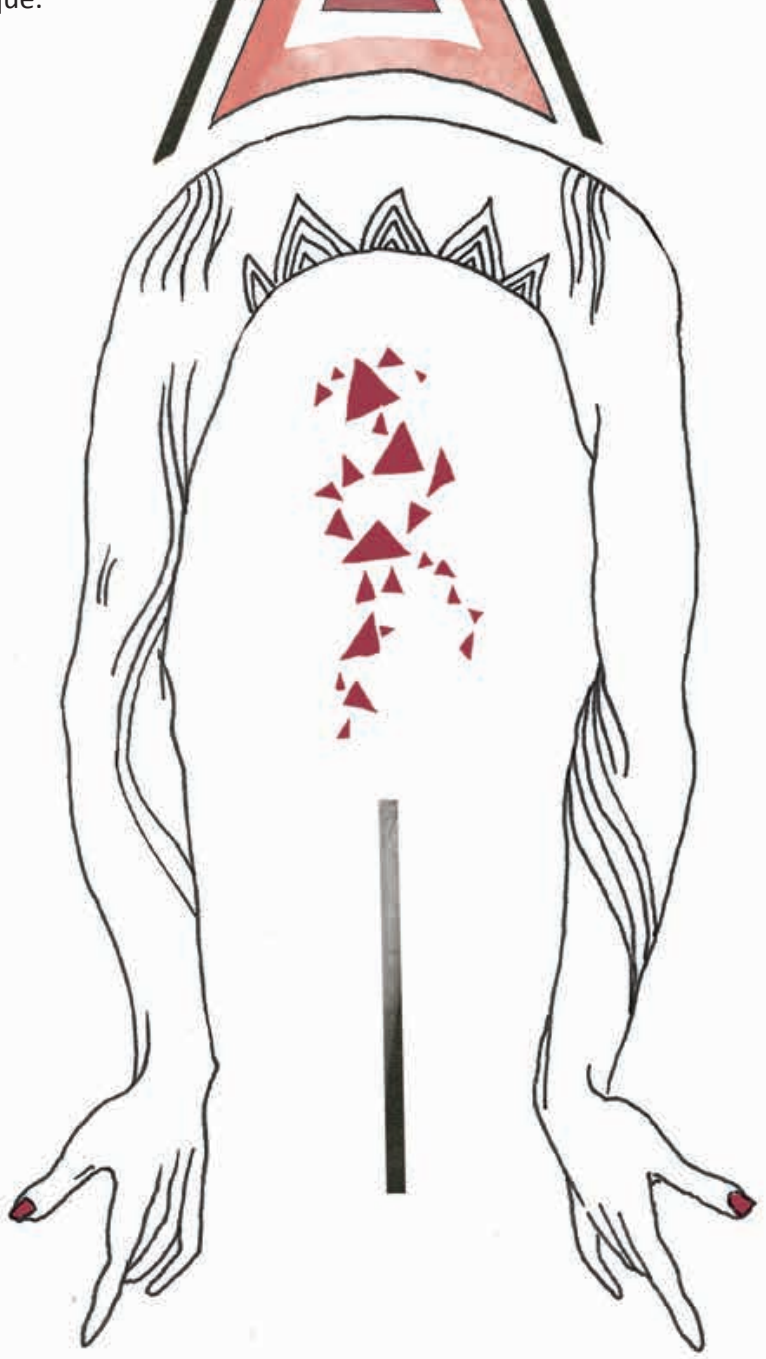


CHAPTER 5 


\section{Introduction}

The need for innovative, competency-based curricula that promote team-based and lifelong learning, leadership skills, and longitudinal relations with patients and the community is shared across continents. ${ }^{1-5}$ To put such curricula to practice, medical schools often use problem-based learning (PBL) and/or community-based education (CBE) as methods and philosophies of teaching and learning. ${ }^{1,6}$ Positive effects and experiences with these curricula in different parts of the world have been thoroughly described. ${ }^{6-12}$ Critique, however, is also widespread; particularly the effect of $P B L$ is subject to a long-lasting debate. ${ }^{13-17} \mathrm{PBL}^{\prime} \mathrm{s}$ appropriateness for different parts of the world has also been debated, as number of problems that arose during PBL implementation have been attributed to cultural differences. ${ }^{9,} 18,19$ Another major concern with $\mathrm{PBL}$ and other innovations is the considerable (financial) effort it takes to implement and sustain innovations. ${ }^{4,20}$ Especially low and middle income countries, burdened with specific problems such as poor quality of secondary schools and scarce resources, struggle to deliver this effort. ${ }^{21-25}$

Sub-Saharan Africa arguably faces the world's largest portion of these problems and struggles to keep pace with global innovations. ${ }^{2}$ The total expenditure of subSaharan African medical education is three percent of the North American budget, while the North American population is less than half the size of the sub-Saharan African population. ${ }^{1}$ The estimated expenditure per sub-Saharan African medical graduate is ten times lower than the expenditure per North American graduate. ${ }^{1}$ Despite their low budget, many sub-Saharan African medical schools have introduced innovations such as team-based and problem-based learning, and feel that curricular innovations contribute to increasing the quality of their graduates. ${ }^{23,26}$ At the same time, however, they mention poor infrastructure and faculty shortages as major impediments to the success of their curricula. ${ }^{23,26}$

Considering the opposite voices of PBL's effect around the world, and the specific needs and problems facing sub-Saharan Africa, the question is whether PBL and CBE curriculum reforms are worth the effort for sub-Saharan African medical schools. Previous research on outcomes of curricular innovations in sub-Saharan Africa is scarce, following the region's underrepresentation in the literature, particularly beyond SouthAfrica and Nigeria. ${ }^{23}$ Though single curriculum implementations have been well described, ${ }^{11,23,24,27}$ (comparative) evidence on outcomes, such as graduates' preparedness for practice, is largely lacking. Furthermore, successful innovation attempts have been documented, but failed attempts often go unnoticed, while their lessons are equally important to the medical education community. ${ }^{24}$ This study aims to contribute to an evidence base for sub-Saharan African medical schools that informs whether, and how, curricular innovation is worth their effort. We investigated how students feel prepared for practice comparing students from three curricula in a sub-Saharan African context: an innovative PBL/CBE curriculum that successfully coped with implementa- 
tion challenges, an innovative PBL/CBE curriculum that heavily suffered from implementation challenges, and a conventional curriculum. This comparison entails two opposite curricula on the innovative-conventional continuum and two opposite curricula on the continuum of positive and negative experiences with innovations, reflecting the diversity of outcomes that medical schools in sub-Saharan Africa can expect from reforming their curriculum.

\section{Methods}

\section{Setting}

We conducted the study in 2012 in Mozambique, a country facing major challenges in health care and medical education. Mozambique ranks below the regional average regarding medical workforce and income, while facing a heavier disease burden than the regional average. ${ }^{28}$ Based on suggestions of a number of international experts in medical education and a characterization by the Sub-Saharan African Medical Schools Study as "an instructive example of African medical education" ${ }^{29}$ we selected the Faculty of Health Sciences of the Catholic University of Mozambique, located in the country's second-largest city Beira, as representing an innovative PBL/CBE curriculum that successfully coped with implementation challenges. For representing a conventional curriculum we selected the only other Mozambican medical school producing graduates until then: the Faculty of Medicine of Eduardo Mondlane University in the capital city Maputo. Beside running a conventional curriculum, the school introduced an innovative PBL/CBE curriculum in 2008, which was abandoned in 2012 because it heavily suffered from implementation challenges. We selected this curriculum to represent the opposite of a successful innovative implementation, and refer to it as discontinued innovative curriculum.

The innovative curriculum of the Catholic University of Mozambique started in 2000 and graduates 35 doctors on average each year. The curriculum-wide main instructional method is small group PBL sessions, added with lectures, laboratory training, communication and clinical skills sessions with real patients, a four-year community program with attachments to families, and clinical rotations in the final two years. The conventional curriculum of Eduardo Mondlane University delivers an average of 80 doctors annually after its foundation in the late 1960s. The six-year curriculum is discipline-based and the main instructional method is lectures, added with laboratory training and clinical rotations in years 3-6. The school also runs a community program with visits to public health sites. The discontinued innovative curriculum of Eduardo Mondlane University used PBL as curriculum-wide main instructional method, added with lectures, laboratory training, communication and clinical skills sessions, a community program and clinical rotations from the fourth year onwards. 


\section{Data collection and analysis}

This study was a follow-up of a previously reported study on graduates' preparedness for challenges in Mozambican health care practice, ${ }^{30}$ for which data were collected simultaneously. Approval was granted by the Deans of the schools and the Ethical Review Board of the Dutch Association for Medical Education. We used mixed methods ${ }^{31}$ to paint a broad picture of how the different curricula prepared students for practice.

We adapted an existing validated questionnaire used in large-scale international research ${ }^{32}$ to the purpose of our study. The questionnaire was translated into Portuguese and cross-checked by JF and BM, and administered to fifth-year students of the three curricula. The students from the discontinued innovative curriculum had followed the innovative curriculum in years 1-4. The study was conducted two months after the start of their fifth year and abandonment of the innovative curriculum. The curriculum ran parallel to the conventional curriculum and students from the latter had followed the conventional curriculum since year 1 . The questionnaire was anonymous and participation was voluntary. All students whom we approached - during lectures, rotations and PBL sessions - participated (response rate 100\%). Due to logistic constraints we were unable to reach all fifth-year students and we approached all students we were exposed to: 36 of 42 innovative curriculum students (85.7\%), 67 of 103 conventional students (65.0\%), and 37 of 111 discontinued innovative curriculum students $(33.3 \%)$. The samples' mean age was 25.5, 26.0 and 24.3, respectively, and $36.1 \%, 53.7 \%$ and $54.1 \%$, respectively, was female. Using SPSS Version 19.0 (IBM Corp., Armonk, NY) we calculated means and standard deviations, and we assessed differences between the three groups using independent-samples $t$-tests. We estimated and categorized effect sizes (ES) using Cohen's $d$.

We conducted semi-structured interviews with a purposive sample of five innovative curriculum students ( 3 male, 2 female), five conventional students ( 3 male, 2 female), and 2 discontinued innovative curriculum students ( 1 male, 1 female) (all fifthyear). The former two groups were part of the wider data collection mentioned above. We obtained verbal and written informed consent. The interviews, conducted by JF, lasted 40-60 minutes and were audio recorded. Questions focused on how students felt their education prepared them for their future work and aspects they appreciated or missed in their education. The interviews were transcribed verbatim and we conducted member checks. We used Atlas.ti Version 6.2 (Scientific Software Development, GmbH, Berlin, Germany) for thematic analysis. A coding framework of themes that emerged from the data was developed and applied during several rounds of iterative data analysis, conducted by JF and a subsample by BM. The themes and their interpretation were discussed in the research team until consensus was reached.

In addition, we collected context information about the schools, the work environment and the curricula by observations in educational sessions, community visits, hospital visits and informal interviews with educational leaders and key staff. This was reported daily in a reflexive research journal. 


\section{Results}

With a comparative perspective we discuss for each curriculum how students felt prepared for practice and how features of their curriculum contributed to or hindered their preparedness. We present the quantitative and qualitative findings in an integrated manner.

\section{Innovative curriculum}

A diverse range of teaching and learning modes were emphasized well in the innovative curriculum, and students valued these highly as a preparation for work (table 1). Interviewees mentioned they valued the small group PBL sessions because it linked theory with practice, and encouraged an independent and inquiring attitude that prepared them for the work situation where teachers were not present. The questionnaire respondents confirmed this impact of PBL philosophy, rating 'teacher as main information source' lowest for its emphasis in the study program and for how it prepared for work (table 1). However, interviewees also expressed difficulties with PBL, especially during the first year, such as insecurity about what to study and where to find information, and hesitance to speak up during group sessions.

Interviewees appreciated the communication and clinical skills sessions, in which they practiced with real patients in a university clinic, as a useful and important preparation for practice that encouraged a holistic approach towards patients. Questionnaire respondents felt they were competent to 'communicate effectively with patients' (mean 4.6, table 2), and this competency was often mentioned as a strong point of their study program (respondents were asked to name competencies from table 2 that they regarded as strong and weak points of their study program). However, the transition from the sheltered environment of the university clinic in years 3-4 to the harsh reality of patient overload in the hospital internships in year 5, was characterized by some interviewees as hard. Questionnaire respondents, similarly, often mentioned 'performing well under pressure' as a weak point of their program. Furthermore, interviewees complained about the quality of clinical teaching during the internships, and noted that many clinical teachers did not support the PBL method and discouraged questions from students, which students felt hindered their learning. 


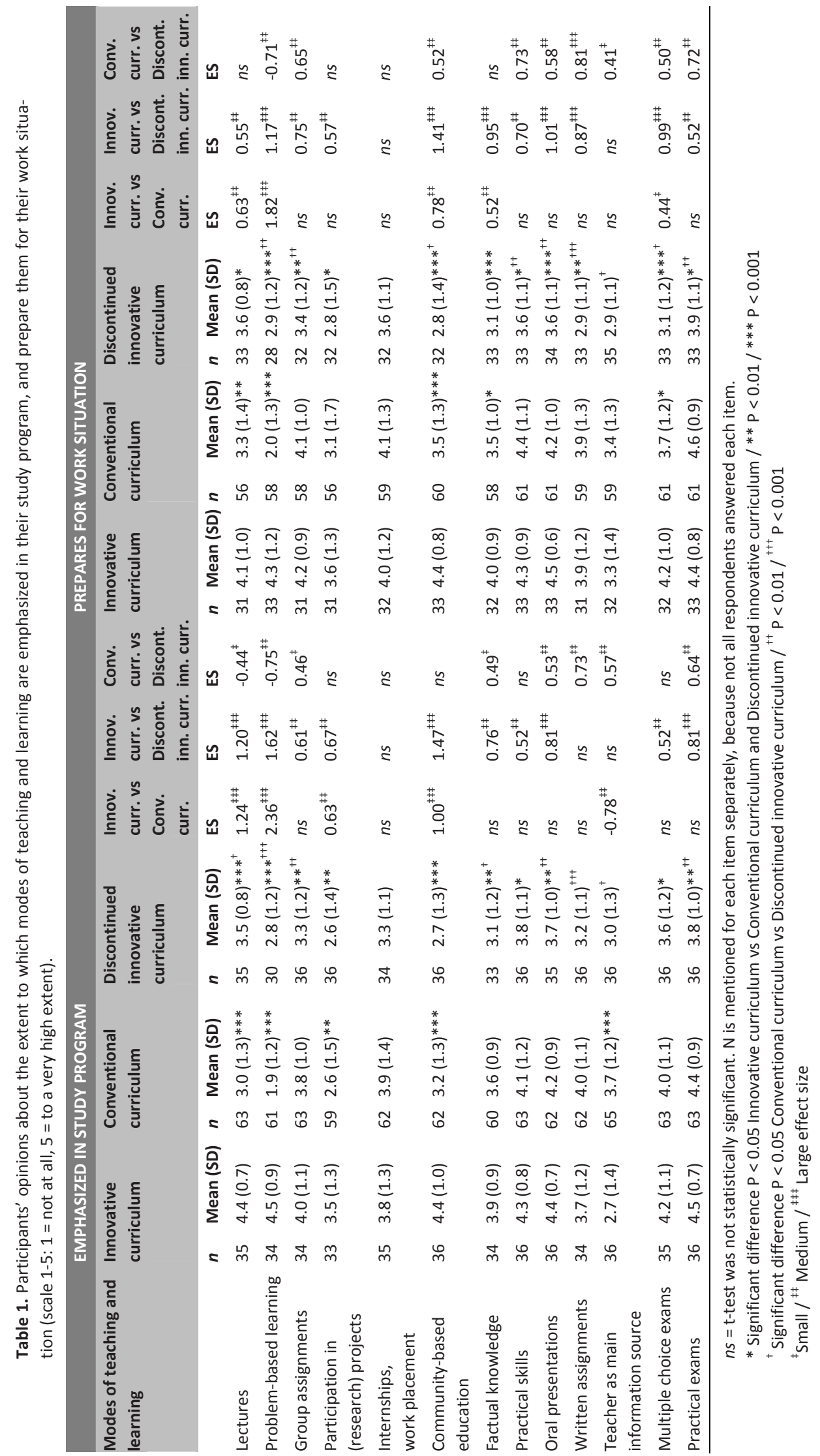




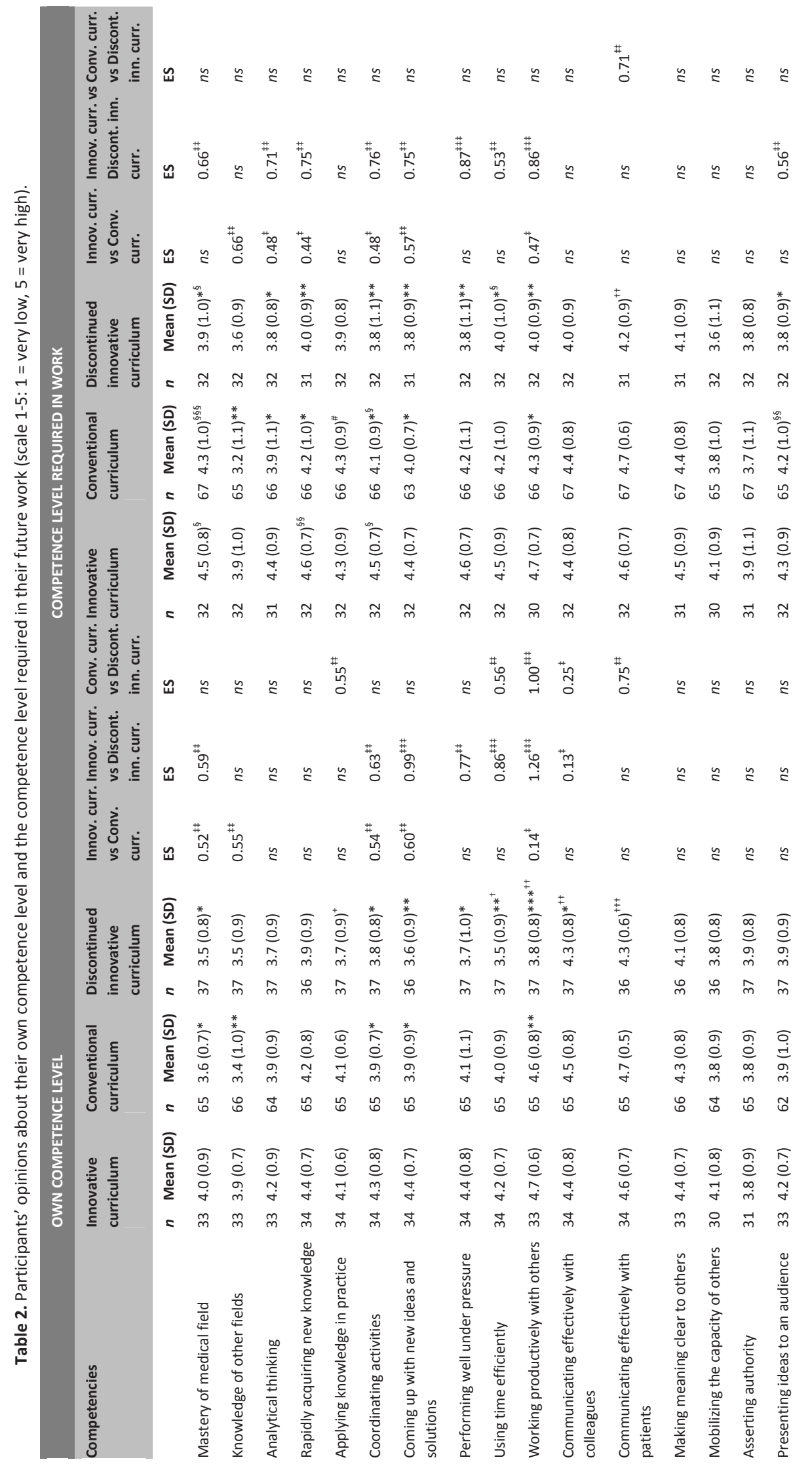




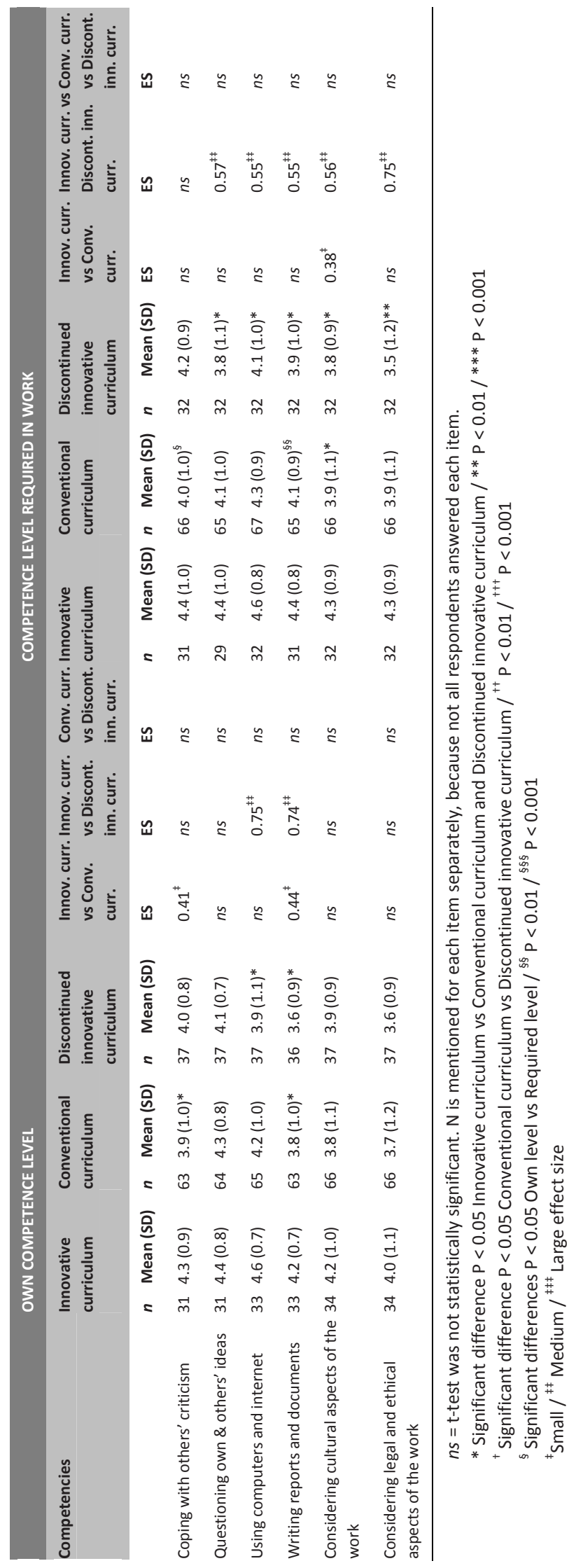


Table 2 shows that students generally felt competent for a diverse range of competencies (means 3.8 - 4.7), also at the level they thought required for practice. They noted their mastery of the medical field, however, not being up to the level required in practice yet (effect size for this difference between own and required level, not reported in table 2, was -0.60), though they often mentioned 'mastery of medical field' as a strong point of their study program. They rated the required level for work for a number of competencies significantly higher than students from the other curricula, suggesting that the former expected their future work environment to be more demanding on diverse aspects, possibly because their curriculum emphasized a more diverse range of skills and competencies. Overall, students were satisfied about their study program and its usefulness for their future work (mean 4.0 and 4.5, respectively, table 3), owing, in particular, to its encouragement of an inquiring and independent attitude, its holistic approach towards patients, and its emphasis on a diverse range of skills and competencies.

\section{Conventional curriculum}

Students rated nearly all teaching and learning modes as less emphasized in their study program and as a lesser preparation for work compared with students from the innovative curriculum (table 1). Only 'teacher as main information source' was significantly more emphasized compared with the latter, confirming the more substantial role of teachers in the conventional curriculum compared with the PBL curriculum. Instead of diverse emphases, the conventional curriculum strongly focused on two elements: lectures and internships. The latter started in year 3 already, which interviewees valued highly as a good preparation for practice that allowed them to learn practical skills and cope with the demanding work environment in Mozambican hospitals. Questionnaire respondents often mentioned 'applying knowledge in practice' and 'performing well under pressure' as strong points of their program. The internships also provided an opportunity to practice communication skills, which were not an official curriculum component. Students rated their competence level to 'communicate effectively with patients' highest of all competencies (mean 4.7, table 2), comparable with innovative curriculum students.

The internships' effectiveness, however, as well as patient safety, was compromised by inadequate clinical teaching and supervision, and a lack of teachers serving as role models. Interviewees noted shortages of motivated teachers, also among lecturers, which they felt negatively affected their preparation for practice. They expressed feeling left on their own to prepare themselves for practice, and that the curriculum's graduates were not well enough prepared. Additionally, interviewees reported severe shortages of learning materials and resources, which further hindered their learning. If being free to choose again, $31.3 \%$ of the questionnaire respondents would not choose their medical school again because of dissatisfaction with the quality of the study pro- 
gram and/or the teaching, compared with $5.9 \%$ of the innovative curriculum students (table 4).

Table 3. Participants' thoughts on whether they would choose for the same medical school if they were free to choose again.

\begin{tabular}{llll} 
Would you choose the same Medical School? & $\begin{array}{l}\text { Innovative } \\
\text { curriculum }\end{array}$ & $\begin{array}{l}\text { Conventional } \\
\text { curriculum }\end{array}$ & $\begin{array}{l}\text { Discontinued } \\
\text { innovative } \\
\text { curriculum }\end{array}$ \\
Yes & $70.5 \%$ & $58.2 \%$ & $59.5 \%$ \\
$\begin{array}{l}\text { No, because I am not satisfied with the quality of the study pro- } \\
\text { gram and/or the teaching. }\end{array}$ & $3.9 \%$ & $37.6 \%$ \\
$\begin{array}{l}\text { No, I would not choose to study Medicine again, because of the } \\
\text { difficult conditions that students/doctors in Mozambique are } \\
\text { faced with. }\end{array}$ & $11.8 \%$ & $7.5 \%$ & $2.9 \%$ \\
\begin{tabular}{l} 
No, other reasons. \\
\hline
\end{tabular} & $11.8 \%$ & $3.0 \%$ & - \\
\hline
\end{tabular}

Table 4. Participants' opinions about how satisfied they are with their study at medical school (scale 1-5: $1=$ very dissatisfied, 5 = very satisfied), and how useful they feel it is for their future work (scale 1-5: $1=$ not useful at all, 5 = very useful).

\begin{tabular}{|c|c|c|c|c|c|c|c|c|c|}
\hline & \multicolumn{2}{|c|}{$\begin{array}{l}\text { Innovative } \\
\text { curriculum }\end{array}$} & \multicolumn{2}{|c|}{$\begin{array}{l}\text { Conventional } \\
\text { curriculum }\end{array}$} & \multicolumn{2}{|c|}{$\begin{array}{l}\text { Discontinued } \\
\text { innovative } \\
\text { curriculum }\end{array}$} & \multirow{2}{*}{$\begin{array}{l}\text { Innov. curr. } \\
\text { vs Conv. } \\
\text { curr. } \\
\text { ES }\end{array}$} & \multirow{2}{*}{$\begin{array}{l}\text { Innov. curr. } \\
\text { vs Discont. } \\
\text { inn. curr. } \\
\text { ES }\end{array}$} & \multirow{2}{*}{$\begin{array}{l}\text { Conv. curr. } \\
\text { vs Discont. } \\
\text { inn. curr. } \\
\text { ES }\end{array}$} \\
\hline & $n$ & Mean (SD) & $n$ & Mean (SD) & $n$ & Mean (SD) & & & \\
\hline $\begin{array}{l}\text { Satisfaction with } \\
\text { study program }\end{array}$ & 36 & $4.0(0.7)$ & 67 & $3.3(0.9)^{* * *}$ & 37 & $3.1(0.9)^{* * *}$ & $0.84^{\ddagger \neq \ddagger}$ & $1.11^{\ddagger \neq \ddagger}$ & ns \\
\hline $\begin{array}{l}\text { Study program's } \\
\text { usefulness for work }\end{array}$ & 36 & $4.5(0.7)$ & 67 & $4.2(0.9)^{*}$ & 37 & $3.4(1.1)^{* * *^{+++}}$ & $0.36^{\ddagger}$ & $1.19^{\ddagger \ddagger \ddagger}$ & $0.82^{\ddagger \neq \ddagger}$ \\
\hline
\end{tabular}

$n s=$ t-test was not statistically significant. $\mathrm{N}$ is mentioned for each item separately, because not all respondents answered each item.

* Significant difference $\mathrm{P}<0.05$ Innovative curriculum vs Conventional curriculum and Discontinued innovative curriculum /** $\mathrm{P}<0.01 / * * * \mathrm{P}<0.001$

${ }^{+}$Significant difference $\mathrm{P}<0.05$ Conventional curriculum vs Discontinued innovative curriculum $/{ }^{\text {t+ }} \mathrm{P}<0.01 /$ ${ }^{+++} \mathrm{P}<0.001$

${ }^{\ddagger}$ Small / ${ }^{\ddagger \ddagger}$ Medium / ${ }^{\ddagger \neq \ddagger}$ Large effect size

Interviewees noted that the curriculum strongly focused on medical knowledge, and questionnaire respondents most often mentioned 'mastery of medical field' as a strong point of the program, despite expressing that their mastery was not up to the level required in practice yet (effect size, unreported in table 2 , was -0.77), comparable with innovative curriculum students. Moving beyond medical knowledge to other aspects of the medical profession, however, was missed in the curriculum by some interviewees. Similarly, questionnaire respondents most often mentioned 'considering legal and ethical aspects of the work', 'considering cultural aspects of the work' and 'knowledge of other fields' as weak points of the program. Students rated their competence level 
generally lower than innovative curriculum students, with significant differences for seven competencies (table 2). Overall, students were not very satisfied nor very dissatisfied about their study program (mean 3.3, table 3), characterized by inadequate teaching, poor resources, and a limited scope of curriculum elements. They were more appreciative of the program's usefulness for work (mean 4.2, table 3), owing to the practical orientation and early start of internships, and the emphasis on medical knowledge. Both satisfaction and usefulness, however, were rated significantly below innovative curriculum students.

\section{Discontinued innovative curriculum}

Interviewees from the discontinued innovative curriculum valued similar aspects as students from the innovative curriculum: the encouragement of PBL to develop an inquiring and independent attitude, and a focus on communication and clinical skills. 'Analytical thinking' was one of the competencies most often mentioned by questionnaire respondents from both innovative curricula as a strong point of their study programs. However, emphases on these innovative elements were not strong enough to compensate for the lack of quality of the curriculum elements in general. Students rated nearly all teaching and learning modes as less emphasized in their study program and as a lesser preparation for work compared with students from the other curricula, with many significant differences (table 1). They also rated their competence levels averagely lower than students of the other curricula for nearly all competencies, though not all differences were significant (table 2). Similar to students from the other curricula, respondents reported their 'mastery of medical field' not being up to the level required in practice yet (effect size, unreported in table 2, was -0.41). Although, like students from the other curricula, they often mentioned this competency as a strong point of the program, students from the discontinued innovative curriculum most often mentioned this as a weak point as well.

Interviewees, and respondents who provided comments at the end of the questionnaire, felt the innovative methods, particularly PBL, were not a good option for their medical school due to some major complications: a complete disorganization of the curriculum, a lack of commitment from staff, and the absence of learning materials and resources. They noted that teachers were not prepared nor motivated enough to tutor the PBL sessions, that there were no resources for self-study as required in PBL, and that they felt completely left on their own. This severely hindered students' learning and preparation, and as a result they felt unconfident and unprepared to face practice. $37.6 \%$ of the questionnaire respondents would not choose their medical school again because of dissatisfaction with the quality of the study program and/or the teaching (table 4). Educational leaders and staff who were interviewed informally mentioned the same complications as reasons why the curriculum was abandoned, and particularly emphasized the lack of staff commitment due to the fact staff were not involved in 
decision making and curriculum planning. Overall, students were not very satisfied about their study program and its usefulness for their future work and rated this significantly lower than students from the other curricula (mean 3.1 and 3.4, respectively, table 3). Positively valued innovative aspects were overshadowed by inadequate teaching, disorganization, lack of staff commitment and severe shortages of learning materials.

\section{Discussion}

Our results suggest that if conditions are favorable, innovative PBL/CBE curricula seem preferable over conventional curricula to prepare students for work, even, and perhaps especially, in a resource-poor context in sub-Saharan Africa where graduates are left on their own to deal with complex patient cases. The innovative curriculum in our study outperformed the conventional curriculum in terms of preparing students for practice. The inquiring and independent attitude, the holistic approach towards patients and the diverse range of skills and competencies, which innovative curriculum students found valuable preparations for work, is consistent with global research reporting positive effects of PBL on students' and doctors' social and cognitive skills and competencies. ${ }^{6,10}$ PBL seems to fit the cultural context of sub-Saharan Africa and of its students, who mentioned similar difficulties, valued aspects and behaviors of adapting to PBL compared with studies conducted elsewhere. ${ }^{18,19,23}$

Our results, however, also suggest that if conditions are unfavorable, PBL/CBE curricular innovation does not seem preferable over conventional curricula to prepare students for work in a sub-Saharan African context. The discontinued innovative curriculum in our study showed a complete reverse picture. Though students valued the same innovative aspects as students from the other innovative curriculum, major complications severely impeded their preparedness for practice. Conditions for successful curriculum change have been extensively covered in the literature. ${ }^{33}$ The discontinued innovative curriculum did not meet some of the features that have been identified as most essential for successful curriculum change: participation by organization members and human resource development. ${ }^{33} \mathrm{~A}$ dedicated group of staff members promoting the change has often been found one of the key aspects for sustainable reform. ${ }^{20}$ Notably, such a group was present in the successfully implemented innovative curriculum in our study, and absent in the discontinued curriculum. Curricular innovation evidently is challenging anywhere, though sub-Saharan African medical schools face additional challenges due to material and human resource shortages unparalleled in other regions. $^{26,34,35}$ So while positive effects of innovative curricula might have an extra dimension in sub-Saharan Africa, an extra dimension is also added to potentially negative effects. In other words, in sub-Saharan Africa the stakes of innovation seem to be higher: if things go well they might go very well, but if things go bad they might go very bad. 


\section{Strengths and limitations}

A strength of this research is that it contributes to a medical education evidence base for an underrepresented region in the literature. A limitation is that we studied students' perceived rather than actual preparedness for practice based on self-ratings, while students' self-assessment skills are limited. ${ }^{36}$ Further, perceptions of preparedness for practice are merely one curriculum outcome, insufficient for definitive judgments about a curriculum's appropriateness. Our findings need to be interpreted accordingly.

Rather than three curricula we might have compared two schools, as two curricula were implemented in the same school. However, we found many significant differences between the two curricula at the same school. The disorganization of the discontinued innovative curriculum might have negatively affected the conventional curriculum students, who might have performed better if their school did not run a parallel disorganized program. The conventional curriculum, however, showed a steady reputation since the school's foundation, and students' perceptions match those of a study conducted at this school prior to the curriculum change. ${ }^{37}$

The innovative curriculum in our study was established for more than a decade while the discontinued innovative curriculum was in an earlier stage, and was abandoned two months before our data collection, which might have negatively affected the performance of the latter's students. The abandonment at this stage, however, is not only a limitation but also a strength of this study, as it provided a unique comparative study opportunity to investigate the consequences that curricula heavily suffering from implementation challenges have on students' skills and competencies.

\section{Implications and future research}

Less than innovative curriculum students but more than discontinued innovative curriculum students, conventional curriculum students felt considerably well prepared for practice, owing, particularly, to four years of internships. Early clinical exposure is essential for students' preparedness for practice. ${ }^{38}$ In sub-Saharan Africa especially, students need clinical experience to familiarize themselves with the demanding work environment that is burdened with patient overload and material and human resource shortages. Although the innovative curriculum offered early clinical experience as well, in years 3-4 this took place in a sheltered environment as part of skills training. A notable advantage was that students gained a certain level of skills before being 'thrown in the deep' of hospital rotations where supervision was inadequate and patient safety was compromised. Patient safety guidelines present a major challenge to early clinical

exposure anywhere, ${ }^{38}$ but might be additionally challenging in sub-Saharan African health care considering shortages of qualified and motivated clinical teachers and patient overload. The internship's effectiveness in the conventional curriculum was indeed heavily compromised. Until conditions are favorable, sheltered before real clinical 
experience might be a better option for sub-Saharan African curricula. Further research might focus on how to incorporate more realistic elements of the demanding subSaharan African context, such as time pressure, in skills training.

This study contributes to an evidence base for sub-Saharan African medical schools considering whether and how curricular innovation is worth their effort. Though many sub-Saharan African medical schools face similar issues, ${ }^{26}$ differences between their curricula and between sub-Saharan African countries are large. ${ }^{39}$ A straightforward answer to how curriculum innovation should take shape across this region would ignore important contextual differences. To a certain extent, however, our results might be transferable to other sub-Saharan African medical schools, that recognize features described in this study and might draw lessons from our findings. Inadequate curriculum planning and organization, insufficient commitment from staff, and resource shortages severely impeded the effectiveness of the discontinued innovative curriculum in this study. At the same time, the other innovative curriculum successfully overcame the challenges its sub-Saharan African context posed, due to dedicated efforts and involvement of key staff. Before embarking on innovative journeys, medical schools need to assess their capability and motivation for innovation, e.g. by measuring their organizational readiness for curriculum change, ${ }^{40}$ and reconsider their plans accordingly before students are affected by dysfunctional curricula.

Many medical schools in sub-Saharan Africa and beyond might feel considerably tempted to innovate for different reasons, e.g. international competition, financial motives, or 'fitting in with the rest' ${ }^{1,25}$ Voices warning about non-critical adoption of existing educational models, and emphasizing cross-cultural differences and the importance of local circumstances and priorities, however, become louder in the literature. $^{1,41}$ In sub-Saharan Africa, local priorities for medical education are the quantity and quality of faculty and infrastructure issues, $1,23,26,34,35$ which our study confirms as well. The discontinued innovative curriculum, rather than focusing on these priorities, seemed to make these even more pressing. Curriculum innovation in sub-Saharan Africa might focus on how scarce resources can be utilized in ways that support priorities, in contrast to countering them. This way, innovation would rightly serve as a means to an end, rather than a goal on its own. More examples of such ways, covering experiences, best practices and outcomes, are needed in the literature. ${ }^{34}$ Future research might therefore examine how curriculum innovation can contribute to Sub-Saharan African priorities, in sustainable and cost-effective ways, and fit with local sub-Saharan African contexts. Most likely these innovations will look differently for each medical school, though we can draw lessons from each other's successes and, equally important, each other's failures.

\section{Acknowledgements}

The authors wish to thank the Research Centre for Education and the Labour Market of Maastricht University for providing the REFLEX questionnaire. The authors are indebted 
to the participants in this study and to the staff of the participating institutions who facilitated this study.

\section{References}

1. Frenk J, Chen L, Bhutta ZA, Cohen J, Crisp N, Evans T, et al. Health professionals for a new century: transforming education to strengthen health systems in an interdependent world. Lancet 2010;376(9756):1923-58.

2. Gukas ID. Global paradigm shift in medical education: issues of concern for Africa. Med Teach 2007;29(9):887-92.

3. World Health Organization. Transformative scale up of health professional education. An effort to increase the numbers of health professionals and to strengthen their impact on population health. 2011. http://whqlibdoc.who.int/hq/2011/WHO_HSS_HRH_HEP2011.01_eng.pdf.

4. Amin Z, Hoon Eng K, Gwee M, Dow Rhoon K, Chay Hoon T. Medical education in Southeast Asia: emerging issues, challenges and opportunities. Med Educ 2005;39(8):829-32.

5. Lam TP, Wan XH, Ip MS. Current perspectives on medical education in China. Med Educ 2006;40(10):940-9.

6. Neville AJ. Problem-based learning and medical education forty years on. A review of its effects on knowledge and clinical performance. Med Princ Pract 2009;18(1):1-9.

7. Green-Thompson LP, Mclnerney P, Manning DM, Mapukata-Sondzaba N, Chipamaunga S, Maswanganyi T. Reflections of students graduating from a transforming medical curriculum in South Africa: a qualitative study. BMC Med Educ 2012;12:49.

8. Gwee MC, Tan $\mathrm{CH}$. Problem-based learning in medical education: the Singapore hybrid. Ann Acad Med Singapore 2001;30(4):356-62.

9. Khoo HE. Implementation of problem-based learning in Asian medical schools and students' perceptions of their experience. Med Educ 2003;37(5):401-9.

10. Koh GC, Khoo HE, Wong ML, Koh D. The effects of problem-based learning during medical school on physician competency: a systematic review. CMAJ 2008;178(1):34-41.

11. Iputo JE. Faculty of health sciences, walter sisulu university: training doctors from and for rural South african communities. MEDICC Rev 2008;10(4):25-9.

12. Jinadu MK, Ojofeitimi EO, Oribabor P. Evaluation of an innovative approach to community-based medical undergraduate education in Nigeria. Educ Health 2002;15(2):139-48.

13. Dochy F, Segers M, Van den Bossche P, Gijbels D. Effects of problem-based learning: a meta-analysis. Learn Instruct 2003;13(5):533-68.

14. Kirschner PA, Sweller J, Clark RE. Why minimal guidance during instruction does not work: An analysis of the failure of constructivist, discovery, problem-based, experiential, and inquiry-based teaching. Educ Psychol 2006;41(2):75-86.

15. Schmidt HG, Rotgans JI, Yew EH. The process of problem-based learning: what works and why. Med Educ 2011;45(8):792-806.

16. Shanley PF. Viewpoint: leaving the "empty glass" of problem-based learning behind: new assumptions and a revised model for case study in preclinical medical education. Acad Med 2007;82(5):479-85.

17. Colliver JA. Effectiveness of problem-based learning curricula: research and theory. Acad Med 2000;75(3):259-66.

18. Frambach JM, Driessen EW, Chan LC, van der Vleuten CP. Rethinking the globalisation of problem-based learning: how culture challenges self-directed learning. Med Educ 2012;46(8):738-47.

19. Frambach JM, Driessen EW, Beh P, Van der Vleuten CPM. Quiet or questioning? Students' discussion behaviors in student-centered education across cultures. Stud High Educ 2013:iFirst Article. 
20. McLean M. Sustaining problem-based learning reform: advice in hindsight! Med Teach 2004;26(8):7268.

21. Osborne C, Needham DM. An experiment with problem-based learning at the University of Zambia. $S$ Afr Med J 2000;90(1):49-50.

22. Banda S, Yikona J. Medical education. Lancet 2001;358(9279):423.

23. Greysen SR, Dovlo D, Olapade-Olaopa EO, Jacobs M, Sewankambo N, Mullan F. Medical education in sub-Saharan Africa: a literature review. Med Educ 2011;45(10):973-86.

24. Mufunda J, Chatora R, Ndambakuwa Y, Samkange C, Sigola L, Vengesa P. Challenges in training the ideal Doctor for Africa: lessons learned from Zimbabwe. Med Teach 2007;29(9):878-81.

25. Carrera LI, Tellez TE, D'Ottavio AE. Implementing a problem-based learning curriculum in an Argentinean medical school: implications for developing countries. Acad Med 2003;78(8):798-801.

26. Chen C, Buch E, Wassermann T, Frehywot S, Mullan F, Omaswa F, et al. A survey of Sub-Saharan African medical schools. Hum Resour Health. 2012;10:4.

27. Kiguli-Malwadde E, Kijjambu S, Kiguli S, Galukande M, Mwanika A, Luboga S, et al. Problem Based Learning, curriculum development and change process at Faculty of Medicine, Makerere University, Uganda. Afr Health Sci 2006;6(2):127-30.

28. World Health Organization. Mozambique: Health profile. 2013. http://www.who.int/gho/countries/moz.pdf.

29. The Sub-Saharan African Medical Schools Study (SAMSS). Site Visit Report: Faculty of Medicine, Catholic University of Mozambique. 2009. http://www.samss.org/samss.upload/wysiwyg/Full\%20Site\%20Visit\%20Reports/Catholic\%20-\%20Mozambique.pdf.

30. Frambach JM, Manuel BAF, Fumo AMT, Van der Vleuten CPM, Driessen EW. "Being a doctor here is a misery" Students' and junior doctors' preparedness for the reality of practice in sub-Saharan Africa. Unpublished manuscript 2013.

31. Schifferdecker KE, Reed VA. Using mixed methods research in medical education: basic guidelines for researchers. Med Educ 2009;43(7):637-44.

32. Research Centre for Education and the Labour Market, Maastricht University. REFLEX questionnaire. http://www.fdewb.unimaas.nl/roa/reflex/.

33. Bland CJ, Starnaman S, Wersal L, Moorehead-Rosenberg L, Zonia S, Henry R. Curricular change in medical schools: how to succeed. Acad Med 2000;75(6):575-94.

34. Kaaya EE, Macfarlane SB, Mkony CA, Lyamuya EF, Loeser H, Freeman P, et al. Educating enough competent health professionals: advancing educational innovation at Muhimbili University of Health and Allied Sciences, Tanzania. PLoS Med 2012;9(8):e1001284.

35. Burdick W. Challenges and issues in health professions education in Africa. Med Teach 2007;29(9):8826.

36. Eva KW, Regehr G. Self-assessment in the health professions: a reformulation and research agenda. Acad Med 2005;80(10 Suppl):S46-54.

37. Ferrinho P, Fronteira I, Sidat M, da Sousa F, Dussault G. Profile and professional expectations of medical students in Mozambique: a longitudinal study. Hum Resour Health 2010;8:21.

38. Brennan N, Corrigan O, Allard J, Archer J, Barnes R, Bleakley A, et al. The transition from medical student to junior doctor: today's experiences of Tomorrow's Doctors. Med Educ 2010;44(5):449-58.

39. Gibbs T. Medical education in Africa: not always a level playing field. Med Teach 2007;29(9):853-4.

40. Jippes M, Driessen EW, Broers NJ, Majoor GD, Gijselaers WH, van der Vleuten CP. A medical school's organizational readiness for curriculum change (MORC): development and validation of a questionnaire. Acad Med 2013;88(9):1346-56.

41. Hodges BD, Maniate JM, Martimianakis MA, Alsuwaidan M, Segouin C. Cracks and crevices: Globalization discourse and medical education. Med Teach 2009;31(10):910-7. 



\section{CHAPTER 6}

\section{Studying cultural complexity with}

\section{activity theory}

In press, in revised form, as:

Frambach JM, Driessen EW, van

der Vleuten CPM. Using activity

theory to study cultural com-

plexity in medical education.

Perspectives on Medical Educa-

tion. 
CHAPTER 6 


\section{Introduction}

Medical educationalists increasingly address importance to the role of culture and cultural differences in medical education: an awareness that is fueled by increasing flows of knowledge, students, teachers, and educational materials, methods and programmes across national, regional and continental borders. ${ }^{1,2}$ While this globalization takes place at a rapid pace in educational practice, research on the effects of globalization, including consequences for national and regional traditions and culture, is largely absent from the field of medical education. ${ }^{1,3}$ Studies that in recent years have responded to the call for (cross-)cultural medical education research highlight how cultural norms and values influence medical education policies and practices. ${ }^{4-10}$ While reviewing these studies, the complexity of researching cultural issues surfaces. How to define what culture is, how to meaningfully operationalize research questions, how to empirically investigate cultural values, how to explain their influence in a context where socio-economic, political, historical, institutional and numerous other factors intermingle are some of the struggling questions for cultural researchers. One wonders if the complexity of the cultural phenomenon might be a reason for its under-investigation in the medical education field.

Complexity, however, is not new to this field. ${ }^{11}$ Teamwork, inter-professional education, and practice-based learning and assessment of general competencies are but a few examples of medical education areas where researchers deal with complex research contexts. Rather than viewing complexity as an obstacle to clear-cut research, recent perspectives underline that "representing complexity well", including its richness of variation and context, serves the understanding of educational problems and processes as a goal of medical education research. ${ }^{11,12}$ Social perspectives on learning, such as communities of practice and socio-cultural theory in general, have proved useful to investigate complexity for example in teamwork and work-based learning settings. ${ }^{12,13}$ The ability of such approaches to consider the role of the social and cultural environments of education systems is promising to investigate cultural complexity as well, as emphasized by recent cross-cultural research that promotes a socio-cultural conceptualization of medical education research and practice. ${ }^{7,9}$

A particular socio-cultural approach that seems useful to study cultural complexity is activity theory. In diverse areas of medical education activity theory has been valued for its focus on illuminating context issues, determining and analyzing key factors that mediate learning, understanding dynamic forces, challenges and conflicts that underlie educational processes, and providing rich descriptions of 'what and how it happens', ${ }^{12}$, 14-19 which all are elements that need to be addressed in research on culture, cultural differences, and cultural effects of globalization. The aim of this paper is to explain how activity theory can be used as a theoretical and practical framework to study cultural complexity in medical education. We discuss activity theory's theoretical background and principles, and we show how activity theory can be applied to the cultural research 
practice by discussing the research steps involved in a cross-cultural study that we conducted. We end with some reflections on the theoretical and practical use of activity theory for (cross-)cultural research.

\section{The theory of activity theory}

With its roots in the works of Russian psychologists Vygotsky, Leontiev and Luria, activity theory is grounded in socio-cultural theory. ${ }^{20}$ Socio-cultural theory is based on the notion that an individual cannot be viewed as separate from its social and cultural environment. ${ }^{21-23}$ Vygotsky emphasized a dialectical perspective of the relationship between man and nature, in which the two continuously affect each other. ${ }^{24}$ The process in which individuals are continuously influenced and formed by their environment is defined as internalization: humans make constant "internal reconstructions of an external operation". ${ }^{24}$ Simultaneously, they construct and shape their environment, which is defined as externalization: a continuous creation of new artifacts which transforms the social and cultural environment. ${ }^{25}$ Activity theory is an elaboration of the sociocultural notion that all human learning and development - and internalization and externalization - takes place in the form of activities. ${ }^{25}$ By analyzing these activities, the complexity of learning and development processes can be described, explained and understood. Engeström introduced five central principles of activity theory that represent the underlying structure and dynamics of activity. ${ }^{26,27}$

The first principle states that the unit of analysis is the activity as a whole. An activity system (figure 1) represents this unit of analysis, and structures the different components of influence on learning, or on activity in general. ${ }^{20}$ The two-sided arrows that run between each of the components indicate that the influence runs both ways. If we take the activity of becoming a doctor as an example, students represent the subject of the activity: the group of individuals that carries out the activity. The subject pursues a certain goal - the object - such as acquiring knowledge and skills, which leads to the outcome of becoming a doctor. During the activity the subject uses tools - mediating artifacts - to achieve its goal, e.g. books, lectures and skills training. Furthermore, the subject interacts with the surrounding context: the activity is governed by a set of implicit and explicit rules; takes place in a specific social and cultural community; and implies certain roles, or a division of labour, for those involved. ${ }^{28,}{ }^{29}$ All components of the activity system influence each other in complex interactions. Moreover, activity systems as a whole interact with other activity systems, ${ }^{27}$ e.g. the activity system of becoming a doctor interacts, and sometimes contradicts, with the activity system of providing safe patient care. ${ }^{15}$ The second principle of activity theory is multi-voicedness: an activity involves a collective of interacting individuals and communities who express different interests and views; students from diverse backgrounds and teachers from diverse disciplines might have different ideas and views about ways to become a doc- 
tor. The third principle emphasizes the historicity of activity: the activity system develops over time and understanding its current form requires knowledge about its past, for example how rules of assessment of clinical skills were developed. The fourth principle focuses on the central role of contradictions as a source of change and development of the activity system: the multi-voicedness of the activity system might lead to tensions, or relations between two components might be contradictory, for example between the subject and a newly introduced mediating artifact (e.g. a new educational method). Such contradictions could be an incentive for change and transformation of the activity. This leads to the final principle, which refers to the possibility of expansive transformations - collective change of the activity, e.g. developing new ways of learning to become a doctor - to result from these contradictions, and from the internalization and externalization processes involved. ${ }^{27}$

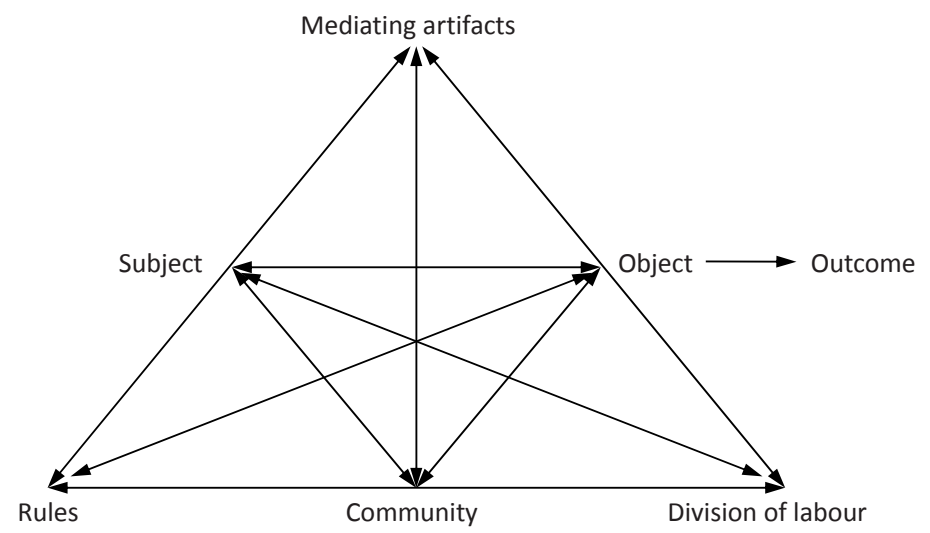

Figure 1. Engeström's activity system. ${ }^{20}$

In sum, activity theory offers a framework for analyzing the complexity of interactions between individuals and their environment by identifying the components of an activity system, their relations, their different voices, their history, their underlying contradictions, and their transformations. These ingredients might enable cultural researchers to capture the tacit, dynamic and multifaceted concept of culture and its effects, as it is manifested in the activity system. Rather than being a static set of shared values and beliefs, culture is a dynamic process situated in a social context, affected by history, social contradictions, transformations and power relations. ${ }^{30}$ Both culture and individuals cannot be viewed, nor researched, separate from their environment. The theory of activity theory supports this view, as does its practice, to which we now turn. A final note on the theory of activity theory is that the above represents a very brief explanation of a complex theory on which many scholars have elaborated. A variety of strands and concepts exist in activity theory, such as theoretical strands focused on under- 
standing, and practical strands focused on designing work-based learning environments. $^{28,29,31}$

\section{The practice of activity theory}

We conducted a study on the cross-cultural applicability of problem-based learning $(\mathrm{PBL})$ in undergraduate medical education in three medical schools located in the Middle East, East Asia and Western Europe, respectively. ${ }^{8,9}$ We used socio-cultural activity theory as a guiding theoretical and analytical framework. To illuminate its use for crosscultural research, we discuss the consecutive steps involved in our study.

\section{Formulating research questions}

We based our research questions on the socio-cultural notions of internalization and externalization. We theorized that PBL, being developed in the activity system of Western medical education, carries an inherent set of cultural norms and values that might contradict with learning approaches and attitudes in different parts of the world. While defining PBL as a mediating artifact in the activity system of becoming a doctor in a particular cultural context, we wondered: a) how do students in this cultural context internalize PBL? And b) how do they externalize their cultural backgrounds in the PBL process? With these questions we aimed to gain insight in the cross-cultural applicability of PBL. Researchers investigating cultural effects of the globalization of other educational tools, methods and programmes, could formulate similar questions. Also researchers focusing on other aspects and expressions of culture in medical education could benefit from the wide range of activity theory to formulate research questions, in a similar way as activity theory has been used to study diverse medical education issues. ${ }^{12,14-19}$ Though focusing on diverse aspects, a shared aim of these studies is to provide rich descriptions of what and how something happens in a dynamic context of contradictions and transformations.

\section{Selecting a methodology}

To address our research questions we needed to consider not only students and PBL, but all components of the activity systems of becoming a doctor in the three study contexts. In line with activity theory, our methodology needed to enable us to investigate the issue as a whole in its natural local settings and to provide rich data. We selected comparative case study research, based on principles of ethnography, to fulfill these needs. Ethnography typically encourages prolonged engagement in fieldwork to arrive at rich, deep and holistic understandings, using a variety of qualitative data collection methods. ${ }^{32}$ Though different methodologies and methods can be used in activity 
theory, ${ }^{31}$ methodologies in qualitative research seem most appropriate; particularly ethnography has been used in activity theory research to study complexity in medical education and health care settings. ${ }^{12,17,33}$ Ethnography's roots in cultural anthropology, moreover, underline its value for cultural researchers.

\section{Collecting data}

Following from our ethnographic case study approach, we employed various qualitative data collection methods, though we emphasize that activity theory allows many different data collection methods. We will discuss how the methods we chose were thought to grasp the different components of the activity systems and their interactions. More practical information about our methods is reported elsewhere. ${ }^{8,9}$ During one month of fieldwork in each local setting we conducted semi-structured, in-depth interviews with first and third-year students, tutors, and key staff involved in PBL, we observed PBL sessions in the first and third year, we reviewed documents such as information booklets for students and internal evaluations of PBL, and we took field notes about our experiences, the curriculum, the institute, and the local context outside the institute. With these diverse data sources we tried to capture the activity system as a whole, though we strongly focused on the activity of PBL, as followed from our research questions.

We developed an interview scheme that covered the components and development of the activity system according to the five activity theory principles. For example, we asked students and tutors about their ideas about PBL and their practices in PBL to identify how they defined the activity of PBL and its components. To identify their social and cultural communities we for example asked how the participants would characterize their cultural background, and which norms and values were important to them, to their family and to their society. We considered the historicity of the activity system by asking questions about the students' previous ideas and ways of learning, for example at secondary school, as well as questions for staff members about the history, process and reasons for implementing and applying PBL. We addressed the multi-voicedness of the activity system by including a diverse range of interview participants, and by asking explicitly about differences in viewpoints among students. We considered contradictions in the activity system by asking for example about difficulties that students experienced in PBL, and difficulties that tutors and staff had while implementing and applying PBL. We also included questions about which aspects went smoothly. We addressed the principle of expansive transformations by questions about change in students' beliefs and behaviors of learning, strategies they had developed to deal with PBL, differences between first and third year students, and adaptations that were made to the process of PBL since its implementation.

Also during the observations we focused on the activity theory principles, though this was less explicit than in the interviews. We took field notes that described stu- 
dents' behaviors, and we focused on signs that showed their internalization of the PBL model and externalization of their cultural learning beliefs and behaviors. Additionally, we filled in an observation sheet that covered aspects of PBL and potential cultural and contextual factors of influence. The practice of activity theory research shows many different ways of collecting data, though their common ground is to yield rich information about the activity system as the unit of analysis.

\section{Analyzing data}

We analyzed our data using template analysis, which is a systematic and hierarchical form of thematic analysis that allows themes to emerge from the data as well as from a theoretical framework, ${ }^{34,} 35$ in our case activity theory. However, different forms of (thematic) analysis can and have been used in activity theory research. ${ }^{12,15,17}$ We defined activity theory concepts such as contradictions, tensions and transformations in the activity system as overarching themes and listed prominent themes that emerged from the data as sub-themes. These included cultural norms and values, which we identified based on participants' answers during the interviews and behaviors observed in fieldwork. We performed a number of iterative coding rounds to identify activity system components and their relations. For each of the three cases we visualized a general activity system of becoming a doctor, with PBL as one of the mediating artifacts. Next, we identified components of this system that were of influence on the activity of problem-based learning, and consequently visualized a more detailed activity system of PBL for each of the cases.

We interpreted each of these systems according to the five activity theory principles to understand their dynamics. We looked at important contradictions, voices, and (historic) transformations, and we analyzed how they came about in the complex interaction between the activity system components. We then compared the activity systems of PBL between the three cases. This way we could describe, without dismissing the institutional and socio-cultural contexts, (differences between) how students internalized aspects of PBL in three different contexts, as well as (differences between) how their cultural backgrounds were externalized in the PBL process in these contexts. In a similar way, researchers of diverse cultural issues might use the structure of the activity system as an organizing principle for the cultural complexity of their research context, without denying or reducing this complexity.

\section{Reporting results}

We reported our results based on two major PBL aspects that we found to contradict with a number of rules, communities and the division of labour in the activity systems across the three cases: self-directed learning and small group discussions. ${ }^{8,9}$ Following the cultural focus of our research questions, we structured the results according to the 
cultural themes we identified that contradicted with and shaped the self-directed learning and group discussion processes of PBL differently across the three cases through students' externalization: group relations, 'face', hierarchy, tradition, uncertainty, achievement and competition. In these themes we integrated our findings on how students internalized the PBL aspects: how it shaped their self-directed learning skills and discussion and communication skills. Alongside the cultural themes we explicitly focused on other contextual factors of influence on the internalization and externalization processes, such as language of instruction, systems of assessment, and the nature of students' secondary education. We illustrated our results with quotes from interview participants, a visual model of our findings, and tables that specified the roles of contextual factors and degrees of internalization and externalization. ${ }^{8,9}$

We did not include the visualized activity systems, which we had developed during data analysis, in the reports of our results, though this is not uncommon in activity theory research. ${ }^{14-16,18}$ In our case we felt the reader would benefit more from a model and structure based on the cultural themes that we found after interpreting and comparing the three cross-cultural activity systems. Cultural researchers could use to their advantage the rich variety in activity theory research of how results can be reported and structured, for example based on contradictions that were found, ${ }^{17,33}$ or on themes that emerged from the data followed by a discussion of how these related with activity theory, ${ }^{15,18,19}$ or on transformations of rules, communities and division of labour, ${ }^{16}$ or on a narrative that reflected the dynamics of the activity system. ${ }^{12}$ For each research question, creative ways have to be found to represent the cultural complexity that was captured in the collection and analysis of the data well on paper, which can be challenging considering the word limitations of (medical education) journals. Visualizations, either of the activity system or a self-designed conceptual model, illustrative quotes and narratives are examples of useful tools.

\section{Drawing conclusions}

Our findings provided insight in the cross-cultural applicability of PBL by describing a complex interaction between PBL, local students, their cultural backgrounds and the local context, which led to students' adaptation as well as adaptation of PBL processes across cultural contexts. We concluded that PBL was applicable in diverse cultural contexts, but that its globalization did not postulate uniform processes and outcomes. ${ }^{8,9}$ More important than an answer to the question 'if PBL could be applied crossculturally', was the increased understanding that our findings raised about 'how' PBL was applied cross-culturally, including key influencing factors, which might serve medical educationalists and institutions across cultures that considered adopting PBL or another foreign educational model. As follows from its theory and practice, conclusions from activity theory research move beyond 'it works' or 'it happens' to 'how it works' 
and 'how it happens' - illuminating complexity - with possible implications for different settings.

Activity theory's nature implies that conclusions can be drawn only for the sociocultural context that was the focus of the study, which is important for cultural researchers to take into account and emphasize. The cultural themes that we described were based on our data from three medical schools, and although these were located in different cultural areas, we could not generalize our findings to those areas outside the schools. By providing rich descriptions of the cultural and contextual factors involved in a particular case, however, relevant factors, dynamics and implications might be recognized for different settings.

\section{Reflections on using activity theory to study cultural complexity}

Activity theory seems a useful theoretical and practical framework for cultural researchers, because it matches current views on culture as a dynamic process situated in a social context, ${ }^{30}$ and contains the ingredients to investigate this in practice. The structure of the activity system can serve as an organizing principle for cultural complexity in a way that values this complexity to increase understanding, rather than to dismiss it as 'noise'. Viewing and analyzing the issue under investigation as a whole, and identifying and interconnecting relevant factors involved, can enable researchers to grasp the reallife complexity of local contexts.

Another feature of activity theory that might be valued by cultural researchers is its focus on contradictions between the interacting components of an activity system. Many contradictions are manifested in cultural interactions and cultural effects of globalization, and a focus on these might illuminate cultural processes and explain cultural transformations, such as exemplified by our study on the cross-cultural applicability of PBL. As well as a possible strength, however, the focus on contradictions might be a possible limitation of activity theory, as there is a danger that it overshadows processes that result from congruence, while these are equally important for understanding cultural dynamics. Even though we paid attention to congruent elements during our data collection and analysis, our focus on contradictions was probably stronger as a result of our activity theory perspective. Some studies using activity theory have set a good example by focusing explicitly on both conflict and congruence in research questions, data collection, analysis and results, ${ }^{17}$ which might be worthwhile for cultural researchers to follow.

A potential difficulty in activity theory, certainly for cultural researchers, is the allencompassing scope of this perspective. Analyzing an activity as a whole, including a historic perspective and factors from the socio-cultural and institutional communities in which the activity is situated, can be a daunting task. Moreover, the activity itself interacts with surrounding activity systems, implying that the analysis might continue infi- 
nitely. Indeed, where does the influence of interconnected activities on cultural values and practices, and vice versa, end? The activity of becoming a doctor, for example, is influenced by numerous other activities, each situated in their own socio-cultural context. In our study we felt challenged to determine the boundaries of the activity systems, including the smaller-scale activity systems of PBL. A challenge for activity theory researchers seems to be to set appropriate boundaries for a study to be feasible, while at the same time do justice to the complexity of a natural setting. We stress that activity theory is not an easy approach to capture complexity: complex phenomena require a complex study approach. Employing an activity theory approach demands a lot from the researchers themselves: the activity system serves as an organizing principle, but it is up to the researchers to identify its components and dynamics, and to make sense from that in relation to their focus and research questions.

An interesting addition to the theory and practice of activity theory might be to consider the role of the researcher as an interacting entity with, or a participant in, the activity system (s)he investigates. Researchers are shaped by their socio-cultural and disciplinary backgrounds, and bring this influence, often unconsciously, to the research practice. Especially cultural influences, in the medical field in particular, ${ }^{30}$ often go unnoticed. Also our study was influenced by researcher bias, as we approached and interpreted the issue with our backgrounds in social and educational sciences and in Western European culture. We took several measures to recognize and address this bias, such as reflexive journaling and member check procedures, but additionally we might have benefitted from placing ourselves explicitly in relation to the activity system we investigated, and analyzing how our socio-cultural and disciplinary backgrounds shaped our understanding of the activity system components and dynamics. Future research on activity theory might elaborate on this issue, which is an essential element that needs to be addressed in cultural research especially.

This paper explained how activity theory might be used as a theoretical and practical framework to study cultural complexity in medical education, such as cultural effects of globalized educational models. There is an urgent need for cross-cultural research to keep up with the fast-growing developments in global medical education practice. ${ }^{1,3}$ Activity theory offers a lens to capture insights in complex local variations from which global medical education can learn. This moreover extends its use to diverse complex research objects in medical education beside (cross-)cultural research. We emphasize, however, that activity theory is merely one variation of a rich variety of socio-cultural perspectives, ${ }^{36,37}$ which offer useful complementary lenses. Similarly as in cultural practice, a rich variation in cultural research approaches serves the goal to represent and understand complexity well. 


\section{Acknowledgements}

In the past years we had many fruitful discussions about activity theory with colleagues from diverse disciplines, which have advanced our understanding. We are grateful to all of them; in particular we thank Tim Dornan, Jeantine de Feijter, Esther Bergman and Fred Stevens.

\section{References}

1. Hodges BD, Maniate JM, Martimianakis MA, Alsuwaidan M, Segouin C. Cracks and crevices: Globalization discourse and medical education. Med Teach 2009;31(10):910-7.

2. Bleakley A, Brice J, Bligh J. Thinking the post-colonial in medical education. Med Educ 2008;42(3):26670.

3. Segouin C, Hodges B, Byrne PN. World conference on medical education: a window on the globalizing world of medical education? Med Teach 2007;29(2-3):e63-6.

4. Gwee MC. Globalization of problem-based learning (PBL): cross-cultural implications. Kaohsiung JMed Sci 2008;24(3 Suppl):S14-22.

5. Jippes M, Driessen EW, Majoor GD, Gijselaers WH, Muijtjens AM, van der Vleuten CP. Impact of national context and culture on curriculum change: a case study. Med Teach 2013;35(8):661-70.

6. Jippes M, Majoor GD. Influence of national culture on the adoption of integrated medical curricula. Adv Health Sci Educ Theory Pract 2011;16(1):5-16.

7. Wong AK. Culture in medical education: comparing a Thai and a Canadian residency programme. Med Educ 2011;45(12):1209-19.

8. Frambach JM, Driessen EW, Beh P, van der Vleuten CPM. Quiet or questioning? Students' discussion behaviors in student-centered education across cultures. Stud High Educ 2013;iFirst Article:1-21.

9. Frambach JM, Driessen EW, Chan LC, van der Vleuten CP. Rethinking the globalisation of problem-based learning: how culture challenges self-directed learning. Med Educ 2012;46(8):738-47.

10. Segouin C, Hodges B. Educating doctors in France and Canada: are the differences based on evidence or history? Med Educ 2005;39(12):1205-12.

11. Regehr G. It's NOT rocket science: rethinking our metaphors for research in health professions education. Med Educ 2010;44(1):31-9.

12. Lingard L, McDougall A, Levstik M, Chandok N, Spafford MM, Schryer C. Representing complexity well: a story about teamwork, with implications for how we teach collaboration. Med Educ 2012;46(9):869-77.

13. Daly M, Roberts C, Kumar K, Perkins D. Longitudinal integrated rural placements: a social learning systems perspective. Med Educ 2013;47(4):352-61.

14. Berragan L. Conceptualising learning through simulation: An expansive approach for professional and personal learning. Nurse Educ Pract 2013;13(4):250-5.

15. de Feijter JM, de Grave WS, Dornan T, Koopmans RP, Scherpbier AJ. Students' perceptions of patient safety during the transition from undergraduate to postgraduate training: an activity theory analysis. Adv Health Sci Educ Theory Pract 2011;16(3):347-58.

16. Pimmer C, Linxen S, Grohbiel U, Jha AK, Burg G. Mobile learning in resource-constrained environments: a case study of medical education. Med Teach 2013;35(5):e1157-65.

17. Toth-Cohen S. Using cultural-historical activity theory to study clinical reasoning in context. Scand $J$ Occup Ther 2008;15(2):82-94.

18. Waters M, Wall D. Educational CPD: an exploration of the attitudes of UK GP trainers using focus groups and an activity theory framework. Med Teach 2008;30(8):e250-9. 
19. Wearn AM, Rees CE, Bradley P, Vnuk AK. Understanding student concerns about peer physical examination using an activity theory framework. Med Educ 2008;42(12):1218-26.

20. Engeström Y. Activity theory and individual and social transformation. In: Engeström $Y$, Miettinen R, Punamäki R-L, eds. Perspectives on activity theory. Cambridge: Cambridge University Press 1999:19-38.

21. Nasir NiS, Hand VM. Exploring Sociocultural Perspectives on Race, Culture, and Learning. Rev Educ Res 2006;76(4):449-75.

22. Rogoff B, Chavajay P. What's Become of Research on the Cultural Basis of Cognitive Development. Am Psychol 1995;50(10):859-77.

23. Stetsenko A, Arievitch IM. The self in cultural-historical activity theory - Reclaiming the unity of social and individual dimensions of human development. Theor \& Psych 2004;14(4):475-503.

24. Vygotsky LS. Mind in Society. The Development of Higher Psychological Processes. Cambridge: Harvard University Press 1978.

25. Engeström Y, Miettinen R. Introduction. In: Engeström Y, Miettinen R, Punamäki R-L, eds. Perspectives on activity theory. Cambridge: Cambridge University Press 1999:1-16.

26. Avis J. Transformation or transformism: Engestrom's version of activity theory? Educ Rev 2009;61(2):151-65.

27. Engeström Y. Expansive learning at work: Toward an activity theoretical reconceptualization. J Educ Work 2001;14(1):133-56.

28. Jonassen DH, Rohrer-Murphy L. Activity theory as a framework for designing constructivist learning environments. Educ Technol Res Dev 1999;47(1):61-79.

29. Sandars J. An activity theory perspective. Work Base Learn Prim Care 2005;3:191-201.

30. Taylor JS. Confronting "culture" in medicine's "culture of no culture". Acad Med 2003;78(6):555-9.

31. Bakhurst D. Reflections on activity theory. Educ Rev 2009;61(2):197-210.

32. Reeves S, Kuper A, Hodges BD. Qualitative research methodologies: ethnography. BMJ 2008;337:a1020.

33. Greig G, Entwistle VA, Beech N. Addressing complex healthcare problems in diverse settings: insights from activity theory. Soc Sci Med 2012;74(3):305-12.

34. King N. Using templates in the thematic analysis of text. In: Cassel C, Symon G, eds. Essential Guide to Qualitative Methods in Organizational Research. London: Sage Publications 2004:256-70.

35. King N. Template Analysis. 2010. http://www.hud.ac.uk/hhs/research/template_analysis/.

36. Tsui ABM, Lopez-Real F, Edwards G. Sociocultural Perspectives of Learning. In: Tsui ABM, Lopez-Real F, Edwards G, eds. Learning in School-University Partnership: Sociocultural Perspectives. New York: Routledge 2009:25-43.

37. Mann K, Dornan T, Teunissen P. Perspectives on learning. In: Dornan T, Mann K, Scherpbier A, Spencer J, eds. Medical Education: Theory and Practice. Churchill Livingstone Elsevier 2011:17-38. 

CHAPTER 7

From cultural complexity to cultural awareness, activity and action

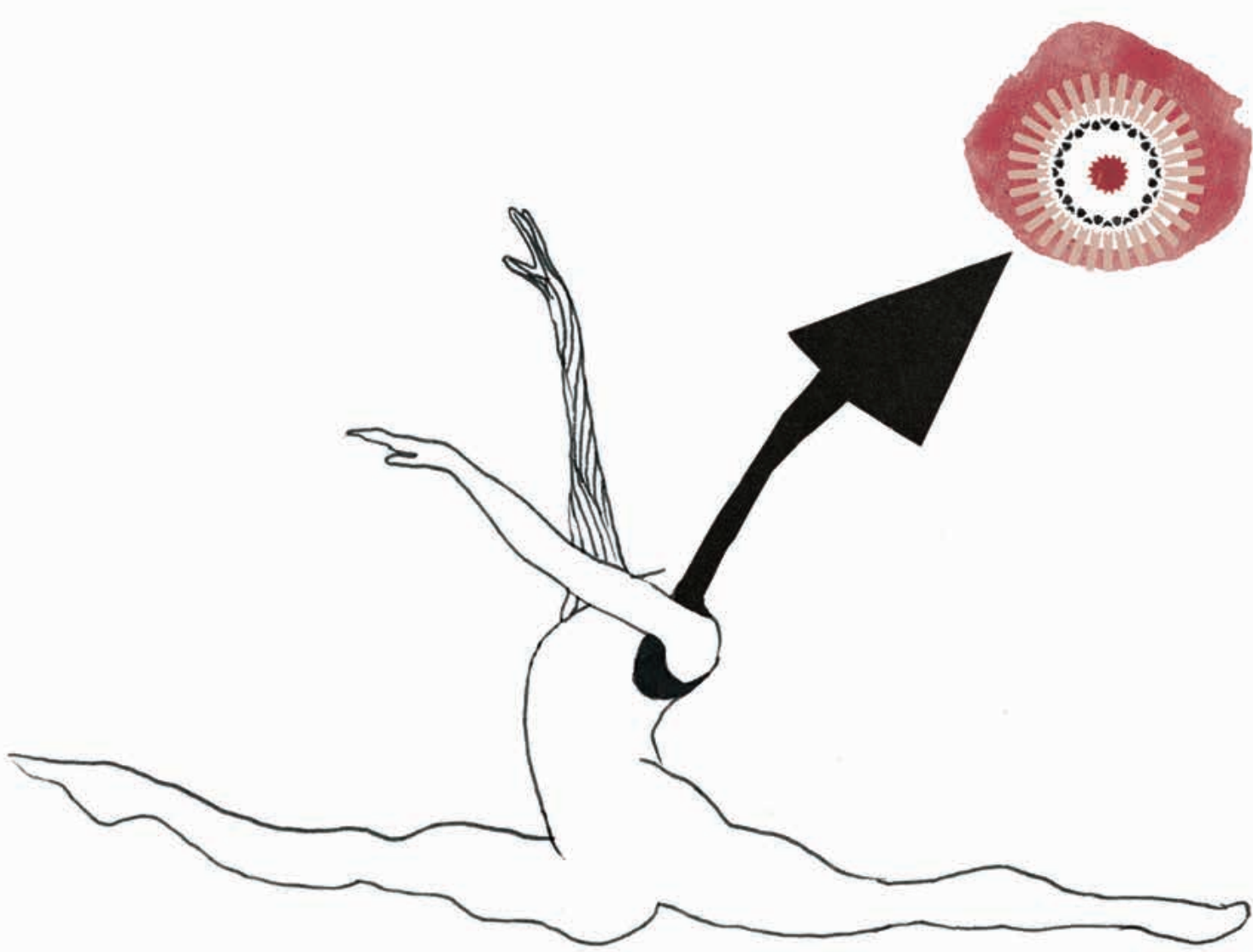


CHAPTER 7 
The aim of this dissertation was to explore the cross-cultural applicability of PBL, by deconstructing the cultural complexity of a number of essential PBL elements across diverse cultural contexts. This chapter summarizes the dissertation's main findings in relation to the two research questions introduced in chapter 1 , discusses practical and critical conclusions and implications guided by the question '(how) is PBL applicable across cultures?', addresses strengths and limitations of the dissertation, and proposes directions for future research.

\section{Main findings}

\section{Research question 1: How is PBL shaped across cultures?}

In chapter 6 it was proposed to view PBL as an activity, influenced by different components of the activity system. The component of main interest to this dissertation is the cultural community in which the activity takes place, which shapes students' beliefs, behaviors and values, which consequently influences the way they shape PBL. The findings of the cross-cultural, comparative case study, reported in chapters 2 and 3 , showed how this shape differed across the three cultural contexts. A number of factors from students' cultural communities were identified that, in the process of interacting with PBL, contradicted with some of PBL's norms and values as a Socratic learning approach. As explained in chapter 1 , a Socratic learning approach can be characterized by a focus on verbal expression, individualism, independency, rationalism, tendency to question and evaluate, self-directed learning and acquiring self-generated knowledge. ${ }^{1}$

In the Middle Eastern context in particular, students expressed uncertainty and a focus on tradition, which influenced the PBL group discussions as students felt anxious to speak up without prior knowledge on the subject matter, and felt inhibited to ask questions. They developed a number of uncertainty-reducing strategies, which resulted in a local shape of PBL group discussions. Also, they developed strategies to cope with the uncertainty involved in the self-directed learning element of PBL, such as a tight network of connections with senior students who could be used as advisors. Furthermore, in the Middle Eastern and East Asian contexts a strong focus on group relations and face was identified, which impacted on the group discussion processes in several ways. Before feeling comfortable to actively participate in the sessions, students felt that group relations needed to be established, which took a period of getting to know each other. In the Middle Eastern case for example, this was managed by changing the groups only once a year. In both contexts, particularly in the East Asian context, students were found to be very conscious of maintaining their own face and others' face in front of the group. This implied that they would only speak up if they were sure to be correct, that they were hesitant to ask questions as they felt it revealed a lack of knowledge, and that they would not challenge their peers' statements, which resulted 
in locally specific shapes of PBL group processes. Acting based on hierarchical relations was another factor that impacted the group discussions, as well as the self-directed learning processes, in both non-Western contexts in particular. Students preferred to let the tutor speak up, as a source of knowledge and a higher status person, and would not challenge tutors' statements, although this was noted to change to due decreasing hierarchical relations in society. Self-directed learning, particularly in the East Asian context, occurred only to the extent that knowledge was not transmitted by professors, whose knowledge was considered more 'truthful' - being higher up the hierarchical ladder - than knowledge derived from students' self-study. In the three contexts, students expressed a strong drive for achievement and competition, though this was least expressed in the Western European context compared with the other two contexts. In the three contexts alike, however, this resulted in decreasing attention to the group discussions if other curriculum aspects were more important for grading, increasing attention if the students' participation in the discussions substantially counted for grading, a potential reluctance to share information in the discussions, and self-directed learning to the extent it contributed to preparing for exams.

Although chapters 2 and 3 mainly focused on how students and their cultural backgrounds shaped PBL, the socio-cultural activity theory approach implied that this could not be separated from the influence of other activity system components on PBL's shape. Many institutional, organizational, curricular, economic and historical factors were found to mediate the activity of PBL. The shape of PBL in relation to cultural factors was therefore not as straightforward as the above description may suggest. In chapters 2 and 3, the assessment system, the scope of PBL implementation in the curriculum, the nature of students' secondary school education, the language of instruction, personality differences between students, and differences between tutors were identified as being of major influence on how PBL processes took shape. In the subSaharan African context described in chapters 4 and 5, the impact of human and material resources on PBL processes and outcomes was emphasized. Shortages of books, internet access, adequately trained tutors and clinical teachers heavily mediated the shape of PBL, and were partly responsible for its abandonment in one case.

Despite differences due to cultural and other contextual factors, the structure of PBL was found to be remarkably similar across the contexts included in this dissertation. From sub-Saharan Africa to East Asia, the structure of brainstorm and reporting sessions was comparable, PBL group sessions and self-study were major curriculum components, group sessions lasted the same amount of time on average, group sizes were similar, and tutors were instructed in similar ways. Comparing PBL structures across the four contexts, the East Asian case deviated most, which could be attributed to the hybrid PBL implementation in this case. While this dissertation mainly focused on the role of PBL processes and outcomes in relation to students; institutional, organizational and structural decisions made by educational leaders and staff were largely left untouched. However, unreported data from interviews and field notes of the studies 
reported in chapters 2-5 suggested that cultural and other contextual factors influenced these decisions as well, and contributed to the cultural and context-specific shapes of PBL, such as the hybrid PBL approach in the East Asian case. Also the shape of the ultimately discontinued PBL curriculum in the sub-Saharan African context, described in chapter 5 , was heavily mediated by academic leadership issues and staff commitment issues.

Though obviously leaving some important constructions of PBL across cultures untouched, the dissertation's findings to this explorative research question show that students across cultures shape PBL group discussions, self-directed learning in PBL, and PBL's general functioning differently through expressions of their cultural backgrounds. Its ultimate shape, however, is dependent on numerous other contextual factors involved in the activity of PBL, which is characterized by dynamic and continuously changing interactions. These findings resonate with previous research described in chapter 1 , which pointed to culturally and contextually shaped PBL processes that might be more challenging for students in non-Western settings, ${ }^{2-8}$ but also suggested that PBL could successfully be implemented across diverse contexts. ${ }^{3,4,9-12}$ This dissertation adds to this research by its wide cross-cultural scope, its detailed analysis of some essential PBL processes, and its emphasis on complexity as a mechanism to understand PBL's shape across cultures.

\section{Research question 2: How does PBL shape learners across cultures?}

As follows from the socio-cultural activity theory perspective, at the same time of being shaped itself, PBL shapes its learners. Across all contexts investigated in this dissertation, students, although to different degrees, experienced similar difficulties when being confronted with PBL for the first time. Insecurity about where and how to find information, about formulating learning objectives based on their own prior knowledge, hesitance to speak up during group sessions, and managing differences between students in the group were commonly reported problems by students across the different contexts. This is consistent with existing research on students' views and behaviors in $\mathrm{PBL},{ }^{13}$ which indicates that $\mathrm{PBL}$ engenders an initial anxiety in its learners anywhere. The findings reported in chapters 2 and 3, however, showed that this anxiety was likely to take a more substantial role in non-Western settings compared with a Western setting, due to the influence of the cultural factors described above that contradicted with some of PBL's Socratic learning principles. In chapter 5, additionally, students were shown to be more anxious due to a context burdened with human and material resource shortages. Beside these differences, however, the findings from chapters 2-5 also showed how PBL gradually shaped students across all contexts in similar ways.

Chapter 2 reported how PBL shaped students' discussion behaviors and skills in the East Asian, Middle Eastern and Western European contexts: students were found to 
build up confidence and comfortableness to participate in the group discussions by speaking up, asking questions to peers and tutors, criticizing knowledge and challenging the statements of others. Chapter 3 showed how PBL shaped students' skills, behaviors and views of self-directed learning: students developed motivation for self-directed learning, an understanding of its purpose, and skills related to searching and finding information, and constructing self-generated knowledge. Chapter 4 generally confirmed that these findings from chapters 2 and 3 were applicable to a sub-Saharan African context as well, and moreover, that the way PBL shaped learners was also detectable after students were graduated. The PBL students and graduates in chapter 4 were found to become self-directed learners, i.e. developing an inquiring and independent attitude, and confident communicators who approached patients in a holistic way. Furthermore, when compared with students and graduates from a conventional curriculum in the same context, the PBL learners showed more motivation and a more diverse range of knowledge and skills, which was partly attributed to the learning environment created by PBL. Chapter 5 showed that even students from a PBL curriculum that heavily suffered from implementation challenges in a sub-Saharan African context, and that eventually was discontinued, recognized the ability of PBL to encourage their communication and self-directed, lifelong learning skills.

Although PBL shaped learners across cultures in a similar direction, however, the extent to which this was crystallized differed substantially across the cases, and was heavily mediated by the same cultural and contextual factors as described previously. The hybrid PBL implementation in the East Asian case implied that students gained a substantial part of their knowledge through lectures, which inhibited the development of self-directed learning skills, as these were not essential for acquiring knowledge to pass exams. Communication skills, however, were encouraged in the East Asian case by students' focus on achievement and competition coupled with the fact that students were graded for their participation in the PBL sessions. In the Middle Eastern case, students expressed a high level of initial anxiety about PBL, due to cultural factors and the traditional nature of their secondary school education, but they experienced a substantial development of self-directed learning and communication skills because the full scope of the PBL implementation virtually left them no choice. In the Western European case, students expressed lower levels of initial anxiety and few problems with building self-directed learning and communication skills in PBL, due to supportive secondary schooling and cultural factors, but consequently this development was less substantial compared with the gap that Middle Eastern students bridged. In the sub-Saharan African context, large differences were found between how the two investigated PBL curricula shaped their students, which was attributed to the implementation, institutionalization and organization of PBL. Due to disorganization, a lack of commitment from staff, and an absence of learning materials, students from the discontinued PBL curriculum developed lower confidence and competence levels compared with students from a conventional curriculum. Students from the successfully implemented PBL curriculum, 
however, developed higher levels than the latter, despite the fact that their curriculum also coped with scarcity of human and material resources.

Similar to the findings to research question 1, the findings to research question 2 show that a complex interaction between PBL, learners, and the other components of the activity system of PBL determine the way learners are shaped. The extent of selfdirected learning and PBL communication skills differs between learners across cultural contexts, though they move in a similar direction. This is consistent with results from review studies on the effects of PBL, that found PBL learners to develop competencies in the social and cognitive domains in particular, e.g. competencies related to communication and self-directed learning. ${ }^{14,15}$ Also, this resonates with previous research that suggested that non-Western students adapt their learning behaviors to PBL when confronted with PBL environments. ${ }^{3,4} 16$ This dissertation adds to this research, again, by its cross-cultural scope and explicit analyses of cultural and contextual complexity.

Furthermore, this dissertation adds to existing research as it connects the way PBL shapes learners with the work context for which they are trained. Chapter 4 described the challenging work environment that PBL graduates faced in a cultural context very different from the one where PBL was originally developed. Also in this context, PBL students and graduates generally appreciated the way PBL shaped their skills and competencies as a useful preparation for practice, that helped them to better cope with the immense challenges that characterized local health care practice. These challenges were of such an intense and complex nature, however, that PBL was unable to fully prepare and equip learners for this environment, although the PBL curriculum seemed to succeed better compared with a conventional curriculum. In sum, the main findings of this dissertation reflect the cultural complexity of PBL across the world, which shapes PBL and its learners in distinct ways. The focus now turns to how these findings inform PBL's cross-cultural applicability.

\section{Conclusions and implications}

\section{(How) is PBL applicable across cultures?}

The complexity of PBL across cultures implies that an answer to this question is also rather complex. Based on the findings discussed above, a number of conclusions and implications can be drawn, that can be distinguished in a practical and a critical discussion of this question.

\section{A practical answer}

Yes, PBL is applicable across diverse cultural contexts. The findings of this dissertation, as well as practice across the world and an extensive body of existing research, show 
that PBL can firmly be established as an educational approach in medical schools across continents. Already since the beginning of PBL's spread across the globe in the 1970s, it has been noticed that PBL does not take the same shape in any institution. ${ }^{17}$ The way PBL is conceptualized and practiced depends on the beliefs and values of decision makers, leaders, teachers and students, which differ even between two proximate and comparable institutions. ${ }^{17}$ This has not been a reason to abandon the approach. Hence, while the findings of this dissertation suggest that PBL processes in cultural contexts unfamiliar with Socratic learning values and norms might differ even more from its original concept and practice in a Canadian context, this does not deny its applicability in these settings.

Nevertheless, this dissertation has identified a number of cultural and other contextual factors that potentially challenge or hinder the implementation and application of PBL, and that influence the degree to which learners develop specific skills and competencies. Instead of (how) is PBL applicable across cultures, the question then becomes: (how) is PBL applicable in a particular context? Primarily, the decision of a medical school whether or not to apply PBL needs to be preceded by addressing the questions: what do we want to achieve and why? Is this achievable and how do we achieve it in our setting? For example, medical school $\mathrm{X}-\mathrm{a}$ fictional school in a fictional context - wants to produce graduates who are self-directed learners, because current graduates are noted to lack lifelong learning skills that are desirable for their job. PBL might be a helpful approach to achieve this objective, but the medical school's context is characterized by strict hierarchical relations, a focus on avoiding uncertainty, a traditional secondary education system, and poor resources. The question is if an implementation of PBL in medical school $X$ is feasible in a way that achieves the objective of delivering actual self-directed learners as intended.

Before deciding to implement PBL, medical school X needs to be aware of the cultural and contextual complexity of its context and analyze which components of the activity system would potentially hinder or enhance the objective of producing selfdirected learners with PBL. Also, it needs to assure that this objective genuinely aligns with the needs and nature of the local work environment. An important component of the contextual analysis is assessing whether medical school $X$, in the first place, owns the capability and motivation necessary for a curriculum change to PBL, for example by measuring its organizational readiness for curriculum change. ${ }^{18}$ Existing literature lists the many factors that determine the success of curriculum change, such as the motivation and need for change, the organizational structure and climate, leadership, financial and human resources, involvement and readiness of staff, and the scope and complexity of the change. ${ }^{18,19}$ The change to a PBL curriculum, specifically, has been noted to be demanding for an organization, both regarding its initial acceptance and its long term institutionalization and sustainability. ${ }^{20-22}$ The findings in this dissertation show that the success of PBL's institutionalization heavily impacts PBL processes and outcomes, and its ultimate continuity. Considering the resource constraints and the focus on avoiding 
uncertainty in medical school $X$, the school's readiness for implementing a PBL curriculum might turn out to be questionable. Additionally, the school might conclude from its cultural and contextual analysis that potential contradictions between local values and the PBL approach are too large to overcome, for example between PBL's focus on student-initiated learning and the context's focus on hierarchical relations and traditional secondary education. In this case, rather than enforcing a curriculum change to PBL that might be doomed to fail, medical school $X$ might better turn its attention to enhancing its readiness for change and familiarizing its local context with PBL norms and values first, or to find a better-suited alternative to PBL that achieves the school's objective as well.

If, however, the findings of medical school $\mathrm{X}^{\prime}$ analysis point to PBL as a favourable and feasible strategy, the next step would be to determine how to implement and apply PBL in a way that best fits its context and objectives. Activity theory might be used as a facilitative tool. Complementary to activity theory's use as an analytical tool that provides insight in cultural and contextual complexity, as explained in chapter 6 , it can be used as a framework for designing and redesigning learning environments. ${ }^{23,}{ }^{24}$ The (potential) contradictions between cultural and other contextual factors and the PBL approach, found in medical school $X^{\prime}$ analysis, can be used as input for designing a contextually sensitive PBL implementation. Also schools that, contrary to medical school X, have implemented and institutionalized PBL for a longer period of time, can use activity theory as a framework for analyzing and redesigning the shape of PBL, in continuous 'cycles of expansive learning'. ${ }^{23}$ A cycle of expansive learning moves from analyzing the activity system and its inherent contradictions, to designing and implementing a new model that acts on these contradictions, to reflecting on the process of the new model, to consolidating the new model or starting a new cycle. ${ }^{23}$ This way, contradictions are not viewed as challenges or hindrances, but as natural occurrences that can be 'exploited' to create optimal, locally adapted learning environments. ${ }^{25}$

Based on contradictions between self-directed learning in PBL and the hierarchical relations and traditional secondary education system that characterize medical school $X^{\prime}$ context, for example, the school might decide to provide more guidance to students in the first year, and gradually move more responsibility to students. In this gradual exposure approach, as discussed in chapter 3, self-directed learning is viewed as an end rather than a means of PBL. ${ }^{26}$ Throughout this dissertation, a number of examples can be found of how advantage can be taken of cultural and contextual factors to optimize local PBL processes and outcomes. Group discussions in the Middle Eastern case, for example, were stimulated by the decision to keep the same groups for the duration of one year, and the same tutor for the duration of a semester, adhering to the value students attached to tight group relations. In the East Asian case, students' focus on achievement and competition was utilized to stimulate their participation in the discussion sessions by grading the sessions. In the Western European case, students' favourable attitude towards peer learning was exploited by introducing more peer learning into 
PBL in the third year of study. In sub-Saharan Africa, resource shortages stimulated clever combinations of means and objectives, such as combining communication skills training with patient care in a university clinic. An example from the literature is provided by Gwee, who argued that Karaoke, as a popular Asian-initiated group activity, can offer "an important lesson for PBL practitioners to understand the need to create a conducive environment for successful group activity" (p. S20). ${ }^{3}$ The joyful and nonjudgmental atmosphere of belonging and participation that characterize Karaoke in Asia can serve as an example for PBL group activity in Asia. ${ }^{3}$ The need for educators who use PBL to "adopt a local flavour that is relevant to the existing culture" has been underlined in the literature. ${ }^{27}$ This flavour should not only stem from ingredients from the local educational context, but also include ingredients from the local work context for which PBL trains its learners. In the sub-Saharan African context described in chapters 4 and 5, for example, learners needed to be prepared for the fact that local health care practice was a far cry from health care as described in their study books.

Thus, the answer to whether and how PBL is applicable in medical school X, depends, first, on an analysis of the cultural complexity of its educational context - including its readiness for curriculum change - and the work context for which its learners are trained. Second, if PBL seems a favourable and feasible approach, its shape depends on the previous complexity analysis, which can be used - continuously - to design a PBL learning environment sensitive to and 'exploitive' of local circumstances. In other words, cultural complexity can be analyzed to raise cultural awareness, from which action can be taken to shape a locally relevant activity of PBL - that will be yet another addition to the existing variety of PBL practices across the world. It needs to be emphasized, however, that this variety also implies variety in PBL outcomes. Though this dissertation shows that outcomes likely move in the same direction, their crystallization is mediated by PBL's contextual shape. In chapter 3 for example, a hybrid PBL implementation was noted to inhibit students' development of self-directed learning skills, which would be important information for medical school $X$ to take into account, considering its main objective of producing self-directed learners. In sum, a practical conclusion of this dissertation is that, yes, PBL is applicable across cultures, but not across all medical schools. In addition, the 'how' part of PBL's cross-cultural applicability is defined by cultural complexity, leading to a rich diversity of PBL processes and outcomes, from which PBL educators across the world can draw lessons.

\section{A critical answer}

The awareness of cultural differences in medical education, to which this dissertation aims to contribute, might take a different direction than concluding to shape locally relevant variants of PBL worldwide. The question '(how) is PBL applicable across cultures?', and even the question '(how) is PBL applicable in a particular context?' are perhaps not the ones that should be asked. In chapter 3, it was already noted that "a 
more fundamental question is whether PBL should be globalised in the first place. It is true that medical education worldwide is in need of reform, but whether one solution should be applied to all contexts is debatable. ( . . . ) Rather than taking on the cultural and contextual challenge of adopting student-centered, problem-based methods, it might be wiser for medical educationalists to rise to the challenge of exploring or creating alternatives that best fit their particular context" (p. 61). In chapter 5, moreover, it was noted that a curriculum change to PBL in one of the schools in a sub-Saharan African context seemed to have made the two local priorities of faculty numbers and infrastructure issues even more pressing. Rather than countering local priorities, it was stated in chapter 5 that "curriculum innovation in sub-Saharan Africa might focus on how scarce resources can be utilized in ways that support priorities. ( . . . ) This way, innovation would rightly serve as a means to an end, rather than a goal on its own" (p. 101). These discussions imply that the central focus of innovation in medical education across the world needs to be on: 'what are the needs and priorities in this particular context?' and subsequently, 'which innovations work best in this particular context to address these needs and priorities?' Medical schools worldwide should be able to ask and address these questions without being (mis)guided by the globalization of dominant educational approaches, such as PBL.

Currently, the probability that PBL does not fit local needs in medical education and health care certainly exists in theory, but its recognition in practice is doubtful. Applying PBL has been noted, also in this dissertation, to deliver self-directed, lifelong learners equipped with collaboration and communication skills, who approach patients with a holistic perspective. Indeed, it seems a rhetorical question to ask who does not want that. The discourse in medical education worldwide is in the advantage of PBL: global standards and guidelines encourage approaches that stimulate self-directed, lifelong learning, professionalism, team skills, communication skills and an awareness of ethical and psychosocial issues, ${ }^{28-31}$ which are all in line with the discourse of PBL. Also a glance at the contents of international medical education journals shows a rich representation of research on PBL-related aspects such as collaborative, small group, and self-directed learning. These phenomena yield a global propaganda for PBL that makes it difficult to resist and contradict the approach, and that has contributed to its - continuing - widespread distribution across the world. Medical schools worldwide have been noted and encouraged to implement PBL for diverse reasons, such as international competitiveness, funding, profiling, following international trends in medical education and 'fitting in with the rest', as well as often a genuine belief, from West to East and North to South, that PBL would serve existing societal and health care needs. ${ }^{4,}$, 20, 32-34 Reports on global standards and guidelines in medical education, such as those referred to above, serve to catalyze motivation and provide justification, and opportunities to funding, for these implementations. Cultural and other contextual differences between educational and work environments across the world, such as those uncovered in this dissertation, however, run the risk of being overlooked or ignored in this process. 
Research presented at medical education conferences and in medical education journals has been noted to assume that medical competence and the way it should be taught and learned has universal elements and is internationally applicable. ${ }^{35,}{ }^{36} \mathrm{An}$ example are the guides on PBL published by the Association for Medical Education in Europe (AMEE). ${ }^{13,17}$ The first section of a 2008 AMEE guide emphasizes that curricular models are heavily mediated by context, and explains the large variety of interpretations and practices of PBL that exist across the world. Its second section nonetheless proposes a "conception of PBL for the $21^{\text {st }}$ Century" informed by the authors' view of PBL as it should be, based on their explicit statement that, as opposed to curricular models, "educational principles are legitimately unconstrained by contexts". ${ }^{17}$ A 2014 AMEE guide presents PBL as a beneficial approach for medical students in general and offers tips for students on how to behave or 'survive' in PBL, considering the range of difficulties they might experience. Strikingly, the guide includes a section entitled "Why should a student study using problem-based learning?", but no section on "why should a student study not using problem-based learning?'. ${ }^{13}$

This is merely one example from the large body of medical education publications that - often implicitly - portray medical education principles, practices, standards and guidelines as internationally applicable. This portrayal, however, not only overlooks important contextual differences, ${ }^{35}$ but moreover runs the risk of instigating a "'new wave' of imperialism" and neocolonialism. ${ }^{37}$ Bleakley et al. have warned against an unreflecting spread of PBL and other educational approaches and technologies that originated in the West, because, according to the authors, these methods promote attitudes that might be essential only from a Western perspective, while their applicability to the settings to which they are exported is rarely questioned. ${ }^{37}$ This dissertation indeed found that PBL presented more potential challenges to students in non-Western contexts compared with a Western context. Other authors, inside and outside medical education, have also criticized the worldwide spread of PBL and other student-centered approaches for their neocolonialist potential to change local discourses into a Western one. ${ }^{38,39}$ Milligan for example wondered: "Students that go through the PBL process do appear to be more questioning, but what questions do they ask? ( . . . ) Will they question the dominant discourse of Western medicine or simply perpetuate it?" (p. 553). ${ }^{38}$ The power of PBL as an "ideology with its own discourse types and inherent assumptions" has furthermore been described by Leung, who claimed that the "introduction of problem-based learning in a medical school clearly alters the culture, basic assumptions and values during students' socialization into medical schools" (p. 170). ${ }^{40}$ In this dissertation, also, it was found that students across diverse cultural contexts moved in a similar direction regarding the development of their self-directed learning and communication and discussion skills, adapting to the norms and values of PBL as a Socratic learning approach.

Summarizing, the worldwide spread of PBL is advantaged by current medical education discourse and the presentation of PBL as an internationally applicable approach, 
but beneath the surface lies an imperialist potential of PBL, as a Western-developed method, to 'colonize' local medical education discourses and alter local students' beliefs and values. In contrast to what its global distribution might suggest, then, PBL indeed should not be viewed as a universally applicable solution for medical schools across contexts in need of reform.

On the other hand, the neocolonialist potential of PBL might present a moral dilemma, but in the practical contexts of medical education this might in fact be a nondiscussion. If medical schools using PBL across the world feel that it serves their purpose, albeit not without challenges, no viable argument might be formulated to deny its applicability in these settings. The finding that PBL changes students' cultural values and attitudes, instead of being interpreted as an imperialist result, might be a conscious goal and a genuine need across medical schools using PBL. This dissertation showed how PBL delivered satisfying results for students, staff and health care practice across diverse contexts. Denying its applicability, in this case, could be argued to precisely represent the immoral side of the dilemma. Moreover, students' cultural values are bound to change continuously, following from the conceptualization, in chapters 1 and 6 , of culture as a dynamic process taking place in a constantly changing social context. Cross-cultural influences and cultural fragmentation are omnipresent characteristics of current societies, in which the influence of PBL likely presents a mere fraction. Medical schools across contexts need to be aware that PBL's global presence might be based on false premises, and carries a neocolonialist potential, to inform their decision whether or not to implement and apply the approach. Either way, however, reflects a legitimate choice.

Another issue for medical schools to be aware of for making an informed decision, is that exploring, creating and applying context-sensitive alternatives for PBL might present equally or even more challenging problems than implementing PBL. First, inventing an alternative would likely demand at least the same amount of commitment from staff as the implementation of PBL. Second, the gap between a new alternative and the enormous lead that PBL has taken internationally, in terms of organizing the educational process, and opportunities to secure funding, student enrolment and accreditation, would be very large for a single medical school to bridge. Advising medical schools in non-Western contexts to create locally sensitive alternatives to PBL, then, would potentially create more problems than current expressions of PBL's imperialist tendencies across these contexts.

Nonetheless, the creation of alternatives deserves some more attention. This dissertation, as well as previous studies, showed how medical schools across cultures shaped context-specific variants of PBL. In a way, these could already be argued to represent an endless range of self-invented 'alternatives'. Standardization and convergence might characterize the global discourse of PBL, while local practice seems characterized by culturally shaped variants and divergence of PBL processes and outcomes. Nevertheless, a call for more fundamental alternatives for PBL seems to become louder 
in the literature. Beside the dominant discourse used by PBL advocates, an alternative discourse that questions PBL's effectiveness can be identified, which has been in existence since PBL's inception. Nowadays, this discourse reflects an accumulation of concerns with the PBL approach, raised by voices from Western, Eastern and Southern contexts, and from high income as well as low income countries. Some of these concerns have also been expressed in this dissertation.

First, PBL has been accused of not living up to its expectations, as it has been argued that evidence of PBL graduates' superiority compared with graduates from conventional curricula is unconvincing. ${ }^{41,42}$ Second, PBL has been criticized for its costs, as its implementation has been noted to demand large financial and human resources, which raises difficulties in many contexts, particularly in low income countries. $8,20,32,42$ Third, beside resource issues, a curriculum-wide implementation of PBL has been found challenging due to an often-noted resistance of staff. $8,21,42$ Finally, concerns have been raised, as emphasized in this dissertation, about cultural differences that might complicate PBL across cultures. A number of alternative approaches have been proposed for schools that struggle with these concerns, such as hybrid as opposed to full PBL implementation, and formats such as case-based and team-based learning. ${ }^{20,42,43}$ Such formats, however, can be criticized for not delivering a substantial, and a substantially different, alternative for PBL as a curriculum-wide approach. ${ }^{44}$

Thus, a substantial need for alternatives to PBL that go beyond local adaptations of PBL-like approaches can be identified, but it seems their development still has a long way to go. The current dominance of a global discourse in the advantage of PBL inhibits medical educationalists worldwide to 'think out of the box'. The latter is likely to be stimulated, however, by increasingly louder voices in the literature arguing and emphasizing that medical curricula across the world need to reflect local circumstances and priorities, not only in terms of content, but also in ways this is taught and learned. ${ }^{30,35}$, 45-48 Local shapes of educational approaches may currently be avoided for fear of not adhering to global standards of excellence in medical education, but this might change owing to an increasing recognition that global standards may not be globally applicable. Moreover, it has been argued that global excellence and local relevance of medical curricula are not mutually exclusive concepts. ${ }^{30,46,49}$ The local relevance of educational approaches may very well be compatible with, and even serve as a criterion for, their global excellence.

To conclude with taking dance as a metaphor for education: a ballerina shows different movements than a latin dancer or a hip hop dancer, but an excellent dancer in each of these styles is easily recognized by audiences across the world. The question which dancer is better than the others is futile and irrelevant: while being equally and recognizably excellent, their excellence cannot be compared. Some audiences, however, enjoy watching Tchaikovsky's swan lake, while other audiences might prefer Cuban salsa. The different styles and fusions of dance that exist across the world cater for these diverse needs, and their rich local varieties characterize and define the field's 
global excellence. Similarly, the global field of medical education could benefit from a rich variety of local approaches. Choreographers who deviated from mainstream styles and experimented with new movements and style combinations, moreover, have created some of the most applauded choreographies in history. This pictures an exciting future landscape of medical education if cultural differences and complexity are embraced.

\section{Strengths, limitations and future research}

\section{Deconstructing cultural complexity}

A strength of this dissertation is that it adds empirical data to a debate that largely has been limited to assumptions at a conceptual level. ${ }^{45,50}$ While the existence of cultural differences in medical education has been discussed and recognized at this level, a lack has been noted of empirical studies, specifically of a comparative, cross-cultural nature, that investigate the nature and the effects of cultural issues and globalization in medical education. ${ }^{35,36}$ This dissertation directly compared two essential PBL aspects across three cultural contexts, and indirectly added a fourth context, in chapters 4 and 5, to the comparison. The latter, moreover, was located in one of the world's most underrepresented regions in medical education research. This scope from Western to Eastern and Southern contexts adds a new dimension to research on PBL: the cultural complexity of its applicability across borders. This research has explored and deconstructed some of this complexity by employing socio-cultural and mixed methods approaches, which have yielded insights in the multifaceted effects of PBL's globalization.

The results of the different studies in this dissertation are not generalizable to other contexts. This was intentionally not the purpose of this research. On the contrary, its intention was rather to uncover the impossibility of generalizing cultural research, as well as curriculum research. The contexts investigated in this dissertation were characterized by a cultural and contextual complexity that characterized their context alone, from cultural factors to curriculum elements. It might be tempting to attribute or generalize the findings from the Western European, Middle Eastern, East Asian and subSaharan African medical schools to their wider region, and this dissertation might indeed be accused of not having resisted this temptation at several instances when interpreting results. Hence, the wide scope of this dissertation can simultaneously be characterized as a potential threat. Comparing three medical schools within rather than across the regions included in chapters 2 and 3 would also have revealed a characteristic cultural complexity for each school, such as exemplified by the comparison of three schools within a sub-Saharan African context in chapter 5. A similar approach in chapters 2 and 3 might have reduced the temptation of using overarching conceptualizations such as Western and Eastern culture, that might be of a potentially misguiding 
nature. The main focus on PBL, furthermore, might have overshadowed other important curriculum features that were of influence on the results, such as communitybased approaches in the Middle Eastern and sub-Saharan African schools. It has been emphasized in the literature that a simple cause and effect relation between PBL and outcomes, such as graduates' competencies, cannot possibly be established, due to the influence of numerous other factors. ${ }^{17,22}$ These factors, moreover, are part of complex, unique contexts that necessarily limit generalizability of findings.

Notwithstanding limited generalizability, the resonance with existing literature that many of the findings in this dissertation displayed, suggest their partial transferability to other contexts. The dissertation's focus on understanding and insight, by attempting to "represent complexity well", as addressed in chapter 6, has provided potentially useful findings for educators in other contexts. It has indeed been suggested that medical education research needs to move "from the imperative of proof to an imperative of understanding, and from the imperative of [generalisable] simplicity to an imperative of representing complexity well" (p. 38). ${ }^{51}$ The cultural and other contextual factors described in this dissertation might serve further analysis of the activity of PBL in diverse contexts, though it should be underlined that the use of these factors is constrained by the contexts and PBL elements focused on in this dissertation. Deconstructing cultural complexity can inform local practice only to an extent to which it has been conducted in its own context. Approaches for studying cultural complexity have been addressed previously in this chapter, and in detail in chapter 6 .

\section{Deconstructing bias and discourse}

Another strength of this dissertation is its attention for research quality. Extensive quality criteria, and techniques that can be used to meet them, exist in both quantitative and qualitative research. These have been carefully reviewed, as overviewed in appen$\operatorname{dix} B$, and incorporated in the different study designs in this dissertation. Specific attention has been given to reflexivity regarding the researcher's role, for example by keeping research diaries and documenting the steps and decisions taken during data collection and analysis. Despite these measures, however, inherently biased views, interpretations and findings were unavoidable, and present a limitation of this dissertation. Although the chapters have been co-authored by researchers from diverse cultural and disciplinary backgrounds, the main research team consisted of researchers with backgrounds in a Dutch cultural context and in social and educational sciences, which have influenced the research from inception to completion. The dissertation's aim, the use of literature, the conceptualization of PBL, the formulation of interview questions, the development of coding schemes, and the interpretation of findings and conclusions have all been shaped by the researchers' previous experiences, such as their extensive experience with PBL in a Dutch setting. The aim and research questions of the dissertation, although being explorative and constructivist in nature, focused on the cross- 
cultural applicability of $P B L$, rather than, for example, on which innovations, including others than PBL, would best serve needs across cultures. This way, paradoxically, the dissertation has contributed to perpetuating the PBL discourse and advantaging its further spread across the world, for which the critical discussion above has warned.

The inherent bias of this dissertation, however, does not imply that the findings lose meaning, but that their meaning should be interpreted with the above limitation in mind. They represent a construction of knowledge that resulted from interaction between the researchers and the participants, as explained in appendix A, while many more potential constructions exist depending on the backgrounds of other researchers and participants. Hence, researchers with different cultural and disciplinary backgrounds might conduct comparable research that addresses more of such constructions. The different insights that this yields, would create a richer and more crossculturally sensitive picture of the shape and role of PBL across cultures. Also, this would contribute to deconstructing, or uncovering, the inherent bias of this dissertation. Second, more fundamental research might be conducted on international discourses in medical education - e.g. from the perspective of critical discourse analysis ${ }^{52}$ - and how they impact on worldwide practices and spread of PBL, and of innovations and globalization in medical education in general. The impact of dominant discourses on the type of research that is conducted deserves attention as well. By deconstructing these discourses and their impact, alternative and overlooked research questions might be identified.

\section{Constructing optimal innovations}

This dissertation has identified a number of cultural and other factors that shape PBL processes and outcomes across cultures. Future research might focus on how such factors could be utilized and managed at a practical level, in diverse contexts, to create optimized group discussions, self-directed learning and other PBL processes, and ultimately, learners' preparation for local practice. As described previously in this chapter, activity theory could be used as a framework for such applied research, in which contradictions serve as triggers for change and improvement, leading to the construction of optimal learning environments. Care should be taken that also congruent components of the activity system receive attention in these analyses, which in this dissertation might have been overshadowed by a focus on contradictions, as explained in chapter 6. Other important aspects that should not be overlooked are the institutionalization and sustainability of PBL, and the impact of human and material resource issues on local PBL practice. In sum, the focus needs to capture the activity as a whole, including its interaction with surrounding activity systems.

Arguably more important than adding yet more studies to the large body of existing research on $\mathrm{PBL}$, however, is that future research should be encouraged to think 'out of the PBL box'. For contexts where PBL might not be a feasible and favourable approach, 
as well as beyond these contexts, researchers might focus on developing viable alternatives for PBL. Existing educational theories, knowledge and insights from diverse contexts can inform these innovations, while local relevance needs to be their main objective and characteristic. Ultimately, this would serve global excellence of the medical education field. Participatory action research and design-based research, in which researchers and participants act together to determine needs and design solutions for local contexts, ${ }^{53-55}$ might be valuable approaches to explore this objective. Rather than the cultural complexity of PBL, this action reflects the cultural complexity, and a cultural awareness, of a rich variety of local medical education activities.

\section{References}

1. Tweed RG, Lehman DR. Learning considered within a cultural context: Confucian and Socratic approaches. Am Psychol 2002;57(2):89-99.

2. Das Carlo M, Swadi H, Mpofu D. Medical student perceptions of factors affecting productivity of problem-based learning tutorial groups: does culture influence the outcome? Teach Learn Med 2003;15(1):59-64.

3. Gwee MC. Globalization of problem-based learning (PBL): cross-cultural implications. Kaohsiung J Med Sci 2008;24(3 Suppl):S14-22.

4. Khoo HE. Implementation of problem-based learning in Asian medical schools and students' perceptions of their experience. Med Educ 2003;37(5):401-9.

5. Lam TP, Wan XH, Ip MS. Current perspectives on medical education in China. Med Educ 2006;40(10):940-9.

6. Conway J, Little P, McMillan M. Congruence or conflict? Challenges in implementing problem-based learning across nursing cultures. Int J Nurs Pract 2002;8(5):235-9.

7. Walker A, Bridges E, Chan, B. Wisdom gained, wisdom given: instituting PBL in a Chinese culture. J Educ Adm 1996;34(5):12-31.

8. Mufunda J, Chatora R, Ndambakuwa Y, Samkange C, Sigola L, Vengesa P. Challenges in training the ideal Doctor for Africa: lessons learned from Zimbabwe. Med Teach 2007;29(9):878-81.

9. Hussain RMR, Mamat WHW, Salleh N, Saat RM, Harland T. Problem-based learning in Asian universities. Stud High Educ 2007;32(6):761-72.

10. Mpofu DJS. Introducing problem-based learning into a traditional medical school: student and staff perceptions of the United Emirates University's innovation. Phd Diss, Maastricht University 1999.

11. Iputo JE. Faculty of health sciences, walter sisulu university: training doctors from and for rural South african communities. MEDICC Rev 2008;10(4):25-9.

12. Kaye DK, Mwanika A, Sewankambo N. Influence of the training experience of Makerere University medical and nursing graduates on willingness and competence to work in rural health facilities. Rural Remote Health 2010;10(1):1372.

13. Bate E, Hommes J, Duvivier R, Taylor DC. Problem-based learning (PBL): Getting the most out of your students - Their roles and responsibilities: AMEE Guide No. 84. Med Teach 2014;36(1):1-12.

14. Koh GC, Khoo HE, Wong ML, Koh D. The effects of problem-based learning during medical school on physician competency: a systematic review. CMAJ 2008;178(1):34-41.

15. Neville AJ. Problem-based learning and medical education forty years on. A review of its effects on knowledge and clinical performance. Med Princ Pract 2009;18(1):1-9. 
16. Lam TP, Khoo US, Chan YS, Cheng YH, Lam KF. The first batch of graduates of a new medical curriculum in Asia: how their teachers see them. Med Educ 2004;38(9):980-6.

17. Taylor D, Miflin B. Problem-based learning: where are we now? Med Teach 2008;30(8):742-63.

18. Jippes M, Driessen EW, Broers NJ, Majoor GD, Gijselaers WH, van der Vleuten CP. A medical school's organizational readiness for curriculum change (MORC): development and validation of a questionnaire. Acad Med 2013;88(9):1346-56.

19. Bland CJ, Starnaman S, Wersal L, Moorehead-Rosenberg L, Zonia S, Henry R. Curricular change in medical schools: how to succeed. Acad Med 2000;75(6):575-94.

20. Carrera LI, Tellez TE, D'Ottavio AE. Implementing a problem-based learning curriculum in an Argentinean medical school: implications for developing countries. Acad Med 2003;78(8):798-801.

21. McLean M. Sustaining problem-based learning reform: advice in hindsight! Med Teach 2004;26(8):7268.

22. Hamdy H. The fuzzy world of problem based learning. Med Teach 2008;30(8):739-41.

23. Engestrom Y. Activity theory as a framework for analyzing and redesigning work. Ergonomics 2000;43(7):960-74.

24. Jonassen DH, Rohrer-Murphy L. Activity theory as a framework for designing constructivist learning environments. Educ Technol Res Dev 1999;47(1):61-79.

25. Greig G, Entwistle VA, Beech N. Addressing complex healthcare problems in diverse settings: insights from activity theory. Soc Sci Med 2012;74(3):305-12.

26. Miflin BM, Campbell CB, Price DA. A conceptual framework to guide the development of self-directed, lifelong learning in problem-based medical curricula. Med Educ 2000;34(4):299-306.

27. Al-Eraky M. The cultural flavours of problem-based learning. Med Educ 2013;47(10):1049.

28. World Federation for Medical Education. Basic Medical Education: WFME Global Standards for Quality Improvement. 2003. http://www.wfme.org/standards/bme.

29. World Federation for Medical Education. Basic Medical Education: WFME Global Standards for Quality Improvement: The 2012 Revision. 2012. http://www.wfme.org/standards/bme.

30. Frenk J, Chen L, Bhutta ZA, Cohen J, Crisp N, Evans T, et al. Health professionals for a new century: transforming education to strengthen health systems in an interdependent world. Lancet 2010;376(9756):1923-58.

31. World Health Organization. Report on the WHO/PEPFAR planning meeting on scaling up nursing and medical education. 2009. http://www.who.int/hrh/resources/scaling-up_planning_report.pdf.

32. Amin Z, Hoon Eng K, Gwee M, Dow Rhoon K, Chay Hoon T. Medical education in Southeast Asia: emerging issues, challenges and opportunities. Med Educ 2005;39(8):829-32.

33. Gibbs T. Medical education in Africa: not always a level playing field. Med Teach 2007;29(9):853-4.

34. Gwee MC, Tan CH. Problem-based learning in medical education: the Singapore hybrid. Ann Acad Med Singapore 2001;30(4):356-62.

35. Hodges BD, Maniate JM, Martimianakis MA, Alsuwaidan M, Segouin C. Cracks and crevices: Globalization discourse and medical education. Med Teach 2009;31(10):910-7.

36. Segouin C, Hodges B, Byrne PN. World conference on medical education: a window on the globalizing world of medical education? Med Teach 2007;29(2-3):e63-6.

37. Bleakley A, Brice J, Bligh J. Thinking the post-colonial in medical education. Med Educ 2008;42(3):26670.

38. Milligan F. Beyond the rhetoric of problem-based learning: emancipatory limits and links with andragogy. Nurse Educ Today 1999;19(7):548-55.

39. Nguyen PM, Elliott J, Terlouw C, Pilot A. Neocolonialism in education: Cooperative Learning in an Asian context. Comp Educ 2009;45(1):109-30.

40. Leung WC. Why is evidence from ethnographic and discourse research needed in medical education: the case of problem-based learning. Med Teach 2002;24(2):169-72. 
41. Colliver JA. Effectiveness of problem-based learning curricula: research and theory. Acad Med 2000;75(3):259-66.

42. Shanley PF. Viewpoint: leaving the "empty glass" of problem-based learning behind: new assumptions and a revised model for case study in preclinical medical education. Acad Med 2007;82(5):479-85.

43. Srinivasan M, Wilkes M, Stevenson F, Nguyen T, Slavin S. Comparing problem-based learning with casebased learning: effects of a major curricular shift at two institutions. Acad Med 2007;82(1):74-82.

44. Lim WK. Dysfunctional problem-based learning curricula: resolving the problem. BMC Med EduC 2012;12(89.

45. Wong AK. Culture in medical education: comparing a Thai and a Canadian residency programme. Med Educ 2011.

46. Celletti F, Reynolds TA, Wright A, Stoertz A, Dayrit M. Educating a new generation of doctors to improve the health of populations in low- and middle-income countries. PLoS Med 2011;8(10):e1001108.

47. World Health Organization. Transformative scale up of health professional education. An effort to increase the numbers of health professionals and to strengthen their impact on population health. 2011. http://whqlibdoc.who.int/hq/2011/WHO_HSS_HRH_HEP2011.01_eng.pdf.

48. Nair M, Webster P. Managing priorities. Med Educ 2012;46(8):733-5.

49. World Health Organization. WHO consultation on the transformative scale-up of medical, nursing and midwifery education. First technical reference group meeting: medical education experts. 2010. http://www.who.int/hrh/resources/medical_experts_first_meeting.pdf.

50. Hodges BD, Segouin C. Medical education: it's time for a transatlantic dialogue. Med Educ 2008;42(1):23.

51. Regehr G. It's NOT rocket science: rethinking our metaphors for research in health professions education. Med Educ 2010;44(1):31-9.

52. Hodges BD, Kuper A, Reeves S. Discourse analysis. BMJ 2008;337(a879.

53. Lingard L, Albert M, Levinson W. Grounded theory, mixed methods, and action research. $B M J$ 2008;337(a567.

54. Miller BM, Eichbaum Q, Brady DW, Moore DE, Jr. Aligning health sciences education with health needs in developing countries. Acad Med 2011;86(11):e10.

55. Collins A, Joseph D, Bielaczyc K. Design research: theoretical and methodological issues. J Learn Sci 2004;13(1):15-42. 


\section{APPENDIX A}

\section{An overview of research paradigms}

Published as:

Bergman E, De Feijter J, Frambach J, Godefrooij M, Slootweg I, Stalmeijer R, Van der Zwet J. AM Last Page: A Guide to Research Paradigms Relevant to Medical Education. Academic Medicine 2012;87(4):545.

AM Last Page is a monthly feature of Academic Medicine published on the journal's last page. 
APPENDIX A 


\section{AM Last Page: A Guide to Research Paradigms Relevant to Medical Education}

Esther Bergman, MSc, PhD student, Jeantine de Feijter, MD, PhD student, Janneke Frambach, MA, MSC, PhD student, Merijn Godefrooij, MD, PhD student, Irene Slootweg, PhD student, Renee Stalmeijer, PhD, assistant professor, Jonne van der Zwet, MD, PhD student, Maastricht University

In order to design or interpret qualitative and quantitative research, one should have some understanding of the assumptions that underpin them. Below, we provide an overview of some of the concepts underlying four philosophical paradigms in medical education research and illustrate the relationships between them.

\begin{tabular}{|c|c|c|c|}
\hline \multicolumn{4}{|c|}{$\begin{array}{l}\text { Paradigm: A philosophical framework that underlies and affects research activities. What are the assumptions underlying one's } \\
\text { views on reality and knowledge? (Synonyms: theoretical or epistemological stance, world view) }\end{array}$} \\
\hline $\begin{array}{l}\text { Positivism } \\
\text { There is one truth, and it } \\
\text { can be observed. }\end{array}$ & $\begin{array}{l}\text { Post-Positivism } \\
\text { There is one truth, but it can } \\
\text { never be truly observed. }\end{array}$ & $\begin{array}{l}\text { Critical Theory } \\
\text { Multiple truths exist, and } \\
\text { they are influenced by power } \\
\text { relations among people. }\end{array}$ & $\begin{array}{l}\text { Constructivism } \\
\text { Multiple truths are } \\
\text { constructed by and between } \\
\text { people. }\end{array}$ \\
\hline \multicolumn{4}{|c|}{ Ontology: Theory of the view on reality. What is the nature of physical and social reality? } \\
\hline$T$ & 1 & $I$ & $I$ \\
\hline $\begin{array}{l}\text { Realism } \\
\text { Reality is objectively observable } \\
\text { and exists independently of } \\
\text { the human knower. The world } \\
\text { is operated by laws of cause } \\
\text { and effect. Variables can be } \\
\text { observed, measured, and } \\
\text { predicted. }\end{array}$ & $\begin{array}{l}\text { Critical Realism } \\
\text { Reality is assumed to exist, } \\
\text { but evidence in research } \\
\text { is fallible due to the } \\
\text { complexity of the enquiry. }\end{array}$ & $\begin{array}{l}\text { Historical Realism } \\
\text { Reality is shaped by } \\
\text { structures of social, political, } \\
\text { cultural, economic, ethnic, } \\
\text { and gender factors. }\end{array}$ & $\begin{array}{l}\text { Relativism } \\
\text { Reality is socially and } \\
\text { experientially based; } \\
\text { multiple realities exist, } \\
\text { change, conflict, and/or } \\
\text { become more crystallized. }\end{array}$ \\
\hline \multicolumn{4}{|c|}{ Epistemologyi Theory of knowledge. What are the origin, nature, and limits of knowledge about reality? } \\
\hline $\begin{array}{l}\text { Badical Objectivism } \\
\text { Knowledge is independent } \\
\text { of the human knower. } \\
\text { People can provide an } \\
\text { objective, value-free } \\
\text { description of reality. }\end{array}$ & $\begin{array}{l}\text { Relative Objectivism } \\
\text { Knowledge is conjectural and } \\
\text { based on hypotheses that } \\
\text { have not yet been falsified. } \\
\text { Objective knowledge about } \\
\text { reality is the ideal, which } \\
\text { cannot be achieved. }\end{array}$ & $\begin{array}{l}\text { Relative Subiectivism } \\
\text { Knowledge is value- } \\
\text { dependent, is influenced } \\
\text { by power relations, and } \\
\text { is the result of interaction } \\
\text { between researcher and } \\
\text { participants. }\end{array}$ & $\begin{array}{l}\text { Radical Subjectivism } \\
\text { Knowledge consists of } \\
\text { constructions that arise } \\
\text { from interaction between } \\
\text { researcher and participants. }\end{array}$ \\
\hline
\end{tabular}

Methodology: Strategic approach to answer the research question and to gain knowledge. What is the research design?

Verification
Knowledge is gained through
hypothesis generation and
testing (deduction). It focuses
on prediction and control of
phenomena. The aim is to
produce generalizable data.

in

$$
\text { Quantitative research }
$$

Iransformation
Knowledge is gained
by raising participants
to a different level of
consciousness and thereby
empowering them.

Qualitative research
Interaction

Knowledge is gained by an inductive approach: recognizing, understanding, developing. and contrasting constructions through dialogue.

As illustrated below, an understanding of research paradigms can guide researchers in designing and performing medical education research. Each step invites the researcher to consider underlying assumptions about knowledge and reality within the field of medical education and related disciplines

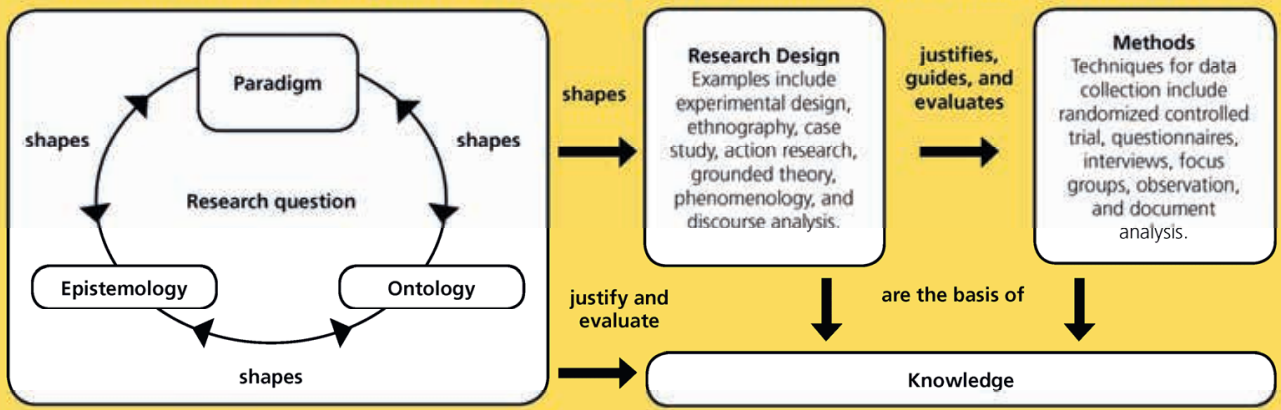

Suggestions for further reading:

- Bunniss S, Kelly DR. Research paridioms in medical education research. Med Educ 2010,44:358-366.

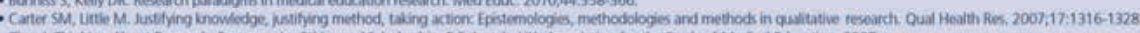

- fling L. Thirking About Reseurch: Framevorks, fthics and Scholarship. Edinbuxgh UK: Association for the Study of Medical Edications 2007. 



\section{APPENDIX B}

\section{An overview of quality criteria for research}

Published as:

Frambach JM, Van der Vleuten CPM, Durning, SJ. AM Last Page: Quality Criteria in Qualitative and Quantitative Research. Academic Medicine 2013;88(4):552.

AM Last Page is a monthly feature of Academic Medicine published on the journal's last page. 
APPENDIX B 


\section{AM Last Page: Quality Criteria in Qualitative and Quantitative Research}

Janneke M. Frambach, MA, MSC, PhD student, Cees P.M. van der Vleuten, PhD, professor of education, Maastricht University, Steven J. Durning, MD, PhD, professor of medicine and pathology, Uniformed Services University of the Health Sciences

Good research in medical education is characterized by evidence that is trustworthy, applicable to (multiple) practical settings, consistent, and neutral (unbiased)-regardless of whether a qualitative or a quantitative approach is used. However, while qualitative and quantitative research share similar standards for good evidence (quality criteria), the conception and operationalization of these quality criteria differ between the two. Below, we provide an overview of these criteria and a number of techniques that researchers can use to meet them. In addition, we note that the criteria are interlinked, and that some of the techniques contribute to multiple criteria at the same time.

\section{Techniques to enhance quality in quantitative research}

Calculate the sample size that is needed for sufficient statistical power (power calculation)

- Describe details of the

educational context and intervention

- Avoid loss of participants or provide information on nonresponses

- Standardize treatment conditions - Use control groups (controlled design)

- Use random or stratified sampling (population generalizability)

- Replicate the study in other contexts fecological generalizability)

- Verify predicted relationships between dependent and independent variables (construct validation)

- Estimate the internal consistency across repeated measures (classical test theory)

- Estimate sources of variance affecting the measurement (generalizability theory)

Estimate item, test, and person parameters fitem response theory)

- Use blinded assessors or coders during data-gathering

- Anonymize respondent identities Let the facts speak for themsetves - Maintain and safeguard the original data for accountability to journals and the public

\section{Quality criteria in quantitative research}

Internal validity The extent to which observed effects can be attributed to the independent variable$$
\text { indept }
$$

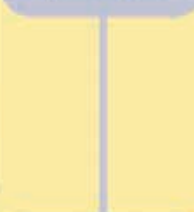

External validity The extent to which the results can be generalized from the research sample to the population

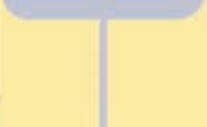

Reliability

The extent to

which the results are consistent if the study would be replicated

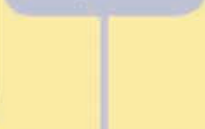

Objectivity The extent to which personal biases are removed and value free information is gathered
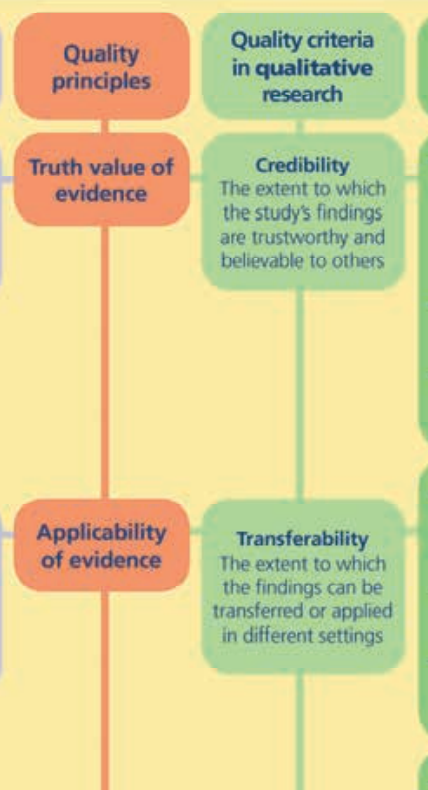

Transferability The extent to which the findings can be transferred or applied in different settings

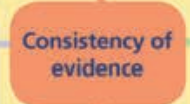

Dependability The extent to which the findings are consistent in relation to the contexts in which they were generated

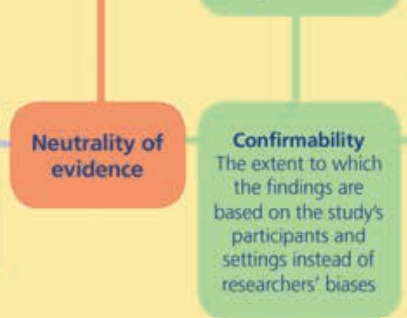

Techniques to enhance quality in qualitative research

Use multiple data sources (data triangulation), methods (methodological triangulation). researchers (investigator triangulation) and theories (theory triangulation) - Collect data for an extended period of time (prolonged engagement)

Ask feedback from participants on the data or interpretation of the data (member checking)

- Make the findings meaningfu to others by describing them and their context in detail (thick description)

- Explain the sampling strategy (e.g. typical case sampling or maximum-variation sampling)

Discuss the findings' resonance with existing literature from different settings

Collect data until no new themes emerge (saturation) Continuously analyze the data to inform further data collection (iterative data collection)

- Continuously re-examine the data using insights that emerge during analysis (iterative data analysis)

Be flexible and open towards the process and topic (flexible) emergent research design)

Search the data and/or literature for evidence that disconfirms the findings

Discuss the research process and/or findings with peers/ experts (peer debriefing)

- Keep a diary to reflect on the process and the researcher's role and influence (reflexivity)

Document the steps and decisions taken in the research, and their motives (audit trail) 



\section{Summary}

Chapter 1 introduces the main concepts of this dissertation, discusses its background, and presents the dissertation's problem statement, aim and research questions. The central concept of this dissertation is problem-based learning (PBL). Since its development in the late 1960s in Canadian medical education, PBL has become a globally distributed product and continues to be spread further across the world. In this dissertation PBL is conceptualized as an educational approach carrying a set of cultural norms and values that reflect the context in which it was originally developed. Consequently, implementing and applying PBL in other contexts, specifically in non-Western settings, might therefore be challenging and imply different PBL processes and outcomes across cultural contexts. Hence, the globalization of PBL can be argued to be characterized by a cultural complexity, which raises questions about its cross-cultural applicability. The aim of this dissertation is to explore the cross-cultural applicability of PBL by addressing the following research questions: 1) How is PBL shaped across cultures? and 2) How does PBL shape learners across cultures? A constructivist, socio-cultural lens that serves as an overarching theoretical perspective in this dissertation, informs the formulation of these questions. Each chapter of the dissertation deconstructs a different element of the cultural complexity of PBL, aimed to enrich understanding about its cross-cultural applicability. Together the chapters form a stepwise uncovering - though not exhaustive - of how PBL is constructed and constructs learners across cultures.

Chapters $\mathbf{2}$ and $\mathbf{3}$ address the cultural complexity of group discussions and self-directed learning in PBL, respectively. The chapters report findings from a qualitative, crosscultural, comparative case study that was conducted in three medical schools, located in the Middle East, East Asia and Western Europe. Using a socio-cultural approach, it was investigated how students' cultural backgrounds shaped group discussions and self-directed learning processes in PBL, as well as how the group discussions and selfdirected learning elements of PBL shaped students. Data were collected by 88 semistructured, in-depth interviews with first-year and third-year students, tutors and key persons involved in PBL, 32 observations of first-year and third-year PBL group sessions, document analysis, and field notes. The data were thematically analysed using the template analysis method. Comparisons were made among the three medical schools and between first-year and third-year students across and within the schools.

Differences in students' cultural backgrounds were found to shape group discussions and self-directed learning processes in PBL differently across the three contexts. In the two non-Western settings in particular, a number of cultural factors were identi- 
fied that contradicted with the cultural values inherent in the PBL approach, which accounted for more challenges experienced by students in PBL in these settings. A focus on uncertainty and tradition, on group relations and face, on hierarchical relations, and on achievement and competition potentially refrained students from speaking up, asking questions, and challenging others during the group discussions, and from developing self-directed learning skills such as formulating learning objectives, searching and finding information, and constructing self-generated knowledge. The relation between cultural factors and the shape of PBL was not straightforward, however, as numerous other contextual factors were identified that heavily mediated the shape of group discussions and self-directed learning processes. For example, the assessment system, the scope of PBL implementation in the curriculum, the nature of students' secondary school education, the language of instruction, personality differences between students, and differences between tutors were identified as being of major influence on how PBL processes took shape.

Besides influencing the shape of PBL, these cultural and other contextual factors also mediated how students were shaped by PBL. Different degrees between the three contexts were found in the development of students' discussion skills and self-directed learning skills. Nonetheless, it was found that the group discussions and self-directed learning elements of PBL gradually shaped students across the contexts in a similar direction. Students were found to build up confidence and comfortableness to participate in the group discussions by speaking up, asking questions to peers and tutors, criticizing knowledge and challenging the statements of others. Also, they were found to develop motivation for self-directed learning, an understanding of the purpose of self-directed learning, and skills related to searching and finding information, and constructing knowledge. In sum, it was found that a complex interaction between PBL, students, their cultural backgrounds and other contextual factors determined the way PBL processes and students were shaped across cultures. It was concluded that, although cultural factors might pose more challenges to applying PBL in non-Western settings, PBL seemed feasible in different cultural contexts. Across these contexts, however, PBL processes and outcomes differed.

Chapters 4 and $\mathbf{5}$ address the complexity of preparing learners for practice by using $\mathrm{PBL}$, and implementing PBL, respectively, in a cultural environment very different from the one where PBL was originally developed. The chapters report findings from a comparative mixed methods study that was conducted in medical schools in a sub-Saharan African context. Chapter 4 investigates the challenges that junior doctors faced in health care practice in this sub-Saharan African context, and how they felt their education had prepared for these. A comparison was made between students and graduates from a PBL curriculum and a conventional curriculum. Chapter 5 investigates curriculum outcomes of PBL implementations in a sub-Saharan African context, by comparing students' preparedness for practice of three curricula in this context: a PBL curriculum that 
successfully coped with implementation challenges, a PBL curriculum that heavily suffered from implementation challenges, and a conventional curriculum. Data for the two chapters were collected simultaneously by 22 semi-structured, individual interviews with junior doctors and fifth-year students, a questionnaire administered to junior doctors and fifth-year students ( $n=194)$, work diaries kept by six junior doctors, informal interviews with educational leaders and key staff, and field notes on observations in educational sessions and community visits. Statistical and thematic analysis was conducted and, in a final interpretation round, the quantitative and qualitative data were integrated.

In chapter 4 six areas of tension between global health care ideals and local health care reality were identified that challenged doctors' motivation and preparedness for practice: 1) serving others versus surviving yourself, 2) treating patients with modern medicine versus managing patients who use traditional medicine, 3) being a clinical doctor versus being a manager and political figure, 4) using required tests and procedures versus dealing with shortages, 5) having global medical knowledge versus confronting a specific local disease burden, and 6) communicating with and respecting patients versus facing communication obstacles and patient overload. Four elements of the PBL curriculum were found to equip students and graduates with skills, attitudes and competencies to better cope with these tensions compared with students and graduates from the conventional curriculum, which seemed to increase their motivation and preparedness for practice: 1) providing an overall positive learning climate, 2) stimulating an inquiring and independent attitude, 3) stimulating a holistic approach towards patients, and 4) stimulating a varied range of knowledge and skills. It was concluded that a PBL curriculum could improve sub-Saharan African doctors' motivation and preparedness to tackle the challenges of health care practice in this region, but that the challenges were of such an intense and complex nature, however, that the curriculum was unable to fully prepare and equip learners for this environment though it seemed to succeed better compared with a conventional curriculum.

In chapter 5, similarly, it was found that the PBL curricula stimulated a holistic approach towards patients and an inquiring and independent attitude among students, which was considered a valuable preparation for sub-Saharan African health care. The preparedness for practice of students from the conventional curriculum was found to be significantly lower than students from the successfully implemented PBL curriculum, but, however, significantly higher than students from the PBL curriculum that heavily suffered from implementation challenges. A disorganization of the curriculum, a lack of staff commitment, a shortage of adequately trained PBL tutors and clinical teachers, and the absence of learning materials and resources severely impeded preparedness for practice of students from the latter curriculum. It was concluded that in subSaharan Africa the stakes of PBL implementation seemed higher than elsewhere: positive outcomes displayed an urgently needed added value to local health care, but this 
could be reversed into negative effects if implementation challenges characteristic for sub-Saharan African contexts were not overcome.

Chapter 6 reflects on how the cultural complexity of PBL, and of cultural issues in medical education in general, can be studied. This methodological chapter elaborates on the socio-cultural approach used in chapters 2 and 3 - socio-cultural activity theory - and proposes it as a useful theoretical and practical framework to study cultural complexity, and in the case of this dissertation, to inform the cross-cultural applicability of PBL. The theoretical background and principles of activity theory are explained, and the research steps involved in the cross-cultural case study of chapters 2 and 3 are discussed to demonstrate activity theory's practical application, from formulating research questions to drawing conclusions. It is described how the activity system, the unit of analysis in activity theory, can serve as an organizing principle to grasp cultural complexity. The chapter ends with reflections on the theoretical and practical use of activity theory for cultural research. It is noted that activity theory does not serve as a shortcut to capture cultural complexity: it is a challenge for researchers to determine the boundaries of their study and to analyze and interpret the dynamics of the activity system.

Chapter 7 summarizes and discusses how the previous chapters have answered the two research questions, and which conclusions and implications this yields for the crosscultural applicability of PBL. The chapter distinguishes a practical and a critical discussion guided by the question: (How) is PBL applicable across cultures? The main findings to the research questions show how a complex interplay between $\mathrm{PBL}$, learners, and other components of the activity system of PBL determines the way PBL and its learners are shaped across cultures. Although these shapes differ across contexts, PBL learners seem to move in a similar direction anywhere. Implementing and applying PBL seems to be more challenging in non-Western settings, but its outcomes seem valuable for diverse work contexts. Based on these findings, a practical answer to the question above is that PBL is applicable across cultures, but not across all medical schools. Its applicability for a particular school depends on an analysis of the cultural complexity of its educational context and the work context for which its learners are trained. If PBL then seems a favourable and feasible approach, its implementation should be carefully designed based on the complexity analysis.

A critical answer might say that the question above is the wrong one to be asked. The central focus of innovation in medical education across the world needs to be on local needs and priorities, which medical schools worldwide should be able to address without being (mis)guided by the globalization of dominant educational approaches such as PBL. PBL's globalization might be based on false premises, and carrying an imperialist potential. A substantial need for alternatives to PBL can be identified, but the current dominance of a global discourse in the advantage of PBL seems to inhibit their development. This dissertation could be argued to be a product of this discourse as 
well. It is argued that the global field of medical education, however, could benefit from a rich variety of local approaches that move beyond the PBL discourse. The chapter ends with addressing the dissertation's strengths, limitations and suggestions for future research, distinguished in three areas: deconstructing cultural complexity, deconstructing bias and discourse, and constructing optimal innovations. 



\section{Samenvatting}

Hoofdstuk 1 introduceert en bespreekt de hoofdconcepten van dit proefschrift en hun achtergrond, en presenteert de probleemstelling, het doel en de onderzoeksvragen. Het centrale concept in dit proefschrift is probleemgestuurd onderwijs (PGO). Sinds de ontwikkeling van PGO eind jaren zestig in medisch onderwijs in Canada, is PGO uitgegroeid tot een wereldwijd gedistribueerd product dat zich onophoudelijk verder over de aardbol verspreidt. In dit proefschrift wordt PGO gedefinieerd als een onderwijsmethode die bepaalde culturele normen en waarden in zich draagt, die de context reflecteren waarin PGO oorspronkelijk ontwikkeld is. Hieruit volgt dat het implementeren en toepassen van PGO in andere contexten, voornamelijk in niet-Westerse contexten, een uitdaging kan zijn. Dit impliceert mogelijke verschillen in PGO processen en uitkomsten tussen culturele contexten. Met andere woorden, de globalisering van PGO wordt gekenmerkt door een bepaalde culturele complexiteit, die vragen oproept over de crossculturele toepasbaarheid van PGO. Het doel van dit proefschrift is het exploreren van de cross-culturele toepasbaarheid van PGO door de volgende onderzoeksvragen te behandelen: 1) Hoe wordt PGO vormgegeven in verschillende culturele contexten? en 2) Hoe worden studenten gevormd door PGO in verschillende culturele contexten? De formulering van deze vragen is ingegeven door een constructivistische, sociaal-culturele blik die in dit proefschrift als een overkoepelend theoretisch perspectief functioneert. Elk hoofdstuk deconstrueert een ander element van de culturele complexiteit van PGO, om zo het inzicht in de cross-culturele toepasbaarheid van PGO te vergroten. Gezamenlijk leggen de hoofdstukken stapsgewijs - alhoewel onvolledig - bloot hoe PGO geconstrueerd wordt en hoe PGO studenten construeert in verschillende culturen.

Hoofdstuk 2 en 3 richten zich op de culturele complexiteit van, respectievelijk, groepsdiscussies en zelfgestuurd leren in PGO. De hoofdstukken rapporteren bevindingen van een kwalitatieve, cross-culturele vergelijkende case studie die uitgevoerd werd aan drie medische faculteiten, gelegen in het Midden Oosten, Oost Azië en West Europa. Middels een sociaal-culturele onderzoeksaanpak werd onderzocht hoe de culturele achtergrond van studenten van invloed was op de vormgeving van groepsdiscussies en zelfgestuurd leren in PGO, evenals hoe de studenten gevormd werden door deze twee PGO elementen. De data werden verzameld door 88 semigestructureerde diepte-interviews met eerstejaars en derdejaars studenten, tutoren, en sleutelpersonen betrokken bij PGO, 32 observaties van eerstejaars en derdejaars PGO groepssessies, documentanalyse en veldaantekeningen. De data werden thematisch geanalyseerd met behulp van de template analysemethode. Vergelijkingen werden gemaakt tussen de drie medische 
faculteiten en tussen eerstejaars en derdejaars studenten binnen en tussen de faculteiten.

Er werd gevonden dat verschillen in de culturele achtergrond van studenten mede verantwoordelijk waren voor een andere vormgeving van de groepsdiscussies en het zelfgestuurd leren in PGO in de drie faculteiten. Met name in de twee niet-Westerse contexten werd een aantal culturele factoren geïdentificeerd die in tegenspraak waren met de culturele waarden inherent aan PGO, wat ervoor zorgde dat studenten in deze contexten het toepassen van PGO als een grotere uitdaging ervoeren. Een focus op onzekerheid en traditie, op groepsrelaties en face, op hiërarchische relaties, en op prestatie en competitie weerhield studenten er potentieel van om te spreken, vragen te stellen en anderen tegen te spreken tijdens de groepsdiscussies, en om vaardigheden in zelfgestuurd leren te ontwikkelen, zoals het formuleren van leerdoelen, het zoeken en vinden van informatie, en het construeren van kennis. Echter, de relatie tussen culturele factoren en de vormgeving van PGO was complex en werd beïnvloed door een groot aantal andere contextfactoren, die bijdroegen aan de vormgeving van groepsdiscussies en zelfgestuurd leren. De wijze examinering, de mate van PGO implementatie in het gehele curriculum, de aard van het middelbaar onderwijs, taal, en individuele verschillen tussen studenten en tutoren werden bijvoorbeeld geïdentificeerd als factoren die van grote invloed waren op de vormgeving van PGO processen.

Naast het beïnvloeden van de vormgeving van PGO, beïnvloedden deze culturele en andere contextfactoren ook hoe studenten gevormd werden door PGO. Tussen de drie contexten werden verschillen gevonden in de mate waarin studenten discussievaardigheden en vaardigheden in zelfgestuurd leren ontwikkelden. De ontwikkeling van deze vaardigheden, echter, volgde dezelfde richting in de drie contexten. Studenten bouwden vertrouwen op om te spreken, vragen te stellen aan medestudenten en tutoren, bestaande kennis te bekritiseren, en anderen tegen te spreken in de groepsdiscussies. Verder ontwikkelden ze motivatie voor en begrip over zelfgestuurd leren, en vaardigheden om informatie te zoeken en vinden, en kennis te construeren. Samenvattend, een complexe interactie tussen PGO, studenten, hun culturele achtergrond en andere contextfactoren bepaalde de manier waarop PGO processen en studenten werden gevormd in verschillende culturen. Er werd geconcludeerd dat, hoewel het toepassen van PGO een grotere uitdaging kon betekenen in niet-Westerse contexten, PGO toepasbaar was in verschillende culturele contexten. Niettemin, tussen deze contexten bestonden verschillen in PGO processen en uitkomsten.

Hoofdstuk 4 en 5 behandelen de complexiteit van, respectievelijk, het voorbereiden van studenten voor de praktijk middels PGO en het implementeren van PGO, in een culturele omgeving die radicaal verschilt van de omgeving waarin PGO oorspronkelijk ontwikkeld is. De hoofdstukken rapporteren bevindingen van een vergelijkende mixed methods studie die uitgevoerd werd in medische faculteiten in een Afrikaanse context. Hoofdstuk 4 onderzoekt de uitdagingen die junior artsen tegenkwamen in de praktijk 
van de gezondheidszorg in deze context, en hoe zij vonden dan hun onderwijs hen hierop had voorbereid. Een vergelijking werd gemaakt tussen studenten en alumni van een PGO faculteit enerzijds en een conventionele faculteit anderzijds. Hoofdstuk 5 onderzoekt curriculum uitkomsten van PGO implementaties in een Afrikaanse context, door de mate waarin studenten voorbereid waren op de praktijk te vergelijken tussen drie curricula in deze context: een PGO curriculum dat implementatieproblemen succesvol te boven kwam, een PGO curriculum dat zwaar gebukt ging onder implementatieproblemen, en een conventioneel curriculum. De data voor de twee hoofdstukken werden gelijktijdig verzameld middels 22 semigestructureerde, individuele interviews met junior artsen en vijfdejaars studenten, een vragenlijst voor junior artsen en vijfdejaars studenten $(n=194)$, werkdagboeken bijgehouden door zes junior artsen, informele interviews met leiders en sleutelpersonen in de faculteiten, en aantekeningen van observaties in onderwijssessies en veldbezoeken. Statistische en thematische analyses werden uitgevoerd, en in een laatste interpretatieronde werden de kwantitatieve en kwalitatieve data geïntegreerd.

In hoofdstuk 4 werden zes spanningsvelden tussen globale idealen en lokale realiteiten in de gezondheidszorg geïdentificeerd, die de motivatie en de mate waarin artsen zich voorbereid voelden op de praktijk aantastten: 1) anderen dienen versus zelf overleven, 2) patiënten behandelen middels moderne geneeskunde versus omgaan met patiënten die traditionele geneeswijzen aanhangen, 3) klinisch werk doen versus management en politiek werk doen, 4) voorgeschreven tests en procedures volgen versus omgaan met extreme tekorten, 5) globale medische kennis hebben versus geconfronteerd worden met een specifieke lokale ziektelast, en 6) respectvol communiceren met patiënten versus overbelast worden met patiënten en obstakels in communicatie. Vier elementen van het PGO curriculum rustten de studenten en artsen uit met vaardigheden en competenties om beter met deze spanningsvelden om te gaan, vergeleken met studenten en artsen van het conventionele curriculum, wat hun motivatie en mate van voorbereiding op de praktijk leek te vergoten: 1 ) het bewerkstelligen van een algemeen positief leerklimaat, 2 ) het stimuleren van een onderzoekende en onafhankelijke houding, 3) het stimuleren van een holistische benadering van patiënten, en 4) het stimuleren van een gevarieerd scala aan kennis en vaardigheden. Er werd geconcludeerd dat een PGO curriculum de motivatie van Afrikaanse artsen en de mate van voorbereiding om lokale uitdagingen in de gezondheidszorg het hoofd te bieden kon verbeteren. Echter, deze uitdagingen waren van een dermate intense en complexe aard dat het curriculum niet in staat was om studenten volledig hierop voor te bereiden, hoewel het PGO curriculum hier beter in leek te slagen dan het conventionele curriculum.

Vergelijkbaar, in hoofdstuk 5 werd gevonden dat de PGO curricula een holistische benadering van patiënten en een onderzoekende en onafhankelijke houding van studenten stimuleerden, wat gekarakteriseerd werd als een waardevolle voorbereiding voor de Afrikaanse gezondheidszorg. De mate waarin studenten van het conventionele 
curriculum voorbereid waren op de praktijk werd significant lager bevonden dan dat van de studenten van het succesvol geïmplementeerde PGO curriculum, maar significant hoger dan dat van studenten van het PGO curriculum dat zwaar leed onder implementatieproblemen. Disorganisatie van het curriculum, een gebrek aan betrokkenheid van staf, een tekort aan adequaat opgeleide PGO tutoren en klinische docenten, en de afwezigheid van leermaterialen en -bronnen belemmerde hevig de mate van voorbereiding op de praktijk van studenten van het laatstgenoemde curriculum. $\mathrm{Er}$ werd geconcludeerd dat de risico's van PGO implementatie in een Afrikaanse context hoger leken dan elders: positieve uitkomsten toonden een urgente toegevoegde waarde voor de lokale gezondheidszorg, maar dit kon mogelijk transformeren in negatieve effecten wanneer de uitdagingen voor PGO implementatie, kenmerkend voor veel Afrikaanse contexten, niet te boven gekomen werden.

Hoofdstuk 6 reflecteert op hoe de culturele complexiteit van PGO, en van culturele kwesties in medisch onderwijs in het algemeen, onderzocht en bestudeerd kunnen worden. Dit methodologisch hoofdstuk gaat dieper in op de sociaal-culturele onderzoeksaanpak die gebruikt werd in hoofdstuk 2 en 3 - activity theory - en draagt deze aanpak uit als een bruikbaar theoretisch en analytisch kader om culturele complexiteit te onderzoeken, en in het geval van deze dissertatie, inzicht te bieden in de crossculturele toepasbaarheid van PGO. De theoretische achtergrond en de principes van activity theory worden uitgelegd. Daarnaast worden de onderzoeksstappen van de cross-culturele case studie uit hoofdstuk 2 en 3 besproken om activity theory's praktische toepassing toe te lichten, van het formuleren van onderzoeksvragen tot het trekken van conclusies. Er wordt beschreven hoe het activity system, de analyse-unit in activity theory, als een organiserend principe kan dienen om culturele complexiteit te benaderen en vast te leggen. Het hoofdstuk eindigt met een reflectie op het theoretische en praktische nut van activity theory voor cultureel onderzoek. Er wordt opgemerkt dat activity theory geen shortcut vormt voor het begrijpen van culturele complexiteit: het is een uitdaging voor onderzoekers om de grenzen van hun studie te bepalen en om de dynamiek van het activity system te analyseren en interpreteren.

Hoofdstuk 7 vat samen en bespreekt hoe de voorgaande hoofdstukken de twee onderzoeksvragen hebben beantwoord, en welke conclusies en implicaties dit oplevert met betrekking tot de cross-culturele toepasbaarheid van PGO. Het hoofdstuk onderscheidt een praktische en een kritische discussie gericht op de vraag: (Hoe) is PGO toepasbaar in verschillende culturen? De centrale bevindingen over de onderzoeksvragen laten zien hoe een complexe interactie tussen PGO, studenten en andere componenten in het activity system van PGO bepalen hoe PGO en studenten gevormd worden in verschillende culturele contexten. Hoewel deze vormen verschillen tussen contexten, lijken PGO studenten en alumni zich wereldwijd in eenzelfde richting te bewegen. Het implementeren en toepassen van PGO lijkt een grotere uitdaging in een niet-Westerse 
omgeving, maar de uitkomsten van PGO lijken waardevol voor de praktijk in diverse culturele contexten. Een praktisch antwoord op bovenstaande vraag, gebaseerd op deze bevindingen, is dat PGO toepasbaar is in verschillende culturele contexten, maar niet in elke faculteit. De toepasbaarheid van PGO voor een bepaalde faculteit hangt af van een analyse van de lokale culturele complexiteit van de onderwijskundige- en werkcontext waarvoor studenten worden opgeleid. Wanneer hieruit zou blijken dat PGO een wenselijke en haalbare onderwijsaanpak voor deze faculteit zou zijn, zou de implementatie nauwkeurig ontworpen en uitgevoerd moeten worden op basis van de complexiteitsanalyse.

Een kritisch antwoord op bovenstaande vraag zou kunnen luiden dat deze vraag niet de juiste is. De centrale focus van innovatie in medisch onderwijs wereldwijd dient zich te richten op lokale behoeften en prioriteiten. Faculteiten wereldwijd zouden deze behoeften en prioriteiten moeten kunnen aanpakken zonder daarbij geleid, of misleid, te worden door de globalisering van dominante onderwijsmethodes zoals PGO. Er kan geargumenteerd worden dat de globalisering van PGO gebaseerd is op onjuiste vooronderstellingen en dat het een imperialistisch potentieel in zich draagt. Een substantiele behoefte aan alternatieven voor PGO kan worden geïdentificeerd, maar de huidige dominantie van een wereldwijd onderwijsdiscours dat in het voordeel is van PGO lijkt de ontwikkeling van alternatieven te belemmeren. Ook dit proefschrift kan bestempeld worden als een product van dit discours. Het medisch onderwijskundig veld wereldwijd, echter, kan baat hebben bij een rijke variëteit aan lokale methodes die het PGO discours overstijgen. Het hoofdstuk eindigt met een bespreking van de sterke en zwakke punten van dit proefschrift en suggesties voor toekomstig onderzoek, onderverdeeld in drie thema's: het deconstrueren van culturele complexiteit, het deconstrueren van bias en discours, en het construeren van optimale innovaties. 



\section{Acknowledgements}

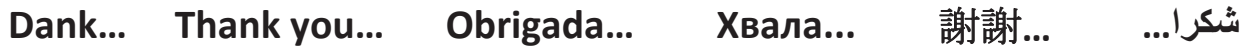

...aan Erik. Als dagelijks begeleider was jij precies wat ik nodig had; we begrepen elkaars gebruiksaanwijzing gelukkig heel goed. Ik ben je ontzettend dankbaar voor je bijzonder oprechte betrokkenheid bij mijn onderzoek en bij mij persoonlijk, voor je kritische no-nonsense blik, voor je ongeëvenaarde vermogen tot enthousiasmeren, en voor je levensgenieter-houding die op mij afstraalt.

...aan Cees, voor je vertrouwen in mij. Ik had geen onderwijskundige achtergrond, werd aangenomen zonder dat er een onderzoeksvoorstel lag, vloog naar Mozambique zonder dat de toestemming voor mijn dataverzameling rond was, en kreeg een contractverlenging in mijn ziekteperiode. Zonder aarzelen durfde jij die risico's te nemen met mij. Het is heerlijk werken als je promotor zo achter je staat.

...to my colleagues at Suez Canal University. Prof.dr. Wagdy Talaat, prof.dr. Somaya Hosny, and the employees of the Medical Education Department, thank you for receiving me so warmly. Dr. Amira Farghaly, thank you for your guidance and dear friendship, without which I would be lost.

...to my colleagues at The University of Hong Kong. Prof.dr. LC Chan, prof.dr. Niv Patil, dr. Philip Beh, dr. LK Chan and last but not least, dr. Amber Yip, thank you for your part in my research, your hospitality, and the excellent arrangements of my stay in Hong Kong.

...às minhas colegas da Universidade Eduardo Mondlane e da Universidade Católica de Moçambique: prof.dr. Mamudo Ismail, dra. Vitória Branco Neves, dra. Eunice Jethá, prof.dr. Josefo Ferro e dr. Konrad Steidel, agradeço-lhe pela sua hospitalidade e o seu apoio. Dr. Bernard Groosjohan, dr. Afonso Fumo e a minha cara amiga dra. Beatriz Manuel, obrigada pelo seu envolvimento e a sua colaboração na pesquisa, e por introduzir-me no seu país maravilhoso.

...to my colleagues at the Wilson Centre, University of Toronto: dr. Simon Kitto, dr. Tina Martimianakis, mr. Robert Paul, prof.dr. Brian Hodges and others. I felt like an island before I met you at the globalization symposium in Paris. The plan was to write the final chapter of this dissertation with your help during a 2 month Wilson Centre visit, but cancer got in the way. This thesis undoubtedly would have benefitted greatly from your input. So be it. My view is on the future and on future collaborations with you. Thank you for keeping your door wide open. 
...aan Fred Stevens, voor de inzichten, tijd en betrokkenheid die je in de eerste drie jaren van mijn promotietraject hebt gestoken, en voor de mensen aan wie je mij geïntroduceerd hebt.

...aan Alice Drenthe. Zonder jouw telefoontje had dit proefschrift er nooit gelegen.

...aan Fanny Evers, voor de dataverzameling in Maastricht.

...aan Mereke, woordkunstenares. "Doe mooie dingen", waren je laatste woorden aan mij, die ik volledig ter harte neem.

...aan Lilian en Nicky, het top-secretaresseteam, waar de deur altijd open staat en waar elke vraag beantwoord wordt. Dank!

...aan mijn kamergenootjes, voor de uniek chille sfeer in onze kamer, en dat jullie het met mij uithielden. Rachelle, Ellen, Jeantine, Greet en Marjo, voor jullie betrokkenheid, begrip, humor, gezelligheid en hulp met van alles en nog wat. Floris en Jorrick, voor wie jullie zijn. Katerina, Lorette, Jimmie en Emmaline, voor jullie bijdrage aan de chillheid van onze kamer.

...aan andere SHE PhD students waar mijn onderzoek en ik op allerlei manieren veel aan hebben gehad: Mariëlle en Dominique, als mede-internationaal-geörienteerden. Jonne, Esther en Irene, als mede-kwalitatief-geörienteerden en als ontzettend waardevolle raadgevers voor een gefrustreerde ik. Mariëtte, Juliette, Ingrid, Joost en Robbert, als geïnteresseerde mede-aio's. Mohamed Al Eraky, Astrid Susilo and Mora Claramita, for your interest and interesting insights and discussions.

...aan mijn collega's bij O\&O, voor de stimulerende werkomgeving en de fijne werksfeer. Speciale dank aan Mascha, Valerie en Herma voor de altijd vlekkeloze en gezellige samenwerking in MHPE en Summer Course, and special thanks to Tim Dornan for your supportive comments.

...aan SHE Collaborates, het team dat 'ongeduldig vol geduld' een plek voor mij bewaarde. Het vooruitzicht om bij zo'n leuke club aan de slag te kunnen was een enorme motivatie om mijn proefschrift zo gauw mogelijk af te ronden.

...aan de Commissie Onderzoeksbeleid FHML, waar ik een boel ins \& outs over het onderzoeksveld geleerd heb, en waar mijn interesse in onderzoek verder is aangewakkerd.

...aan de Observant redactie, voor de kans die ik heb gekregen om mijn persoonlijke ei kwijt te kunnen in mijn columns, want alleen wetenschappelijke artikels schrijven zou wel héél saai zijn.

...aan Renée. De afgelopen tijd bleek jij niet alleen een heel waardevolle collega, maar ook een heel waardevolle vriendin, waar ik megaveel aan heb, van kwalitatief onderzoek tot salsa.

...aan dansgroep Mix en mijn dansvrienden, voor jullie aandeel in mijn dansleven. Als klein meisje raakte ik geïnfecteerd met het dansvirus, waar ik nooit van hoop te genezen. Naast het beste virus dat je kunt hebben, is dans (zowel bekijken als beoefenen) tegelijkertijd het beste medicijn dat je kunt aanwenden tegen elke kwaal, van proefschriftstress tot kanker. 
...aan Janneke, Fanny, Julia, Stephanie en Nicky, voor wie jullie zijn en dat jullie er zijn. Wauw.. wat ben ik gelukkig met zo'n rotsvast beste-vriendinnen-clubje. Een speciaal heel groot dankjewel aan Janneke, voor het illustreren van mijn proefschrift en schaduwproefschrift. Ik ben trots dat jij mijn paranimf bent!

...mojoj dragoj srpskoj familiji, Gordana, Branko, Marina, Govert, Žarko i Gaga, za vaše razumevanje ako sam ponekad zbog posla imala manjka vremena za vas... Hvala velika. Sretna sam sa vama!

...aan Joris, Cinthia, Maike, Jeoffrey, Mia en Louis, voor jullie kiksheid die gewoon te chill is. Beter kan ik het niet verwoorden, maar gelukkig spreken jullie deze taal. Maike, de beste zus en vriendin ter wereld, die zo onvoorwaardelijk achter mij staat. Je bent Kampioen Opvrolijken in kankertijden en Kampioen Motiveren om proefschriftdeadlines te halen. Ik vind het fantastisch dat je tijdens mijn promotie letterlijk achter mij staat als paranimf.

...aan Johan en Philomène. Pap en mam, dankjewel voor $A L L E S$.

...aan Milan, voor alles en meer, ver over de grenzen van waar woorden kunnen komen.

...aan collega's | vrienden | familie* waarmee ik goede gesprekken | discussies | theekransjes | wijntjes | stapavonden* gedeeld heb, die ik hier misschien niet heb genoemd, maar die zeker niet vergeten worden: dank voor de inspiratie | feedback | goede raad | luisterende oren | stressontlading | plezier!*

...to colleagues | friends | family* with whom I've had wonderful conversations | discussions | cups of tea | glasses of wine | parties*, who I maybe haven't mentioned here, but who certainly won't be forgotten: thank you for the inspiration | feedback | good advice | listening ears | stress relief | fun!*

*Omcirkel wat op jou van toepassing is. | Circle what is applicable to you. 



\section{About the author}

Janneke M. Frambach was born on March $16^{\text {th }} 1983$ in Heerlen, the Netherlands. From 2002 to 2006 she studied Arts and Culture at the Faculty of Arts and Social Sciences of Maastricht University. During this Bachelor program she specialized in political culture, completed an internship as a policy advisor on the integration of minorities at the Municipality of Maastricht, and studied sociology for one semester as an exchange student at Universidade do Porto, Portugal. In 2007 she graduated cum laude from the Master program of Arts and Sciences at Maastricht University. In 2008 she received a Master in Management degree cum laude from the Faculty of Economics and Business at the Katholieke Universiteit Leuven, Belgium.

In September 2008 she started working as a researcher at the Department of Educational Development and Research at the Faculty of Health, Medicine and Life Sciences of Maastricht University. In addition to her research activities, she was a mentor and communication skills teacher in the Bachelor of Medicine and Bachelor of European Public Health programs, and a tutor and co-coordinator in the Master of Health Professions Education program and the Summer Course program on problem-based learning. Additionally, she was an advisor of the Research Policy Committee of the Faculty of Health, Medicine and Life Sciences, and a columnist for Maastricht University's newspaper Observant. Currently, she works as an assistant professor for SHE Collaborates, the international project office of the School of Health Professions Education of Maastricht University. Her main research interests are cultural diversity and globalization in medical education, curriculum change and educational innovation across cultures, and qualitative research. Her main personal interests are watching and practicing different styles of dance, and exploring different cultures. 



\section{SHE dissertation series}

The SHE Dissertation Series publishes dissertations of PhD candidates from the School of Health Professions Education (SHE) who defended their PhD theses at Maastricht University. The most recent ones are listed below. For more information go to: www.maastrichtuniversity.nl/she.

Van der Zwet, J. (30-01-2014) Identity, Interaction and Power. Explaining the affordances of doctor-student interaction during clerkships.

Watling, C.J. (22-01-2014) Cognition, Culture and Credibility. Deconstructing Feedback in Medical Education.

Junod Perron, N. (24-10-2013) Towards a learner-centered approach to postgraduate communications skills teaching.

Pratidina Susilo, A. (24-10-2013) Learning to be the Patient Advocate. The Development of a Communication Skills Course to Enhance Nurses' Contribution to the Informed Consent Process.

Alves de Lima, A. (23-10-2013) Assessment of clinical competence: Reliability, Validity, Feasibility and Eductional Impact of the mini-CEX.

Sibbald, M. (09-10-2013) Is that your final answer? How doctors should check decisions.

Ladhani, Z. (05-07-2013) Competency based education and professional competencies: a study of institutional structures, perspectives and practices in Pakistan.

Jippes, M. (01-02-2013) Culture matters in medical schools: How values shape a successful curriculum change.

Duvivier, R. J. (12-12-2012) Teaching and Learning Clinical Skills. Mastering the Art of Medicine.

De Feijter, J.M. (09-11-2012) Learning from error to improve patient safety.

Prescott, L. (09-11-2012) Ensuring the Competence of Dental Practitioners through the Development of a Workplace-Based System of Assessment.

Cilliers, F.J. (05-09-2012) The Pre-assessment Learning Effects of Consequential Assessment: Modelling how the Examination Game is Played.

Spanjers, I. A.E. (05-07-2012) Segmentation of Animations: Explaining the Effects on the Learning Process and Learning Outcomes.

Al-Kadri, H.M.F. (28-06-2012) Does Assessment Drive Students' Learning?

Leppink, J. (20-06-2012) Propositional manipulation for conceptual understanding of statistics.

Van Zundert, M.J. (04-05-2012) Conditions of Peer Assessment for Complex Learning.

Claramita, M. (30-03-2012) Doctor-patient communication in a culturally hierarchical context of Southeast Asia: A partnership approach.

Kleijnen, J.C.B.M. (21-03-2012) Internal quality management and organizational values in higher education

Persoon, M.C. (19-01-2012) Learning in Urology; The influence of simulators and human factors.

Pawlikowska, T.R.B. (21-12-2011) Patient Enablement; A Living Dialogue.

Sok Ying Liaw, (14-12-2011) Rescuing A Patient In Deteriorating Situations (RAPIDS): A programmatic approach in developing and evaluating a simulation-based educational program.

Singaram, V.S. (7-12-2011) Exploring the Impact of Diversity Factors on Problem-Based Collaborative Learning

Balslev, T. (24-11-2011) Learning to diagnose using patient video cases in paediatrics: Perceptive and cognitive processes.

Widyandana, D. (19-10-2011) Integrating Pre-clinical skills training in skills laboratory and primary health care centers to prepare medical students for their clerkships. 
Durning, S.J. (09-09-2011) Exploring the Influence of Contextual Factors of the Clinical Encounter on Clinical Reasoning Success (Unraveling context specificity).

Govaerts, M.J.B. (08-09-2011) Climbing the Pyramid;Towards Understanding Performance Assessment.

Stalmeijer, R. E. (07-07-2011) Evaluating Clinical Teaching through Cognitive Apprenticeship.

Malling, B.V.G. (01-07-2011) Managing word-based postgraduate medical education in clinical departments.

Veldhuijzen, J.W. (17-06-2011) Challenging the patient-centred paradigm: designing feasible guidelines for doctor patient communication.

Van Blankenstein, F. (18-05-2011) Elaboration during problem-based, small group discussion: A new approach to study collaborative learning.

Van Mook, W. (13-05-2011) Teaching and assessment of professional behavior: Rhetoric and reality.

De Leng, B. (8-12-2009). Wired for learning. How computers can support interaction in small group learning in higher education.

Maiorova, T. (29-05-2009). The role of gender in medical specialty choice and general practice preferences.

Bokken, L. (04-03-2009). Innovative use of simulated patients for educational purposes.

Wagenaar, A. (18-09-2008). Learning in internships. What and how students learn from experience.

Driessen, E. (25-06-2008). Educating the self-critical doctor. Using portfolio to stimulate and assess medical students' reflection.

Derkx, H. (18-06-2008). For your ears only. Quality of telephone triage at out-of-hours centres in the Netherlands.

Niessen, Th. (30-11-2007). Emerging epistemologies: making sense of teaching practice.

Budé, L. (05-10-2007). On the improvement of students' conceptual understanding in statistics education.

Niemantsverdriet, S. (26-07-2007). Learning from international internships: A reconstruction in the medical domain.

Marambe, K. (20-06-2007). Patterns of student learning in medical education - A Sri Lankan study in tradtional curriculum.

Pleijers, A. (19-01-2007). Tutorial group discussion in problem-based learning.

Sargeant, J. (21-09-2006). Multi-source feedback for physician learning and change.

Dornan, T. (12-06-2006). Experience-based learning.

Wass, V. (12-05-2006). The assessment of clinical competence in high stakes examinations.

Prince, K. (21-04-2006). Problem-based learning as a preparation for professional practice. 


\section{ICO dissertation series}

The ICO Dissertation Series publishes dissertations of graduate students from faculties and institutes on educational research within the ICO Partner Universities: Eindhoven University of Technology, Leiden University, Maastricht University, Open University of the Netherlands, University of Amsterdam, University of Twente, Utrecht University, VU University Amsterdam, and Wageningen University, and formerly University of Groningen (until 2006), Radboud University Nijmegen (until 2004), and Tilburg University (until 2002). The University of Groningen, University of Antwerp, University of Ghent, and the Erasmus University Rotterdam have been 'ICO 'Network partner' in 2010 and 2011. From 2012 onwards, these ICO Network partners are full ICO partners, and from that period their dissertations are added to this dissertation series. The most recent ones are listed below.

Radstake, H. (14-05-2009). Teaching in diversity: Teachers and pupils about tense situations in ethnically heterogeneous classes. Amsterdam: University of Amsterdam.

Du Chatenier, E. (09-09-2009). Open innovation competence: Towards a competence profile for interorganizational collaboration in innovation teams. Wageningen: Wageningen University.

Van Borkulo, S.P. (26-06-2009). The assessment of learning outcomes of computer modelling in secondary science education. Enschede: University of Twente.

Handelzalts, A. (17-09-2009). Collaborative curriculum development in teacher design teams. Enschede: University of Twente.

Nievelstein, F.E.R.M. (18-09-2009). Learning law: Expertise differences and the effect of instructional support. Heerlen: Open University of the Netherlands.

Visser-Wijnveen, G.J. (23-09-2009). The research-teaching nexus in the humanities: Variations among academics. Leiden: Leiden University.

Van der Rijst, R.M. (23-09-2009). The research-teaching nexus in the sciences: Scientific research dispositions and teaching practice. Leiden: Leiden University.

Mainhard, M.T. (25-09-2009). Time consistency in teacher-class relationships. Utrecht: Utrecht University.

Van Ewijk, R. (20-10-2009). Empirical essays on education and health. Amsterdam: University of Amsterdam.

Seezink, A. (18-11-2009). Continuing teacher development for competence-based teaching. Tilburg: Tilburg University.

Rohaan, E.J. (09-12-2009). Testing teacher knowledge for technology teaching in primary schools. Eindhoven: Eindhoven University of Technology.

Kirschner, F.C. (11-12-2009). United brains for complex learning. Heerlen: Open University of the Netherlands.

Wetzels, S.A.J. (18-12-2009). Individualized strategies for prior knowledge activation. Heerlen: Open University of the Netherlands.

Zitter, I.I. (04-02-2010). Designing for learning: Studying learning environments in higher professional education from a design perspective. Utrecht: Utrecht University.

Koopman, M. (11-02-2010). Students' goal orientations, information processing strategies and knowledge development in competence-based pre-vocational secondary education. Eindhoven: Eindhoven University of Technology. 
Platteel, T. (11-02-2010). Knowledge development of secondary school L1 teachers on concept-context rich education in an action-research setting. Leiden: Leiden University.

Mittendorff, K. M. (12-03-2010). Career conversations in senior secondary vocational education. Eindhoven: Eindhoven University of Technology.

Moolenaar, N.M. (01-06-2010). Ties with potential: Nature, antecedents, and consequences of social networks in school teams. Amsterdam: University of Amsterdam.

Duijnhouwer, H. (04-06-2010). Feedback effects on students' writing motivation, process, and performance. Utrecht: Utrecht University.

Kessels, C.C. (30-06-2010). The influence of induction programs on beginning teachers' well-being and professsional development. Leiden: Leiden University.

Endedijk, M.D. (02-07-2010). Student teachers' self-regulated learning. Utrecht: Utrecht University.

De Bakker, G.M. (08-09-2010). Allocated online reciprocal peer support as a candidate for decreasing the tutoring load of teachers. Eindhoven: Eindhoven University of Technology.

Groenier, M. (10-09-2010). The decisive moment: Making diagnostic decisions and designing treatments. Enschede: University of Twente.

Bonestroo, W.J. (24-09-2010). Planning with graphical overview: Effects of support tools on self-regulated learning. Enschede: University of Twente.

Vos, M.A.J. (30-09-2010). Interaction between teachers and teaching materials: On the implementation of context-based chemistry education. Eindhoven: Eindhoven University of Technology.

Kostons, D.D.N.M. (05-11-2010). On the role of self-assessment and task-selection skills in self-regulated learning. Heerlen: Open University of the Netherlands.

Bruin-Muurling, G. (21-12-2010). The development of proficiency in the fraction domain: Affordances and constraints in the curriculum. Eindhoven: Eindhoven University of Technology.

Slof, B. (28-01-2011). Representational scripting for carrying out complex learning tasks. Utrecht: Utrecht University.

Fastré, G. (11-03-2011). Improving sustainable assessment skills in vocational education. Heerlen: Open University of the Netherlands.

Min-Leliveld, M.J. (18-05-2011). Supporting medical teachers' learning: Characteristics of effective instructtional development. Leiden: Leiden University.

Van Blankenstein, F.M. (18-05-2011). Elaboration during problem-based small group discussion: A new approach to study collaborative learning. Maastricht: Maastricht University.

Dobber, M. (21-06-2011). Collaboration in groups during teacher education. Leiden: Leiden University.

Jossberger, H. (24-06-2011). Towards self-regulated learning in vocational education: Difficulties and opportunities. Heerlen: Open University of the Netherlands.

Schaap, H. (24-06-2011). Students' personal professional theories in vocational education: Developing a knowledge base. Utrecht: Utrecht University.

Kolovou, A. (04-07-2011). Mathematical problem solving in primary school. Utrecht: Utrecht University.

Beausaert, A.J. (19-10-2011). The use of personal developments plans in the workplace. Effects, purposes and supporting conditions. Maastricht: Maastricht University

Favier, T.T. (31-10-2011). Geographic information systems in inquiry-based secondary geography education: Theory and practice. Amsterdam: VU University Amsterdam.

Brouwer, P. (15-11-2011). Collaboration in teacher teams. Utrecht: Utrecht University

Molenaar, I. (24-11-2011). It's all about metacognitive activities; Computerized scaffolding of self-regulated learning. Amsterdam: University of Amsterdam.

Cornelissen, L.J.F. (29-11-2011). Knowledge processes in school-university research networks. Eindhoven: Eindhoven University of Technology.

Elffers, L. (14-12-2011). The transition to post-secondary vocational education: Students' entrance, experiences, and attainment. Amsterdam: University of Amsterdam.

Van Stiphout, I.M. (14-12-2011). The development of algebraic proficiency. Eindhoven: Eindhoven University of Technology. 
Gervedink Nijhuis, C.J. (03-2-2012) Culturally Sesitive Curriculum Development in International Cooperation Enschede: University of Twente.

Thoonen, E.E.J. (14-02-2012) Improving Classroom Practices: The impact of Leadership School Organizational Conditions, and Teacher Factors Amsterdam: University of Amsterdam.

Truijen, K.J.P (21-03-2012) Teaming Teachers. Exploring factors that influence effictive team functioning in a vocational education context Enschede: University of Twente.

Maulana, R.M. (26-03-2012)Teacher-student relationships during the first year of secondary education. Exploring of change and link with motivation outcomes in The Netherlands and Indonesia. Groningen: University of Groningen.

Lomos, C. (29-03-2012) Professional community and student achievement. Groningen: University of Groningen.

Mulder, Y.G. (19-04-2012) Learning science by creating models. Enschede: University of Twente.

Van Zundert, M.J. (04-05-2012) Optimising the effectiveness and reliability of reciprocal peer assessment in secondary education. Maastricht: Maastricht University.

Ketelaar, E. (24-05-2012) Teachers and innovations: on the role of ownership, sense-making, and agency. Eindhoven: Eindhoven University of Technology.

Logtenberg, A. (30-5-2012) Questioning the past. Student questioning and historical reasoning Amsterdam: University of Amsterdam.

Jacobse, A.E. (11-06-2012) Can we improve children's thinking? Groningen: University of Groningen.

Leppink, J. (20-06-2012) Propositional manipulation for conceptual understanding of statistics Maastricht: Maastricht University.

Van Andel, J (22-06-2012) Demand-driven Education. An Educational-sociological Investigation. Amsterdam: VU University Amsterdam.

Spanjers, I.A.E. (05-07-2012) Segmentation of Animations: Explaining the Effects on the Learning Process and Learning Outcomes. Maastricht: Maastricht University.

Vrijnsen-de Corte, M.C.W. Researching the Teacher-Researcher. Practice-based research in Dutch Professional Development Schools, Eindhoven: Eindhoven University of Technology.

Van de Pol, J.E. (28-09-2012) Scaffolding in teacher-student interaction. Exploring, measuring promoting and evaluating scaffolding. Amsterdam: University of Amsterdam.

Phielix, C. (28-09-2012) Enhancing Collaboration through Assessment \& Reflection [Samenwerking Verbeteren door middel van Beoordeling en Reflectie]. Utrecht: Utrecht University.

Peltenburg, M.C. (24-10-2012) Mathematical potential of special education students. Utrecht: Utrecht University.

Doppenberg, J.J. (24-10-2012) Collaborative teacher learning: settings, foci and powerful moments. Eindhoven: Eindhoven University of Technology.

Kenbeek, W.K. (31-10-2012) Back to the drawing board. Creating drawing or text summaries in support of System Dynamics modelling. Enschede: University of Twente.

De Feijter, J.M. (09-11-2012) Learning from error to improve patient safety. Maastricht: Maastricht University.

Timmermans, A.C. (27-11-2012) Value added in educational accountability: Possible, fair and useful? Groningen: University of Groningen.

Van der Linden, P.W.J. (20-12-2012) A design-based approach to introducing student teachers in conducting and using research. Eindhoven: Eindhoven University of Technology. 


\section{o}

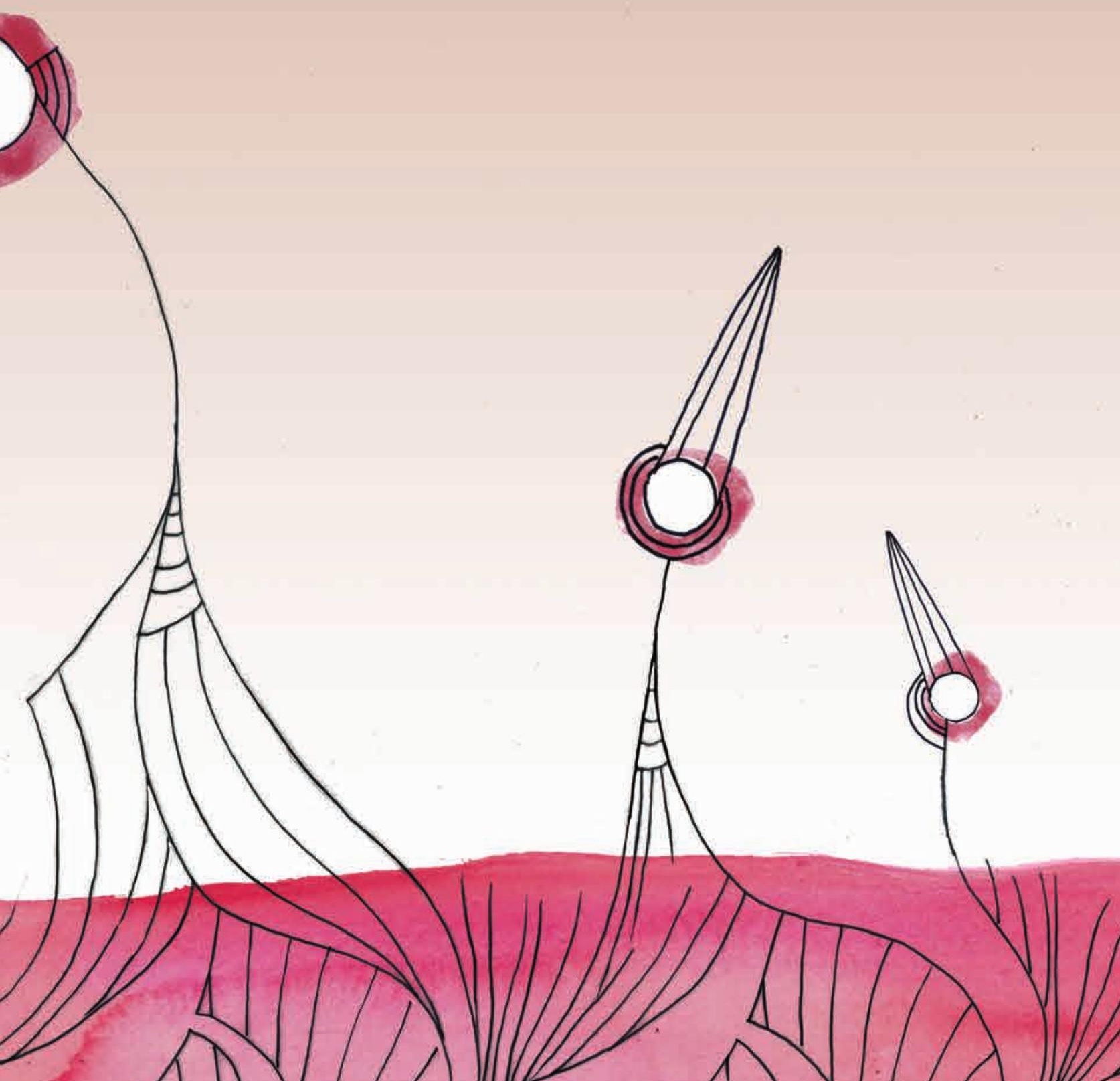

